\author{
Universidade de São Paulo \\ Instituto de Astronomia, Geofísica e Ciências Atmosféricas
}

Departamento de Astronomia

João Luiz Martins Basso

\title{
Microphysical Analysis and Modeling of Amazonic Deep Convection
}

São Paulo 

João Luiz Martins Basso

\section{Microphysical Analysis and Modeling of Amazonic Deep Convection}

Dissertação apresentada ao Departamento de Ciências Atmosféricas do Instituto de Astronomia, Geofísica e Ciências Atmosféricas da Universidade de São Paulo como requisito parcial para a obtenção do título de Mestre em Ciências Atmosféricas.

Área de Concentração: Meteorologia Orientador: Prof. Dr. Ricardo Hallak Versão Corrigida. O original encontra-se disponível na Unidade.

São Paulo 

I dedicate to my father João Constante Basso and mom Regina Maria Martins Basso for the effort and strength of will of raising me, my brother Cristiano Martins Basso and my sisters Margie Helena Martins Basso, Camila Martins Basso and Bibiana Martins Basso on days like this. I would never be where I am now if they had not sacrified their priorities and lives for me and my siblings. 



\section{Acknowledgements}

To my family for the support, love and care from the day I was born until today;

To my colleagues and friends, and special thanks to Rafael Cesário de Abreu, Luana Ribeiro Macedo, Vitor da Silva Lopes, André Seiji Wakate Teruya and mastermind Professor Ricardo Hallak for the support and honesty through this work;

For the people who live in this country and pay their taxes so I can have the government's aid to finish my studies;

To Professors Rachel Albrecht and Maria Assunção Faus da Silva Dias that have accepted to participate in the work project qualification;

To CAPES for the financial support; 



\section{Abstract}

Atmospheric moist convection is one of the main topics discussed on weather and climate. This study purpose is to understand why different and similar cloud microphysics parameterizations produce different patterns of precipitation at the ground through several numerical sensitivity tests with the WRF model in the simulation of a squall line case observed on the Amazon region. Four different bulk microphysics parameterizations (Lin, WSM6, Morrison, and Milbrandt) were tested, and the main results show that statistical errors do not change significantly among each other for the four numerical domains (from $27 \mathrm{~km}$ up to $1 \mathrm{~km}$ grids). The correlations between radar rainfall data and the simulated precipitation fields show the double-moment parameterization Morrison scheme was the one that displayed better results in the overall: While Morrison scheme show 0.6 correlation in the western box of the $1 \mathrm{~km}$ domain, WSM6 and Lin schemes show 0.39 and 0.05, respectively. Nevertheless, because this scheme presents good correlations with the radar rain rates, it also shows a fairly better system lifecycle, evolution, and propagation when compared to the satellite data. Although, the complexity that the way microphysics variables are treated in both one-moment and double-moment schemes in this case study do not highly affect the simulatios results, the tridimensional vertical cross-sections show that the Purdue Lin and Morrison schemes display more intense systems compared to WSM6 and Milbrandt schemes, which may be associated with the different treatments of the ice-phase microphysics. In the specific comparison between double-moment schemes, the ice quantities generated by both Morrison and Milbrandt schemes highly affected the system displacement and rainfall intensity. This also affects the vertical velocities intensity which, in its, turn, changes the size of the cold pools. Differences in ice quantities were responsible for distinct quantities of total precipitable water content, which is related with 
the verticallly integrated ice mixing ratio generated by Morrison. The system moves faster in Milbrandt scheme compared to Morrison because the scheme generated more graupel quantities, which is smaller in size than hail, and it evaporates easier in the processes inside the cloud due to its size. This fact also changed the more intense cold pools intensity for Milbrandt scheme compared to Morrison. 


\section{Resumo}

A convecção atmosférica é um dos principais tópicos discutidos no tempo e clima. O objetivo deste estudo é entender por que diferentes e semelhantes parametrizações de microfísica de nuvens produzem diferentes padrões de precipitação no solo através de vários testes numéricos de sensibilidade com o modelo WRF na simulação de um caso de linha de instabilidade observado na região amazônica. Quatro diferentes parametrizações microfísicas de tipo bulk (Lin, WSM6, Morrison e Milbrandt) foram testadas, e os principais resultados mostram que os erros estatísticos não se alteram significativamente entre si para os quatro domínios numéricos (da grade de $27 \mathrm{~km}$ até a de $1 \mathrm{~km}$ ). As correlações entre dados pluviométricos de radar e os campos de precipitação simulados mostram que o esquema Morrison de parametrização de duplo momento foi o que apresentou melhores resultados, no geral: enquanto o esquema de Morrison mostra correlação 0,6 na caixa oeste do domínio de $1 \mathrm{~km}$, os esquemas WSM6 e Lin mostram 0,39 e 0,05, respectivamente. No entanto, como esse esquema apresenta boas correlações com as taxas de chuva do radar, ele também mostra um ciclo de vida, evolução e propagação do sistema relativamente melhores quando comparado aos dados de satélite. Embora a complexidade com que as variáveis microfísicas são tratadas nos esquemas de um momento e de duplo momento neste estudo de caso não afetam muito os resultados simulados, as seções transversais verticais tridimensionais mostram que os esquemas de Purdue Lin e Morrison exibem mais intensos em comparação com os esquemas WSM6 e Milbrandt, que podem estar associados aos diferentes tratamentos da microfísica da fase de gelo. Na comparação específica entre esquemas de momento duplo, as quantidades de gelo geradas pelos esquemas de Morrison e Milbrandt afetaram muito o deslocamento do sistema e a intensidade da chuva. Isso também afeta a intensidade das velocidades verticais que, por sua vez, altera o tamanho 
das piscinas frias. As diferenças nas quantidades de gelo foram responsáveis por quantidades distintas de conteúdo total de água, que está relacionado com a razão de mistura de gelo verticalmente integrada gerada por Morrison. O sistema se move mais rápido no esquema de Milbrandt comparado a Morrison porque o esquema gerou mais quantidades de graupel, que é menor em tamanho do que o granizo, e evapora mais facilmente nos processos dentro da nuvem devido ao seu tamanho. Este fato também mudou a intensidade das piscinas frias mais intensas, porém menores em extensão horizontal, para o esquema Milbrandt em comparação com Morrison. 


\section{List of Figures}

2.1 Schematic diagram representing the circulation that is resultant from the differential warming between the continent and the oceans in the summer.

2.2 Schematic diagram representing the Walker cell circulation under normal conditions. source: NOAA . . . . . . . . . . . . . . 25

2.3 Schematic diagram representing the Walker cell circulation under El Niño conditions. source: NOAA .................. 26

2.4 Squall line cross section representation. . . . . . . . . . . . . . . . 30

2.5 Squall line cross section representation conceptual model. . . . . . . . . . . 31

2.6 Conceptual motel of a squall line trailing stratiform area. . . . . . . . . . . 31

2.7 Schematic surface pressure, wind, and precipitation fields during the mature stage of a squall line. . . . . . . . . . . . . . . . . . . 32

2.8 Wind shear role and the development of new cells. . . . . . . . . . . . . . 32

2.9 Cloud hydrometeor sum in a vertical cross section over a fixed latitude point with temperature isotherms. . . . . . . . . . . . . 39

3.1 Region of the case study. . . . . . . . . . . . . . . . . . . 41

3.2 Boxes used for the rain rates sum. . . . . . . . . . . . . . . . . . 43

3.3 Resumo da legenda da figura (aparece na lista de figuras) . . . . . . . . . 47

3.4 Example of amplitude and phase errors in numerical simulations. . . . . . 49

4.1 GOES 13 satellite temperature hilighted infrared images for September $08^{\text {th }}$ from 0100 to 0800 UTC. . . . . . . . . . . . . . . 53

4.2 GOES 13 satellite temperature hilighted infrared images for September $08^{\text {th }}$ from 1000 to 1500 UTC. . . . . . . . . . . . . . . . 54 
4.3 GOES 13 satellite temperature hilighted infrared images for September $08^{\text {th }}$ from 1600 to 1930 UTC. . . . . . . . . . . . . . . . 55

4.4 Rawinsonde data for September $08^{t h}, 2014 \ldots \ldots \ldots$. . . . . . . . 57

4.5 Rawinsonde data for September $08^{t h}, 2014$. . . . . . . . . . . . 58

4.6 Sea Level Pressure and Wind at $10 \mathrm{~m}$ from GFS (left) and WRF(right) . . 60

4.7 Streamlines and Wind Velocity from GFS (left) and WRF (right) models at $250 \mathrm{hPa} \ldots \ldots \ldots \ldots \ldots$

4.8 WRF rain rates for September $08^{t h}, 2014$ from 0800 to 1500 UTC. . . . . . 63

4.9 WRF rain rates for September $08^{\text {th }}, 2014$ from 0800 to 1500 UTC. . . . . . 64

4.10 Hodograph for September $08^{t h}, 2014$ at 1500 UTC. . . . . . . . . . . 65

4.11 Radar reflectivity data for September $08^{t h}, 2014 \ldots \ldots$. . . . . . . 67

4.12 Radar radial velocity data for September $08^{t h}, 2014$. . . . . . . . . . . 68

$4.13 \mathrm{WRF}$ and radar sum for the rain rates for September $08^{\text {th }}, 2014 \ldots \ldots$. . 71

4.14 CMORPH rain rates for September 08 ${ }^{\text {th }}, 2014$ from 1700 to 2000 UTC. . . 72

4.15 Radar rain rates for September $08^{\text {th }}, 2014$ from 1700 to 2000 UTC. . . . . 73

4.16 WRF rain rates for September $08^{\text {th }}, 2014$ from 1700 to 2000 UTC. . . . . 76

4.17 WRF rain rates for September 08 ${ }^{\text {th }}, 2014$ from 1700 to 2000 UTC. . . . . . 78

4.18 Radar and WRF rain rates sum for the southern box. . . . . . . . . . . 79

4.19 WRF rain rates for September $08^{t h}, 2014$ from 1700 to 2000 UTC. . . . . . 80

4.20 WRF rain rates for September 08 ${ }^{\text {th }}, 2014$ from 1700 to 2000 UTC. . . . . . 82

4.21 WRF CTL grid gust front analysis. . . . . . . . . . . . . . 84

4.22 WRF CTL grid gust front analysis. . . . . . . . . . . . . . . 85

4.23 GOES-13 satellite infrared highlighted image for September $08^{\text {th }}$ before the event. ........................... 86

4.24 WRF perturbation potential temperature fields for September $08^{\text {th }}$ from 1500 to 1900 UTC. . . . . . . . . . . . . . . . 89

4.25 WRF Top of the Atmosphere outgoing longwave radiation fields for September $08^{\text {th }}$ from 1500 to 1900 UTC. . . . . . . . . . . . . . . . 90

4.26 WRF simulated CAPE for September $08^{t h}, 2014 \ldots \ldots \ldots$

4.27 WRF CTL microphysical properties cross-section . . . . . . . . . . . . 94

4.28 WRF CTL rain and microphysical properties. . . . . . . . . . . . . 96

4.29 WRF CTL rain and microphysical properties. . . . . . . . . . . . . 97 
4.30 WRF CTL rain and microphysical properties. . . . . . . . . . . . . . 99

4.31 WRF reflectivity fields for September $08^{\text {th }}$ from 1630 to 1830 UTC. . . . . 103

4.32 WRF vertical velocity fields for September $08^{\text {th }}$ for 1500 and 1630 UTC. . 104

4.33 WRF minimal and maxima vertical velocities September $08^{\text {th }}$ from 1200 to 0000 UTC. . . . . . . . . . . . . . . . . . . . 104

4.34 WRF minimal perturbation potential temperature in the surface for September $08^{\text {th }}$ from 1200 UTC to 0000 UTC. . . . . . . . . . . . . . . 104

4.35 WRF zonal winds fields and vapor mixing ratio (for box 3) difference between the two schemes for September $08^{\text {th }}$ for 1600 and 1700 UTC. . . . . 105

4.36 WRF summed mixing ratios for September $08^{\text {th }}$ at 1700 UTC. . . . . . . . 106

4.37 WRF summed mixing ratios for September $08^{\text {th }}$ at 1830 UTC. . . . . . . . 106

4.38 WRF summed mixing ratios for September $08^{\text {th }}$ at 1700 and 1830 UTC. . . 107

4.39 IWP for each box for September $08^{\text {th }}$ between 1200 and 2400 UTC. . . . . 108

4.40 WRWP for each box for September $08^{\text {th }}$ between 1200 and 2400 UTC. . . . 110

5.1 Detailed scheme with the conclusions with respect to cloud microphysics parameterization tests. . . . . . . . . . . . . . 114 



\section{List of Tables}

3.1 Sizes in gridpoints for the sum of the rain rates boxes in September $08^{\text {th }}$, 2014 from 1700 UTC to 2330 UTC. . . . . . . . . . . . . . . 43

3.2 Physical characteristics of the Control Run . . . . . . . . . . . . . 48

4.1 Variables errors for domain 1 and 4 for September $08^{\text {th }}, 2014$ at 1500 UTC. 70

4.2 a) Purdue Lin . . . . . . . . . . . . . . . . . . . . 70

4.3 b) Milbrandt . . . . . . . . . . . . . . . . . . . . . . . . 70

4.4 c) Morrison . . . . . . . . . . . . . . . . . . . . . . . . . 70

4.5 d) WSM6 . . . . . . . . . . . . . . . . . . . 70

4.6 Radar data correlations with the WRF simulations for the sum of the rain rates boxes in September 08 ${ }^{\text {th }}, 2014$ from 1700 UTC to 2330 UTC. . . . . . 71

4.7 Radar data correlations with the WRF simulations for the sum of the rain rates boxes in September 08 $8^{\text {th }}, 2014$ from 1730 UTC to 2330 UTC. . . . . . 75

4.8 Cold Pool fraction for September $08^{\text {th }}, 2014$ from 1500 UTC to 1900 UTC. 87 



\section{Contents}

1. Introduction . . . . . . . . . . . . . . . . . . . . . 19

1.1 Objectives . . . . . . . . . . . . . . . . . . . . 21

2. Literature Revision . . . . . . . . . . . . . . . . . . . . . . . 23

2.1 Amazon Region Convection and Climatology . . . . . . . . . . . . . . 23

2.2 Formation of the Convection over the Amazon Basin . . . . . . . . . . . 27

2.3 Squall Lines . . . . . . . . . . . . . . . . . . . . . . . . . . . . . . . . . . . . 29

2.4 The Mesoscale Model WRF . . . . . . . . . . . . . . . . 33

2.4.1 Microphysics Parameterization . . . . . . . . . . . 34

2.4 .2 Cumulus Parameterization . . . . . . . . . . . . 36

2.5 Microphysics and Thermodynamics Features Inside a Cloud Development . 37

3. Materials and Methods ..................... 41

3.1 Observed Data . . . . . . . . . . . . . . . 41

3.2 Radar Data . . . . . . . . . . . . . . . . . . . . . . . . . 42

3.3 Rain and Ice water Path . . . . . . . . . . . . . . . . 43

3.4 CPC MORPHing technique - CMORPH . . . . . . . . . . . . . 44

3.5 Global Forecasting Model - GFS . . . . . . . . . . . . . . . 45

3.6 GOES-13 Satellite Imagery . . . . . . . . . . . . . . . . . 45

3.7 Case study of September $08^{t h}, 2014 \ldots \ldots \ldots$. . . . . . . . . . 45

3.8 Methodology for the WRF mesoscale simulations . . . . . . . . . . . . 46

3.9 Control Run Experiment . . . . . . . . . . . . . . . . . . . . 47

3.10 Cold Pools identification . . . . . . . . . . . . . . . . . . 48

3.11 Errors Calculations . . . . . . . . . . . . . . . . . . . 49 
4. Results and Discussion . . . . . . . . . . . . . . 51

4.1 Case study of September $08^{\text {th }}, 2014 \ldots \ldots \ldots \ldots \ldots \ldots$

4.2 Synoptic Overview . . . . . . . . . . . . . . . . . . . . . 51

4.3 GOES-13 Infrared Images . . . . . . . . . . . . . . . . . . 51

4.4 GFS and Rawinsonde Analysis . . . . . . . . . . . . . . . 555

4.5 Comparison between WRF $27 \mathrm{~km}$ Control Run Experiment and the GFS data . . . . . . . . . . . . . . . . . 58

4.6 Analysis of the $9 \mathrm{~km}$ and $3 \mathrm{~km}$ Grids $\ldots \ldots \ldots \ldots$

4.7 Mesoscale Overview . . . . . . . . . . . . . . . . . . . . . . . . 64

4.8 Study of the WRF $1 \mathrm{~km}$ resolution grid errors . . . . . . . . . . 69 69

4.9 System Lifecycle, Evolution and Propagation . . . . . . . . . . . . 71

4.10 Cold Pool and CAPE Analysis . . . . . . . . . . . . . . . . . 83

4.11 Microphysical Vertical Cross-Sections Analysis of the 1km Resolution Grid 92

4.12 WRF Reflectivity, Vertical Velocity, and Microphysics Analysis . . . . . . 99

5. Conclusions . . . . . . . . . . . . . . . . . . . . 111

6. Suggestion for Further Studies . . . . . . . . . . . . . . . . . 115

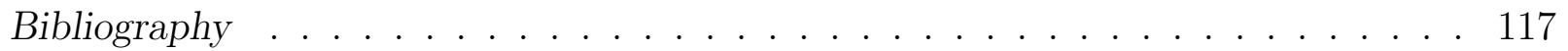


Chapter 1

\section{Introduction}

The Amazon region plays an essential role on both global and local climate. Its physiographic characteristics are very peculiar due to large differences in aspects like its vegetation and local hydrology when compared to the rest of the world. It is one of the cleanest continental places on Earth and can be compared to the ocean regions when it comes about air pollution (Andreae, 2007). Especially in terms of cumulus convection, the Amazon region plays a strong, and important role in several physical aspects in both local, regional, continental, and global scales. Examples are the effects of convection on the energetics and vertical transport of mass and momentum from the tropospheric low levels to the higher ones. With the purpose of exploring particular characteristics of the Amazon convection, among others meteorological phenomena observed in that region, field missions like the large-scale Biosphere-Atmosphere Experiment (LBA,) and the posterior campaigns promoted by the CHUVA Project, and recently the Green Ocean Amazon (GOAmazon), were promoted as large projects developed with international collaboration. Through these programs, aspects as particulate matter and physical processes like the quantification and the characterization of the vertical structure of the microphysics species of precipitating clouds, are becoming themes of interest of the Brazilian and international academic community. This work intends to show how cloud microphysics works in the Amazon region, mainly is respect to deep convection, which controls the mesoscale phenomena observed in that region.

The measurements made through the aforementioned projects in the Amazon region have been turning possible the comparison between such new set of data and numerical simulations obtained by distinct meteorological models. One of the most used numerical models in regional scales nowadays is the Weather Research and Forecasting (WRF) 
(Skamarock et al., 2008) that can be configured to simulate since large-scale systems to those composed by local deep convective clouds (Pereira Filho et al., 2002; Abreu, 2016; Lopes, 2017). Despite the main GOAmazon goal is focused on the analysis of the air pollution effects in the Amazon region, some of its measurements are useful for meteorological purposes, such as rawinsondes and radar observations, both of them obtained in high temporal resolutions. Thus, beyond contributing to the model evaluation, these measurements help researchers in their hard work of verifying how realistic are deep tropical convection simulations, which necessarily make use of highly complex parameterizations schemes to reproduce mesoscale phenomena (Milbrandt and Yau, 2005; Morrison et al., 2005). In addition, and even more difficult to perform, is the evaluation of cloud-resolving numerical simulations, as in this work. It is important to highlight that several questions yet not well answered nowadays are associated with the understanding of how distinct kinds of microphysical parameterizations available in the WRF model produces different responses in the mesoscale (Morrison and Milbrandt, 2010; Gettelman and Morrison, 2015). Therefore, there is a clear need in evaluating these parameterizations among each other at the light of their particularities and common features (Van Weverberg et al., 2012). A major fact in this type of comparison is to determine how different cloud microphysics parameterizations impact the convection generated by WRF model in a real case, how this convective activity organizes in mesoscale systems, how is their evolution, and how these simulations describe their life cycle.

Focusing in high spatial resolution simulations (horizontal grids with $1 \mathrm{~km}$ of spacing between points) (Mass et al., 2002), this work intends to contribute to a better understanding of the observed differences in the physical characteristics of convective precipitating systems in the Amazon region as derived from numerical simulations of the atmosphere using different cloud microphysics parameterizations. The motivations for the work reside in some unanswered questions that come to light about the subject that can be put as follows: Why similar microphysics parameterizations schemes generate large differences on the patterns of rainfall and microphysics quantities (Morrison and Milbrandt, 2010, Gettelman and Morrison, 2015)? How can similar double-moment microphysics parameterizations affect the simulation of Amazon convective systems, like three-dimensional morphology and horizontal propagation? Why the same double-moment microphysics parameterizations impact the intensity, positioning and the vertical distribution of hydrometeors inside the 
convective cells (Van Weverberg et al. 2012)? To reach this purpose, the evaluation of bulk one and double-moment parameterization schemes are done over the Amazon region in a real case convective system observed during the GOAmazon project.

\subsection{Objectives}

The main objective of this study is to analyze a Squall Line observed in the Amazon region using atmospheric model simulations runs with different microphysics parameterizations studying its thermodynamic stability, horizontal and vertical distribution of microphysical species, updraft and downdraft morphology and intensities, and temporal and spatial rainfall patterns.

The secondary objectives comprehend:

- Analyze and evaluate microphysics species generated by the atmospheric model against the observed and estimated microphysics data in a control experiment;

- Understand how similar cloud microphysics parameterizations produce different rainfall patterns in a system through sensibility experiments tests;

- Compare two essentially distinct microphysics parameterizations (one-moment against double-moment) among each other through tsensibility experiments tests. 
Chapter 2

\section{Literature Revision}

\subsection{Amazon Region Convection and Climatology}

The tropical convection is mainly regulated by the large-scale meteorological phenomena. These phenomena are the Hadley cell, the Intertropical Convergence Zone (ITCZ), the Walker cell, the intraseasonal oscillation between 30 and 60 days, the atmospheric waves, and the penetration of extratropical cold fronts in the Amazon Basin (De Oliveira and Nobre, 1986; Molion, 1987). Besides the circulation patterns cited above, the South Atlantic Convergence Zone (SACZ) is a system that is present mostly during the summer that exerts a big influence over the region. The SACZ is characterized by a NW-SE oriented cloud band that covers a large-scale area over most parts of the Amazon region, reaching the subtropical areas in direction to the coastal regions of Brazil (Nobre et al., 2009).

The Amazon region is characterized by strong convective activity and has two very well defined seasons: The dry season comprehends the months between May and September, and the wet season between November and March (Fisch et al., 1998). Molion (1987; 1993) studied both the mesoscale and large-scale circulation patterns observed in the Amazon region and associated them with the main dynamic processes that cause and organize the regional precipitation. According to this work, there are three kinds of mechanisms that force rainfall over the region:

- The diurnal convection resultant from diurnal surface heating and large-scale favorable conditions;

- Squall lines originated in the N/NE of the South America Atlantic Coast; 
- Convective systems that can be associated with the penetration of frontal systems over the S/SE region of Brazil and reach the Amazon region.

The main factor that shows the Amazon region importance on climate is associated with surface heating combined with the latent heat release in the atmosphere. The most frequent systems that cause rainfall over this region are the squall lines (SL) and convective systems with no defined shape.

Fisch et al. (1998) affirm that the rainfall heterogeneity over the Amazon region is a consequence of the monsoon regime over South America that occurs during the austral summer, in contrast with its acting area during the austral winter. According to the same authors, the region climate is very distinct from other regions and is resultant from interactions between meteorological phenomena in which precipitation and cloudiness are essential factors.

Machado and Rossow (1993) study mesoscale convective systems that originate from agglomerated of Cumulonimbus clouds, and present space scale between 20 and $200 \mathrm{~km}$ and, sometimes, presenting between 200 to $2000 \mathrm{~km}$ (Orlanski, 1975). These kind of convective systems are larger than any other systems when referring to convective storms (Houze, 2004) and are also the systems that make the biggest part of the vertical energy transference in the tropical troposphere (Laurent et al., 2000).

Through streamline fields analyses for low $(850 \mathrm{hPa})$ and high $(250 \mathrm{hPa})$ levels in between 1970 to 1975, Molion (1987) observed that there is a displacement of the high pressure systems in both summer and winter seasons. As a response to the change in the large-scale pattern, the mainly meridional winds in the summer become zonally behaved in the winter at high levels. Though, at the low levels, there are no significant changes in the high pressure systems positioning. The author explains that this flow change in high levels between the winter and summer occurs due to the latent heat release (from the water vapor condensation inside the troposphere), and the differences in the sensible heat flux caused by strong surface warming that happens in the summer. This heating induces the cloud formation through the thermally forced convection in which the moist and warm air superposes the low level layers over the continent, while the dry air trends downward over the oceanic adjacent areas, as it is shown in Fig. 2.1. This warming causes mass convergence in lower levels and mass divergence in higher levels of the atmosphere, which originate the Bolivian High $(\mathrm{BH})$. The $\mathrm{BH}$ is also a determinant factor that drives deep 
convection in the Amazon Basin.

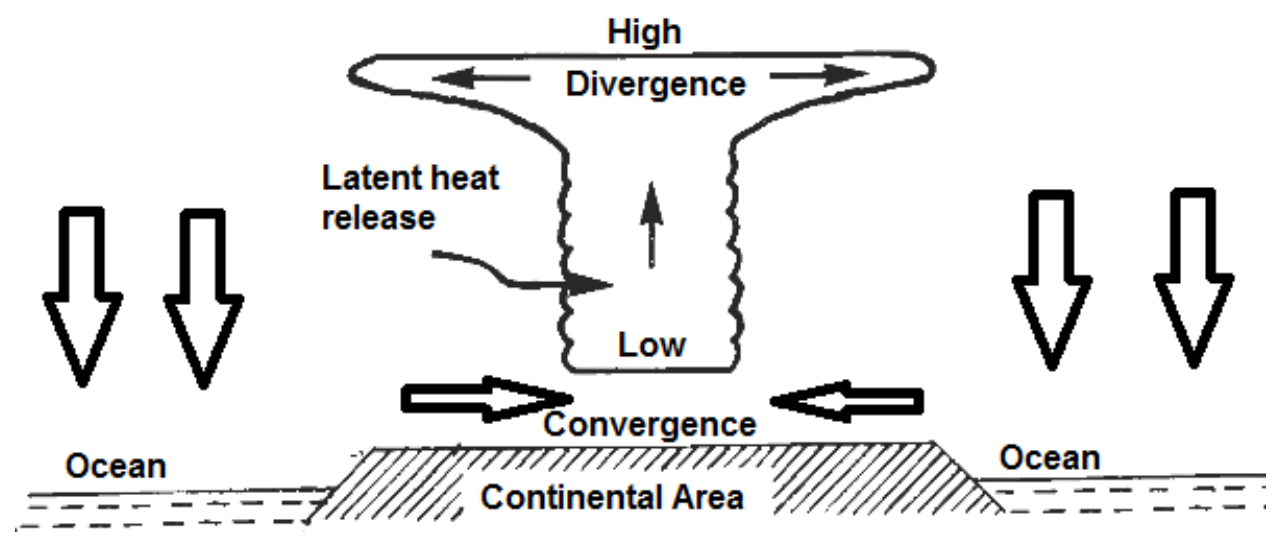

Figure 2.1: Schematic diagram representing the circulation that is resultant from the differential warming between the continent and the oceans in the summer.

The atmospheric circulation over the tropical area has patterns modulated by the thermodynamical characteristics in the Atlantic and Pacific tropical oceans (Ferreira and Mello, 2005). As a consequence of that, positive and negative anomalies of the Sea Surface Temperature (SST) over these oceans basins perturb and change the Hadley and Walker cells circulation. As it can be visualized in Fig. 2.2, the circulation pattern under normal conditions shows very good conditions to cloud formation over the north of South America and over the southernmost part of Asia, and good conditions over the western part of Africa. In contrast, we can see that this pattern is changed under El Niño conditions (Fig. 2.3 where the convection is more intense in western North America and also over western Africa.

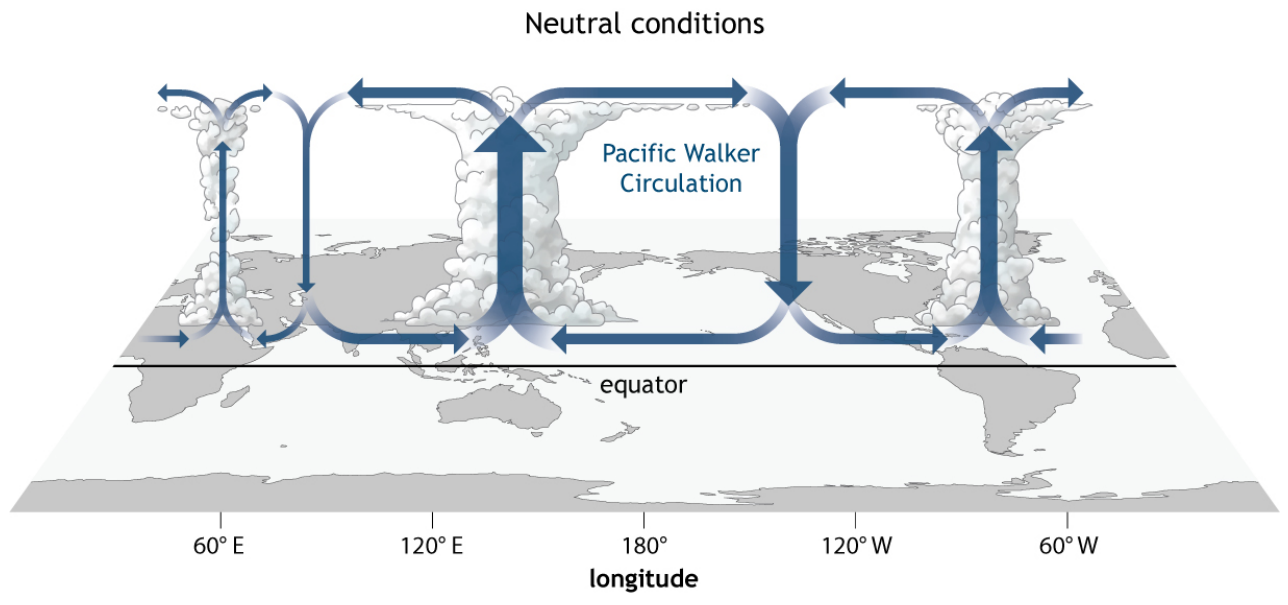

NOAA Climate.gov

Figure 2.2: Schematic diagram representing the Walker cell circulation under normal conditions. source: NOAA 


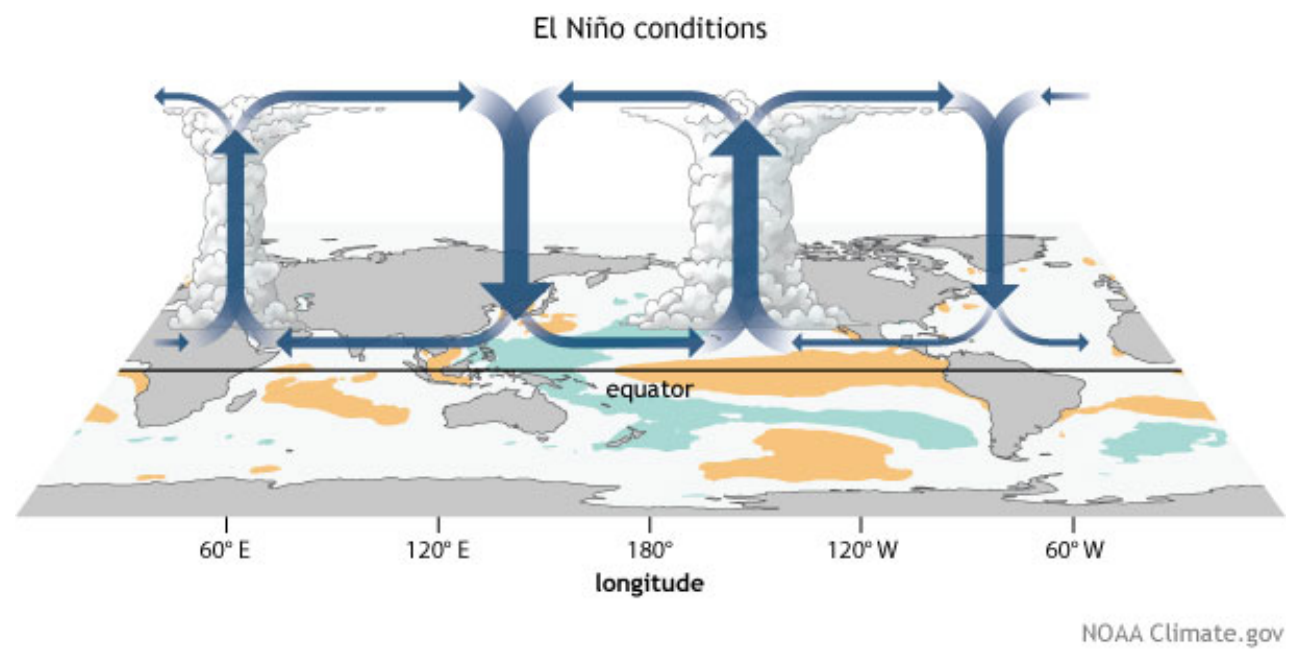

Figure 2.3: Schematic diagram representing the Walker cell circulation under El Niño conditions. source: NOAA

As it was already mentioned, cold frontal systems eventually reach the Amazon region. Besides causing precipitation during the winter, they can significantly affect its weather. This phenomenon is known by locals as chill because it causes temperature and moisture to fall. It reaches the Amazon region through the southwest, where these systems are more commonly observed (Fisch et al. 1998). However, the Amazon region suffers larger influence from the easterly winds that transport moist air masses from the Tropical Atlantic Ocean. This moist affects substantially the mesoscale systems that are observed in the Amazon (Drumond et al. 2014). Thus, the combination of the strong surface heating and the influence of the moist air masses transported to the continental region by the easterly winds make the region very propitious to the formation of convective storms.

Velasco and Fritsch (1987) studied the dynamic and structural characteristics of the Convective Mesoscale Systems (CMS) over the tropical region and over the mid-latitude of both South and North America using satellite imagery and conventional sounding data. The comparison between CMS over South and North America in the mid-latitudes shown that both are similar. The largest difference found was that the South American CMS are, in average, $60 \%$ bigger than those found over North America. Another interesting fact about the CMS is that both have a nocturnal behavior and occur mostly in continental areas. Those that originated over the oceanic region between the time of this study were mainly developed inside a tropical storm. Also, even with a strong convective activity over the tropical area of South America, the Amazon region do not show large quantities of CMS, as it is noted for the southeastern part of North America. 
Cohen et al. (1989) focused their studies in SL over the Amazon, and have found that on average these systems have $1400 \mathrm{~km}$ length and $170 \mathrm{~km}$ width. On the other hand, a more recent study accomplished in between the experiment WETAMC/LBA (Cohen et al. 2000) showed that the SL present, on average, $779 \mathrm{~km}$ length and $128 \mathrm{~km}$ width.

Machado et al. (2002) affirm that the combination of different instruments allows the description of the diurnal cycle of clouds, thermodynamics variables, and precipitation. Also, the relationships among them and their response to diurnal cycle are fundamental to the understanding of physical mechanisms and feedbacks that control the daily variability of the convection. Machado et al. (2002), in their first approach, say that the solar heating and large-scale features are the main factors controlling the diurnal cycle.

Laurent et al. (2002) based on GOES-8 infrared satellite images for every 30 minutes, assumed that low brightness temperatures were associated with deep convection over the Amazon basin during the Wet Season Atmospheric Mesoscale Campaign Large-Scale Biosphere Atmosphere (WETAMC/LBA) experiment. In their work, they have also affirmed that this assumption is only valid for tracking the tropical convective systems over their whole life cycle, because the regions that form this kind of systems also present thick Cirrus clouds generated by deep convection. Machado et al. (2002) also used GOES-8 infrared satellite images, among other instruments, in order to investigate the diurnal cycle of tropical convection during the WETAMC/LBA. The satellite images were used in the purpose of catching the initiation and dissipation of convective systems, as well as its diurnal modulation of total/high/convective cloud fraction, and the diurnal evolution of the size spectrum.

\subsection{Formation of the Convection over the Amazon Basin}

The clouds over the tropics and the mid-latitudes generally organize multiple cells of cumulonimbus into a mesoscale system. These convective systems are substantially difficult to be simulated by numerical weather forecasting models due to their complexity compared to synoptic systems which are larger and occur over a larger time period (Zipser, 1977). Over the Amazon region, three different mechanisms are responsible in the formation of the convection: the diurnal local warming, SL and the penetration of frontal systems from the southern and southeastern regions of Brazil. 
Carvalho (1989) study the diurnal convection over South America associating the upper air circulation with the convection. Through this analysis, the results obtained indicate that the diurnal convection is directly related to the $\mathrm{BH}$ and the Northeastern Through that are formed during the summer.

The convective aglomerates are studied by De Oliveira and Nobre (1985) through 1977 and 1981 with the use of satellite imagery. Through their analysis, they found that, in general, the frontal systems originated in the southern and southeastern parts of Brazil aid the formation of cloudiness that is oriented from NW to SE over South America. Also, this system reaches its peak during the summer.

On the other hand, the SL over the North and the Northeast of Brazil are reviewed by Cohen et al. (1989). Through this work, with the satellite images analyzes between 1979 and 1986, it was shown that the genesis of the SL's is directly associated with the sea breeze and the maximum frequency occur between April and August.

Over the years, the scientific community looked for pieces of evidence that add one more trigger to the formation of convective systems. Roy (2009) investigates the vegetationclimate interactions in disturbed rain forests of Amazonia. The study focus in the decrease in the precipitation simulation by circulation models and the observed increase over Rondonia due to the deforestation. Thus, using simulations with the Regional Atmospheric Modeling System (RAMS), the author noted that the temperature gradients between forested and deforested areas trigger organized mesoscale circulations where it generates cloudiness and rain over the deforested patches. Also, due to the large horizontal spatial cover of the Amazon rivers, there is a mesoscale variability of rainfall associated with the interaction of the river breeze with the large scale flow that leads more rain close to the rivers (Nunes et al., 2016; Silva Dias et al., 2002).

The rain over the Amazon basin also presents a difference in the initiation of the rainy seasons between its southern and northwestern region (Kousky, 1988; Marengo et al., 2001). The rainy season begins in the austral spring in southern Amazon, with most of the rain in the austral summer. The austral winter corresponds to the dry season in most of the region. Wet and dry seasons may also be referred with the presence of the South American Monsoon System (SAMS) (Carvalho et al. 2011). Within the SAMS the SACZ is the main feature of the wet season and its presence may endure for several days associated with extreme rainfall in most of central and southeastern Brazil (Carvalho et al., 2004). 
The northern part of the Amazon basin is also affected by the proximity of the ITCZ when it reaches its southernmost position $\left(2{ }^{\circ} \mathrm{S}\right)$ in March-April. It is valid to note that the ITCZ reaches its northernmost position $\left(14^{\circ} \mathrm{N}\right)$ in August-September. The ITCZ position is connected to the sea surface temperature anomalies in the Equatorial Atlantic and its position change cause a considerable impact on rainfall in the Amazon Basin, inclusing the occurrence of drought (Marengo et al., 2011).

\subsection{Squall Lines}

Mesoscale precipitation-producing systems are presented in a vast form of types. Those of which are formed by convective clouds and are organized in a quasilinear fashion are frequently observed around the world and, like the other types, difficult to analyze in details using only observed data. Lines of cumulonimbus clouds associated with a pseudocold front (as the squall front are sometimes called) at the surface are defined as squall lines (Zipser, 1977). They propagate with considerable high speed with respect to the ambient low-level air. Also, they often propagate in the general direction of the squall wind following the cold air behind the squall front (Zipser, 1977).

Hamilton et al. (1945) have already noted that the tropical SL are formed by a region of intense downward wind flows sited under anvil shaped clouds that are formed at the top of the cumulonimbus clouds. The adjacent air at the front of the system, here forward mentioned as gust front, is warmer than the air at the rear of the system and lifts the air to the upper atmosphere due to the temperature gradient and causes the formation of new convective cells.

In Fig. 2.3 it is shown a representation of a SL in a cross section over Barbados on $18^{\text {th }}$ August 1968 presented by Zipser (1977). In this example, it can be noted that the ambient airflow is from front to back at all levels relative to the squall line. The cold air at $150 \mathrm{~m}$ is nearly a material surface separating different air masses. The air ahead of the squall front is lifted and must surely rise to anvil levels (upper levels of the system). The region where the updraft is observed is followed by a dry region. The heavy rain region is denoted at the rear of the updraft region which is defined as the convective region of the storm. Also, at the rear of the heavy rain region there is light rain, which is the stratiform region of the system. 


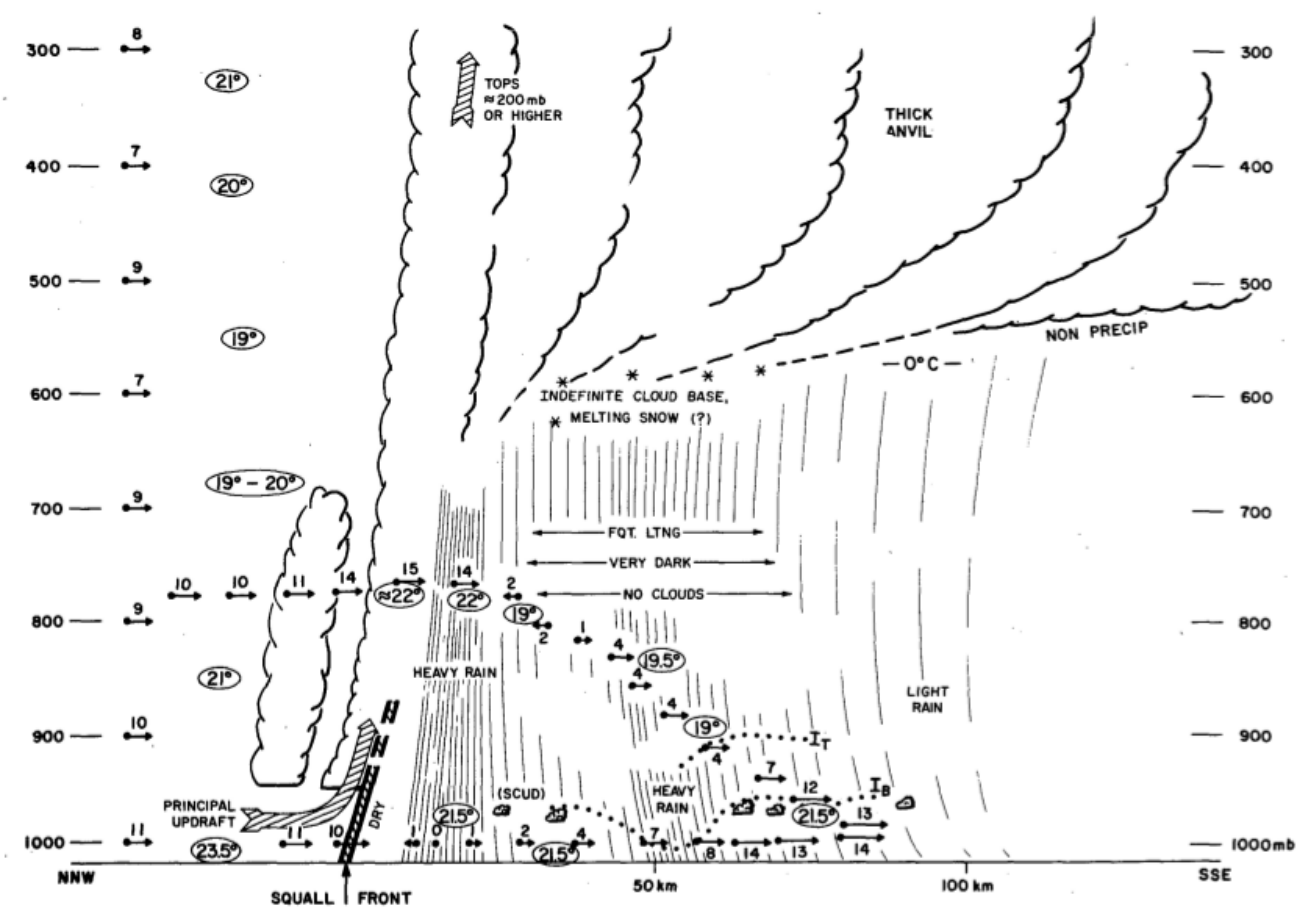

Figure 2.4: Squall line cross section through the case observed in $18^{\text {th }}$ August 1968 (Zipser, 1977).

Houze Jr (1977) (see Fig. 2.5 presents a conceptual model that represents the SL in a cross section as seen by a radar, complemented with the aid of a network of automatic station data and satellite images. In this figure, there is a dark shading region denoted by the radar echo in the melting band and in the heavy precipitation zone of the mature SL element. The light shading region shows weaker radar echoes. The scalloped line indicates visible cloud boundaries and the streamlines show flow relative to the squall line. Dashed streamlines show updraft circulation, thin solid streamlines show convective-scale downdraft circulation associated with mature SL element and wide arrows show downdraft below the base of the anvil cloud.

The ascending airflows transport warm and moist air from the planetary boundary layer to the upper atmospheric levels. Descending airflows transport cold and dry air from the middle of the troposphere to the planetary boundary layer. When they reach the surface they form a cold air pool that produces a convergence zone that is directly associated with the formation of new convective elements at the front of the system which spreads at the rear of the system. As the SL propagates, the older elements weaken and mix themselves with the anvil region until its dissipation. Each element of the SL evolves during a fast growth period with top radar echoes penetrating the tropopause at a maximum altitude 
of approximatelly 16-17 km. Afterwards, they decay to the height of $13-14 \mathrm{~km}$ which corresponds to the anvil height where the elements of the SL are associated with the end of its lifecycle.

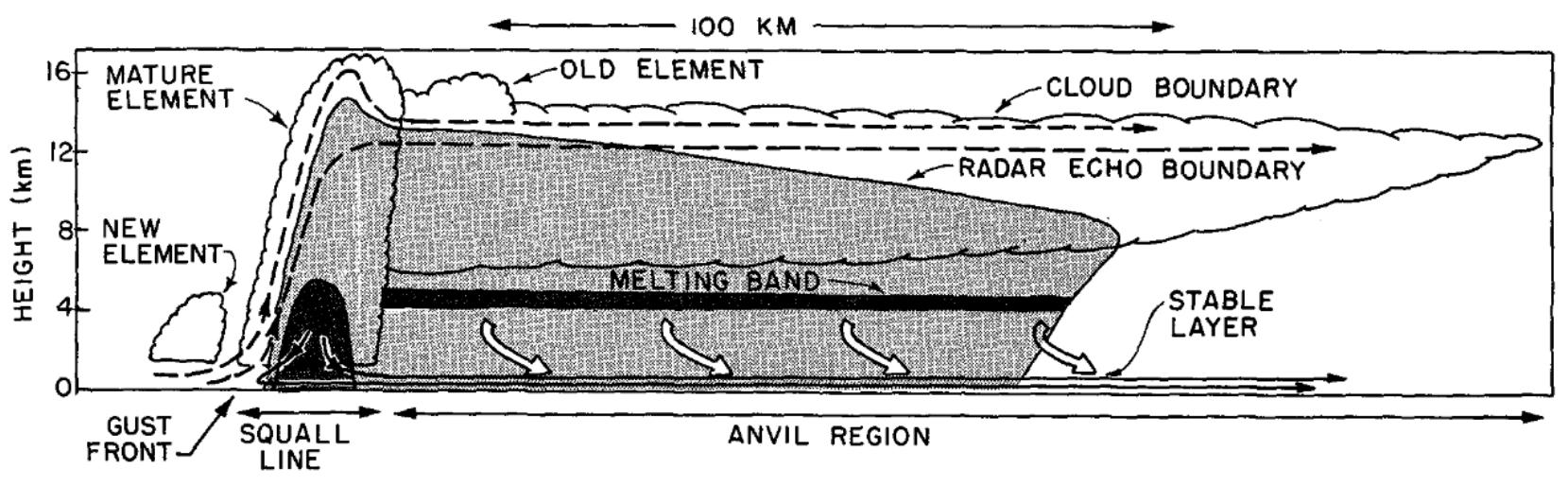

Figure 2.5: Squall line cross section conceptual model acoording to Houze $\mathrm{Jr}$ (1977).

Houze (1989) reviewed the Houze $\operatorname{Jr}(1977)$ model in 1989 in a trailing stratiform conceptual model to show how a SL is seen in a vertical cross-section oriented perpendicularly to a convective line region. He showed that the line shows an area that indicates more intense radar echoes, represented by the orange and yellow shaded areas. These regions where the radar echoes are more enhanced are confined to the leading edge of the system. The second more intense radar echoes are associated with the trailing stratiform precipitation which is generally found at the rear of the system, denoted by the area shaded in green. He also presents the areas where the pressure shows maximum and minimum values.

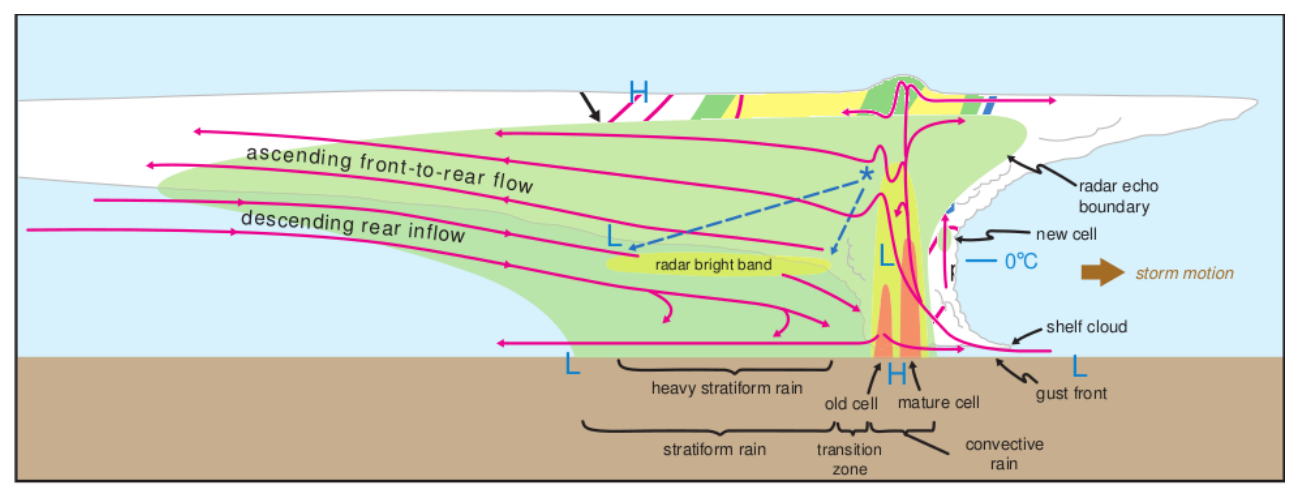

Figure 2.6: Conceptual model of a squall line with trailing stratiform area viewed in a vertical cross-section oriented perpendicularly to the convective line. The green shading indicates the region of precipitation-sized hydrometeors, where radar echo is present. The yellow and orange shading indicates more intense radar echoes. Pressure minima and maxima are also indicated, as is the height of the melting level, which is located just above the height at which a radar bright band is observed. Source: Markowski and Richardson (2011); Houze $(1989)$ 
Johnson and Hamilton (1988) show a schematic of surface pressure, wind and precipitation of a SL during its mature stage. With this model, Johnson and Hamilton (1988) shows that the divergence is right behind the mesohigh center at the surface in Fig. 2.7. The convergence zone is slightly positioned at the rear of the wake low center at the surface. The compensating subsidence and the adiabatic warming ahead of the SL may result in low pressure in the inflow of the convection in Fig. 2.7.

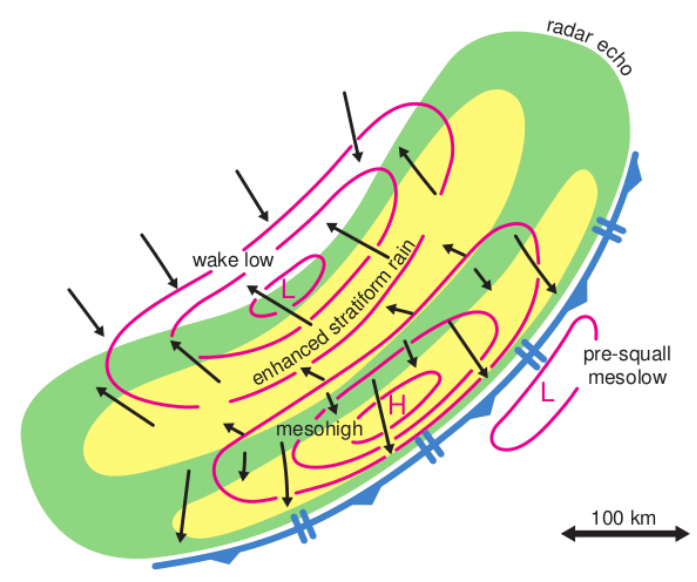

Figure 2.7: Schematic surface pressure, wind, and precipitation fields during the mature stage of a squall line. Arrows indicate actual (as opposed to system-relative) winds. Source: Markowski and Richardson (2011); Johnson and Hamilton (1988)

Rotunno et al. (1988) shows that the formation and the development of a SL are directly associated with the magnitude and the ambient orientation of the wind shear relative to the SL. In an ambient that presents no wind shear (Fig. 2.8 a), the cold pool expands circularly for all of the surface directions. On the other hand, with the presence of vertical wind shear, the cold air pool promotes a preferential region to the genesis of new cells (Fig. $2.8-\mathrm{b})$.

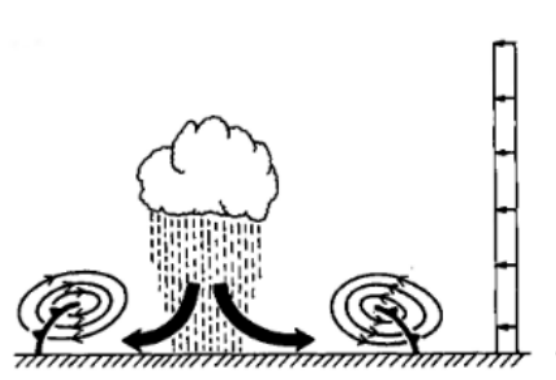

(a)

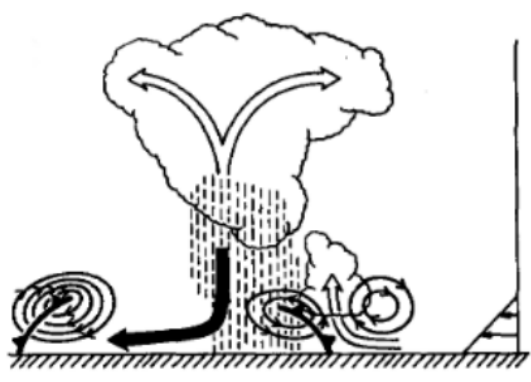

(b)

Figure 2.8: Wind shear role and the development of new cells. a) no wind shear; b) with wind shear. Source: Rotunno et al. (1988) 
During the Amazon Boundary Layer Experiment campaign (ABLE 2B), Garstang et al. (1994) datailed the structure, dynamics, and lifecycle of SL over the coastal Amazon region. They identified six stages: coastal genesis, intensification, maturation, weakening, reintensification, and dissipation. Also, they denoted that there are three different regions inside the system of a SL: the rear part, containing the cumulus clouds towers, the front region that presents more intense convection, and the other layers of the cloud, corresponding to the stratiform portion.

During the LBA and Tropical Rainfall Mesurement Mission, Pereira Filho et al. (2002) shows, in a SL case study occured in January $26^{\text {th }}$ of 1999 , that the cold pool originates at the mid levels (between 400 and $600 \mathrm{hPa}$ ) associated with the cooling caused by evaporation of liquid drops. Also, they showed that the SL convective band is dominated by the cold phase of the microphysics, while the stratiform band is dominated by the warm microphysics.

In a case study occured in May $30^{\text {th }}$ of 2008, Alcântara et al. 2014) shows the influence of the mid and low level jets in the physical processes associated with the clouds. Through this study, they concluded that a deep and intense jet occurrence up to the mid levels causes more ventilation inside the cloud, which implies in more evaporation and dryness and then more entrainment. This directly affects the SL ascending and descending airflows and the cold pool, and consequently, its propagation speed and duration.

\subsection{The Mesoscale Model WRF}

WRF model is a compressible non-hydrostatic model that is part of a complex system of numerical regional weather modeling. It has been widely used by researchers and operational centers for weather forecasts (Skamarock et al., 2008).

The physic schemes that are implemented in the WRF model are divided into five types: a) Microphysics; b) Planetary Boundary Layer; c) Cumulus; d) Terrain Surface Model; and e) Radiation. In this work, the most relevant parameterizations are associated with the precipitation development, i.e., Microphysics and Cumulus. This does not mean that the other parameterizations are irrelevant but the main focus is to study how the microphysics affects the convection generated in a case study.

The temporal integration of the physic schemes is made using the third-order Runge- 
Kutta numerical method to the resolution of differential equations by default. This option can be changed for the second-order Runge-Kutta numerical method (Skamarock et al. 2005). The equations of the dynamic-core variables are implemented in the MKS system and the radiation, surface, planetary boundary layer, and cumulus physics trends are primarily solved, followed, then, by the microphysics parameterization, so that the model can maintain its numerical stability conditions in the end of the time-step after some adjustments.

\subsubsection{Microphysics Parameterization}

Water vapor, water cloud, ice cloud and precipitation (including liquid, hail, and snow) fields are microphysics processes explicitly solved in the WRF, i.e., when these processes can be reproduced by the circulation dynamics in each grid point of the domain (Skamarock et al. 2005).

There are two categories of microphysical parameterizations and they change by the way they represent the size distribution of particle types. Bin parameterizations represent the particle size spectrum into separate intervals and the particle concentrations are predicted for each interval. This type of representation makes the numerical scheme very expensive in computational time terms because changes in each bin can result in conversions in between particle types and increase or decrease of particle sizes, which requires a predictive equation for each bin. As gretaer the number of bins, the greater the number of predictive equations. Nowadays, to overcome such computational constrain, Bulk Microphysical parameterizations are used in operational regional models around the world. This type of microphysical parameterization assumes one assigned analytic form for the size spectrum of each particle type. The most common ones are the exponential and gamma distributions, while the evolutions of the size spectra fields are obtained by solving predictive equations for the moments (Warner, 2010).

One-moment microphysical schemes only predict the particle mixing ratio, while the double-moment microphysical schemes can predict both the particle mixing ratio and the particle total number concentration. According to Milbrandt and Yau (2005), the doublemoment schemes are better than one-moment schemes because the shape and the slope parameters evince that the mass mixing ratio and the total number concentration are always monotonically related, regardless of the choice of the predictive variable. However, 
both quantities are not dependent on each other, making this assumption invalid. If particles are growing by water vapor diffusion, for example, the total number does not change, but the total mass changes. On the other hand, if growing is started by aggregation or breakup, the total mass keeps constant and the total number of particles change. So, with this assumption, the one-moment schemes are tested and shown here, but the focus will be given to double-moment microphysics schemes in the further analyzes. Also because, following the concept that the higher the degree of freedom of the meteorological model the better the simulation (Warner, 2010; Mass et al., 2002; Morrison et al., 2005; Milbrandt and Yau, 2005).

Some of the schemes that can be used in the WRF model are:

- Purdue Lin Scheme: This scheme was developed for research purposes of a relatively sophisticated microphysics. Its name was given because it was made in reference to the cloud scheme of the University of Purdue (in the USA), and all its parameterizations schemes were made by (Lin et al., 1983) and (Rutledge and Hobbs, 1983). It includes six kinds of hydrometeors: water vapor, cloud water, rain, cloud ice, graupel, and snow.

- WRF Single-Moment 3 Scheme (WSM3): This scheme uses the bulk microphysics parameterization scheme and comprehends the representation of the ice properties inside the cloud, like the sedimentation of ice crystals fall, ice mass, diameter and the relationship with the concentration number among others (Hong et al., 2004). Regarding with the included hydrometeors, this parameterization scheme contains the cloud vapor, water and ice as well as rain and snow. Through this study, and in the implementation of the WSM3 model, Hong et al. (2004) concluded that this scheme is effective in the resolution of mesoscale events in the $25 \mathrm{~km}$ grid. Thus, the scheme can be very effective in the operational meteorology of nowadays (Skamarock et al., 2005).

- WSM5 Scheme: Comparing to the WSM3, WSM5 is more sophisticated and considers the mixing phase of the hydrometeors. It distinguishes these hydrometeors in five different classes. Thus, the supercooled water and the melting snow are considered in the microphysics parameterization (Skamarock et al., 2005). 
- WSM6 Scheme: This one is even more sophisticated than the WSM3 and WSM5 schemes. It includes in its microphysics the processes associated with graupel. Macedo et al. (2012) used this scheme and obtained better results when they compared with the Purdue Lin scheme.

- Morrison Scheme: Morrison scheme is based on the double moment bulk microphysics scheme of (Morrison et al., 2005), which includes six species of water: vapor, cloud droplets, cloud ice, rain, snow, and graupel/hail. The code has a user-specified switch to include either graupel or hail.

- Milbrandt \& Yau Scheme: This is a double moment microphysical scheme that includes separate categories for hail and graupel, with double-moment cloud, rain, ice, snow, graupel, and hail.

\subsubsection{Cumulus Parameterization}

The Cumulus parameterization schemes are sub-grid scale effects regulators of convective clouds. They are used in an attempting to evidence the vertical fluxes generated by not-solved air drafts and the compensated movements outside of the clouds (detraining and entraining). These schemes operate differently from the microphysics schemes because they are activated in vertical columns where they can provide the vertical moist and heat profiles.

Theoretically, only grids with low resolution scales (larger than $10 \mathrm{~km}$ ) are prone to gain useful information by cumulus parameterizations, where the latent heat release of the convective columns in real-time are needed. While the convective eddies have been represented by finer resolution grids (smaller and presenting larger space resolution) in subgrid scales, the cumulus scheme utilization has become more common in the activation of the convection in applications with grid scales between 5 and $10 \mathrm{~km}$. This is not necessary when grids smaller than $5 \mathrm{~km}$ are used because WRF can explicitly simulate eddies under these circumstances (Skamarock et al., 2008). However, according to Zheng et al. (2016) the usage of cloud microphysics alone (i.e., with the cumulus parameterization turned off) may not be sufficient to properly create moist convection and precipitation for warmer periods in weather forecasts.

Some of the Cumulus parameterizations are described below: 
- Kain-Fritsch (KF): It is a modified version from the (Kain and Fritsch, 1990) and (Kain and Fritsch, 1993) based on the Eta model tests. It considers a simple model of cloud with updrafts and downdrafts, also including the simple microphysics effects like entraining and detraining.

- Multi-scale Kain-Fritsch: Improving the horizontal resolution grids is not the only key-point for obtaining better forecasting results. One must improve the parameterization schemes in order to improve dynamical downscaling of global model information. The Multi-scale Kain-Fritsch is a cumulus parameterization that was created to allow the use of cumulus parameterizations in the meso-gamma scale $(2-20 \mathrm{~km})$. Some updates were included in this new scheme which comprises the inclusion of sub-grid scale cloud radiation interactions, a dynamic adjustment time scale, impact of sub-grid scale cloud updraft mass fluxes on grid-scale vertical velocity, and an entrainment methodology based on the lifting condensation level (LCL). All of these updates insert scale dependency for some of these key parameters in KF scheme and, in the overall, the updated KF scheme is found to generally improve the highresolution simulation of longwave and shortwave radiation associated with cloud patterns, and produce precipitation patterns and intensity that are closer to the observations (Zheng et al. 2016).

\subsection{Microphysics and Thermodynamics Features Inside a Cloud Development}

Air parcels in adiabatic ascension in the atmosphere reach the Lifting Condensation Level (LCL) when the air parcel becomes saturated related to the water (Yau and Rogers, 1996) and (Houze Jr, 2014). After the parcel reaches this level and due to the presence of particles in suspension in the atmosphere known as cloud condensation nuclei (CCN) the droplets start to form by heterogeneous nucleation. The droplets begin to grow by condensation where they consume water vapor present in the atmosphere that comes from the rising air parcels that reach the LCL. When the droplet number concentration rises, the quantity of water vapor supplied by the air parcels rising in the atmosphere is not enough to produce more droplets, so the minor droplets evaporate and the larger droplets 
begin to grow larger as they are fed with more water vapor. Thus, the minor droplets supply water vapor to the growth of larger droplets. However, this process is not the only one that causes the droplets growth. In this process, it is noticeable that droplets with more 10 micrometers in diameter are stable, and because of their surface tension produced by its almost spherical curvature, its vapor pressure is lesser than the vapor pressure around smaller droplets. In this way, droplets with more than 10 micrometers grow up at the expenses of smaller droplets. The growing droplets also grow by the collision and coalescence with other droplets. As they rise or fall in the atmosphere and grow by condensation, they can collide with other droplets and grow larger by coalescence or even remain with the same size. This happens because they can collide and keep together, as well as they can collide and split up again. So, the droplets first grow by condensation to a determined droplet size, and after that, they grow by collision and coalescence in a more effective way.

Because of the latent heat release by condensation, the buoyancy of rising air parcels keeps the parcels rising in the atmosphere, and the droplets can eventually trespass the $0{ }^{\circ} \mathrm{C}$ isotherm, which starts the cold phase of the cloud. At this point, the droplets can keep themselves in the liquid state as supercooled (Bergeron process) water as well as they can turn into ice. The ice can form at temperatures higher than $-40{ }^{\circ} \mathrm{C}$ when there are ice condensation nuclei, so it is possible to find different hydrometeors in the ice and liquid phase between 0 and $-40{ }^{\circ} \mathrm{C}$. This layer is known as the mixed-phase of the cloud. Fig. 2.9 shows the idealized cloud microphysics phase in a vertical cross section with the temperature isotherms of $0,-15,-20$ and $-40{ }^{\circ} \mathrm{C}$. It denotes the regions where the cloud presents its mixed-phase. So, between 0 and $-15{ }^{\circ} \mathrm{C}$ the cloud presents supercooled water. Between -15 and $-20{ }^{\circ} \mathrm{C}$ it can present both supercooled water and ice and above 20 and $-40{ }^{\circ} \mathrm{C}$ it presents only ice. It is stressed out that the cloud can present ice below $0{ }^{\circ} \mathrm{C}$ because graupel and hail do not instantly melt below the $0{ }^{\circ} \mathrm{C}$ isotherm. Also, the cloud can contain water and water vapor which are most important in the cloud formation. 


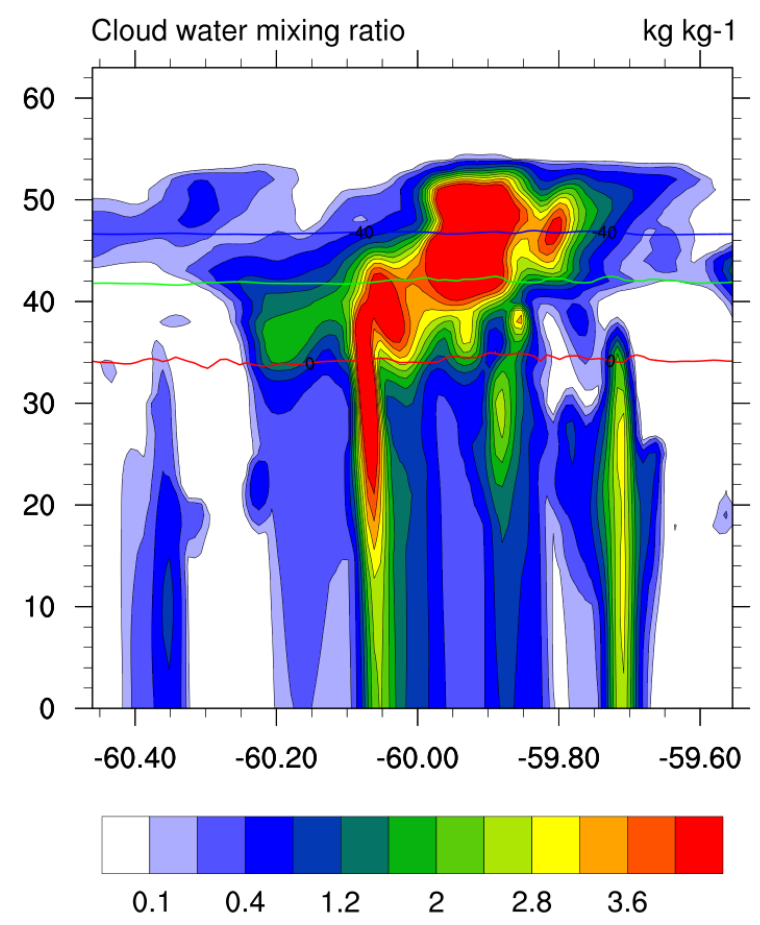

Figure 2.9: Cloud hydrometeor sum in a vertical cross section over a fixed latitude point with temperature isotherms.

The convective clouds present both the convective (newer and stronger cells) and the stratiform (older and weaker cells) regimes. The convective region is characterized by warming the entire troposphere and is dominated by the deposition and condensation processes. The stratiform regime usually cools the lower atmosphere that is dominated by evaporative cooling (Siqueira et al., 2005). At the beginning of weather satellite retrievals of the atmosphere, the first studies began by using Infrared and Visible images retrieved by passive sensors on board of geostationary weather satellites (Velasco and Fritsch, 1987). As the satellite missions increased, the Tropical Rainfall Measuring Mission (TRMM) was launched in 1997 with the first weather radar on board of meteorological satellites together with passive sensors. It was used in several studies to determine the structural descriptions of convective systems as well as for the investigation of possible relationships between rainfall amounts and cloud properties (Nunes et al., 2016, Minnis et al., 2011; Huffman et al., 2007; Ribeiro Macedo et al., 2016). 
Chapter 3

\section{Materials and Methods}

\subsection{Observed Data}

The Green Ocean Amazon (GOAmazon 2014/15) was run over the region of Manaus (see Fig. 3.1) and the central part of the Amazon Basin. The city of Manaus is isolated from the forest in its surroundings and has approximately 2 million inhabitants. The city is sufficiently large to present the urban heat island effect up to $3{ }^{\circ} \mathrm{C}$ relative to the forest (De Souza and dos Santos Alvalá, 2014).

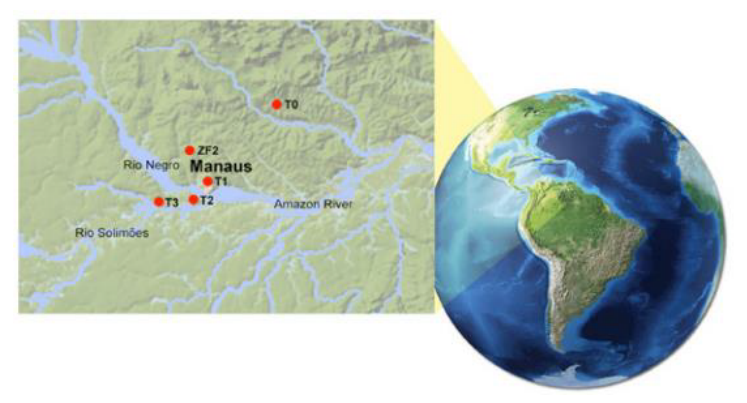

Figure 3.1: Region where the IOP1 and IOP2 were run and the region of interest.

The GOAmazon measurements were made between January $1^{\text {st }}$ to December $31^{t h}$. Two intensive operations periods (IOP) that included aircrafts, additional personnel, and instrumentation over the surface regions were conducted during both dry and wet seasons in 2014. The IOP1 comprehended January $1^{\text {st }}$ to March $31^{\text {th }}, 2014$ and the IOP2, between August $15^{\text {th }}$ and October $15^{\text {th }}, 2014$. In this phase, nine surface automatic stations were available inside and around Manaus. The GOAmazon2 was run in 2015.

The upper air sounding informations available from 6 to 6 hours through the available GOAmazon data over Manaus, and Manacapuru is, more specifically, used in this work. 
These data include the wind speed $\left(\mathrm{m} \mathrm{s}^{-1}\right)$ and direction (degrees), atmospheric pressure $(\mathrm{hPa})$, temperature $\left({ }^{\circ} \mathrm{C}\right)$ and relative humidity $(\%)$ and is used in the purpose of analyzing the atmospheric instability through the computation of several instability indexes to access the possibility of storm development in the region of interest. The data is also used to make a comparison between observed and simulated data.

\subsection{Radar Data}

The meteorological radar from the Sistema de Proteção da Amazônia (SIPAM) is a S-band radar sited at $3.1489{ }^{\circ} \mathrm{S}$ and $59.9914^{\circ} \mathrm{W}$. Its data includes the corrected reflectivity and the radial velocity with $2 \mathrm{~km}$ of horizontal spatial resolution and $0.5 \mathrm{~km}$ of vertical spatial resolution.

The comparison between this data can be done using the reflectivity fields generated by WRF runs of $1 \mathrm{~km}$ horizontal grid spacing, which is derived from the simulated rain rate fields produced by microphysical parameterizations. The Z-R relationship used in this study is given by 3.1. The model reflectivity is degraded to a $2 \mathrm{~km}$ horizontal spatial grid, so that it is possible to compute the correlations between both observed and simulated data. The method that is applied here computes the sum, considering all grid points in a horizontal box, of both radar and model rain rates for 4 specific boxes that are shown in Fig. 3.2. In the sequence, the correlation between both observed and simulated rainfall data are computed.

$$
Z=178.0 * R^{1.44}
$$

The boxes here mentioned have $2 \mathrm{~km}$ horizontal resolution each and they present different sizes, which can be checked in Table 3.1 that shows the box sizes. This choice of boxes was made intentionally to check if the size of the boxes matters when accounting the precipitation rates in this case. 
Table 3.1 - Sizes in gridpoints for the sum of the rain rates boxes in September 08 ${ }^{\text {th }}$, 2014 from 1700 UTC to 2330 UTC.

\begin{tabular}{lll}
\hline & East-West & North-South \\
Southern Box (1) & 41 & 41 \\
Eastern Box (2) & 57 & 56 \\
Northeastern Box (3) & 29 & 29 \\
Northwestern Box (4) & 29 & 29 \\
\hline
\end{tabular}

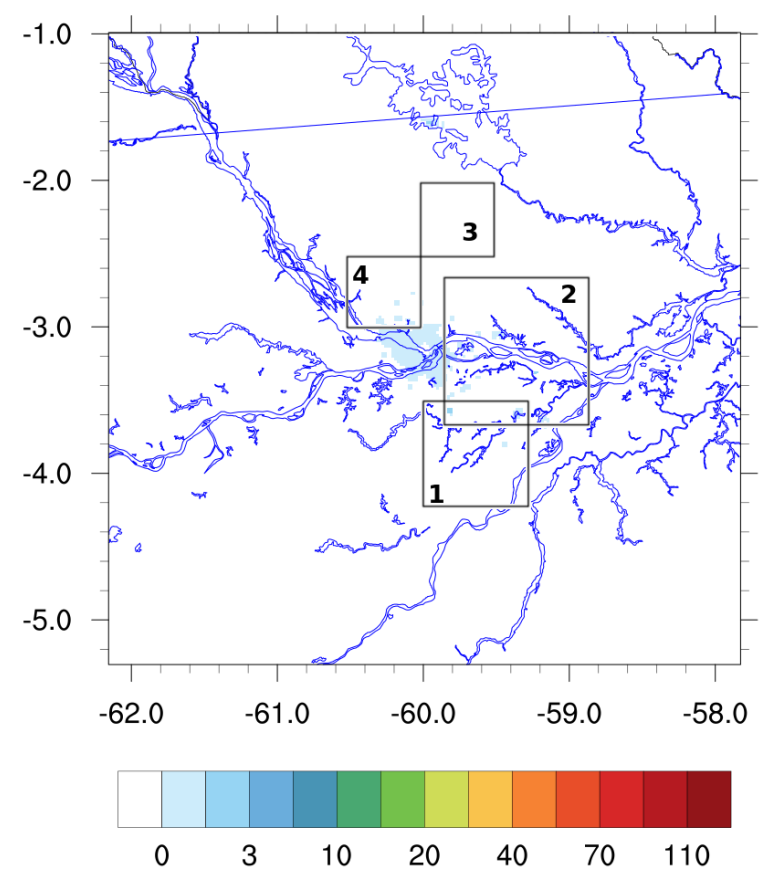

Figure 3.2: Boxes around the radar radius used for the rain rates sum calculations and other analyzes.

\subsection{Rain and Ice water Path}

The Warm Rain Water Path (WRWP) and the Ice Water Path (IWP) are estimated by integrating the Rain Water Content (RWC) and Ice Water Content obtained by the radar data inside the boxes cited in the previous section through a similar methodology used by Petersen and Rutledge (2001) and Carey and Rutledge (2000).

The RWC is estimated by the CAPPI data from the lower level $(0.5 \mathrm{~km})$ to the region below the freezing level $(4.5 \mathrm{~km})$ as it was observed by the sounding data through the following equation: 


$$
\begin{gathered}
R W C=3.44 * 10^{-3} * Z^{4 / 7} \\
W R W P=\int_{0.5 \mathrm{~km}}^{4.5 \mathrm{~km}} R W C d h\left[\mathrm{~g} \cdot \mathrm{m}^{-2}\right]
\end{gathered}
$$

where $\mathrm{Z}$ is the reflectivity given by $\mathrm{mm}^{6} \mathrm{~m}^{-2}$. The IWP is obtained by integrating the IWC from 7 to $20 \mathrm{~km}$ where the temperatures presented in the soundings are close to -10 to $-12{ }^{\circ} \mathrm{C}$ by the following equations:

$$
\begin{gathered}
I W C=1000 * \pi * \rho_{i} * N_{0}^{3 / 7} *\left[5 * 10^{-18} *(Z / 720)\right]^{4 / 7} \\
I W P=\int_{7 k m}^{20 k m} I W C d h\left[g \cdot m^{-2}\right]
\end{gathered}
$$

where $\rho_{i}=917 \mathrm{~kg} \mathrm{~m}^{-3}$ is the density of ice and $\mathrm{N}_{0}=4^{*} 10^{6} \mathrm{~m}^{-4}$ is the intercept parameter of an assumed inverse exponential distribution for ice.

\subsection{CPC MORPHing technique - CMORPH}

CMORPH is a technique that produces global precipitation analyses at very high spatial and temporal resolution. It uses precipitation estimates that have been derived from low orbiter satellite microwave observations exclusively. The microwave observations features are transported via spatial propagation information that is obtained entirely from geostationary satellite infrared data. The precipitation estimates are derived from the passive microwaves aboard the NOAA-15, 16, 17 and 18 (AMSU-B), DMSP 13, 14 and 15 (SSM/I), and AMSR-E and TMI aboard NASA's Aqua and TRMM spacecraft, respectively. These estimates are generated by algorithms of Ferraro et al. (2000) for AMSU-B, Ferraro (1997) for SSM/I and Kummerow et al. (2001) for TMI. This technique is not a precipitation estimation algorithm but a means by which estimates from existing microwave rainfall algorithms can be combined. Therefore, this method is extremely flexible such that any precipitation estimates from any microwave satellite source can be incorporated. 


\subsection{Global Forecasting Model - GFS}

The analyses of the Global Forecasting Model (GFS) is available for every six hours and are daily produced by the National Centers of Environmental Prediction (NCEP) for 0000, 0600, 1200 and 1800 UTC. The vertical distribution of data is available for 27 pressure levels between 1000 and $1 \mathrm{hPa}$ and $0.5^{\circ}$ spatial resolution. This dataset is used for the identification of synoptic phenomena that were present in each selected case study, as well as for the comparison between WRF simulation made in low-resolution grids.

The GFS analyzes are used to generate the sea level pressure, $10 \mathrm{~m}$ AGL wind speeds, streamlines, and isotachs at $250 \mathrm{hPa}$ fields. Notwithstanding, the specific humidity, streamlines and temperature at $850 \mathrm{hPa}$, relative vorticity at $500 \mathrm{hPa}$ and the moisture transport will be generated to give not only a synoptic overview of the case study but also to check de WRF model predictability. Also to run WRF, the GFS analyzes are used as initial and boundary conditions in this case study.

\subsection{GOES-13 Satellite Imagery}

The satellite infrared images available for every 30 minutes from the Divisão de Satélites e Sistemas Ambientais - Instituto Nacional de Pesquisas Espaciais (DSA-INPE) is used in the purpose of identifying the start and the end of deep convective events and to distinguish between convective and stratiform parts of each observed system. These data is chosen to detect deep convection development because it shows the cloud brightness temperature. In this work, for image pixels with brightness temperatures below $0{ }^{\circ} \mathrm{C}$, the pixel is considered as a "cold cloud"pixel.

\subsection{Case study of September 08 $8^{\text {th }}, 2014$}

The case selection has been made through the analysis of the rain gauge data and the satellite imagery collection from DSA-INPE. This case was selected because the accumulated rainfall reached up to $56 \mathrm{~mm}$ between the beginning and the end of the day at September $08^{\text {th }}, 2014$. It was also selected because the GOAmazon data were available. It can be noted that other 3 convective cases identified with this methodology were eliminated because of lacking data. 


\subsection{Methodology for the WRF mesoscale simulations}

The numerical weather prediction model WRF allows exploring a large portion of meteorological phenomena that can comprise the large and/or the micro atmospheric scale. It can simulate the atmospheric conditions through real data, i.e., where the initial conditions are provided through the analysis of atmospheric current conditions and through idealized conditions like sea breeze, SL, large-scale eddies and other kinds of atmospheric phenomena (Skamarock et al., 2008).

At first, the model is configured covering the entire South America as indicated by Fig. 3.3 with $27 \mathrm{~km}$ grid points distance (D01) and therefore with $54 \mathrm{~km}$ space resolution (2 $\Delta \mathrm{x})$. The selected case comprehends September $08^{\text {th }}$ to $09^{t h}, 2014$ and the simulations were performed for $72 \mathrm{~h}$ from September $07^{\text {th }}, 2014$ at 0000 UTC to September $09^{\text {th }}, 2014$ at 0000 UTC except for the $1 \mathrm{~km}$ domain that was run from September 08 ${ }^{\text {th }}, 2014$ at 1200 UTC to September $09^{\text {th }}, 2014$ at 0000 UTC. D01 was used to compare the model runs with the large-scale atmospheric patterns from the GFS real data analysis previously cited because of its resolution. As a second step, three new grids are nested within the G27: one with 9 (D02), other with 3 (D03) km and another one with 1 (D04) km grid points spacing, also shown in Fig. 3.3. D02 was also used to analyze the synoptic conditions because it is an intermediate grid between the synoptic scale to the mesoscale conditions that were analyzed with D03 and D04. The D01 and D02 grids have simulation outputs for each hour, while D03 and D04 have outputs for every 30 minutes to better demonstrate the weather simulations for the case study. This configuration planning follows the computational availability at the Laboratory of Mesoscale Meteorology, which provides a cluster of 96 INTEL nodes to run WRF in the parallel mode. 


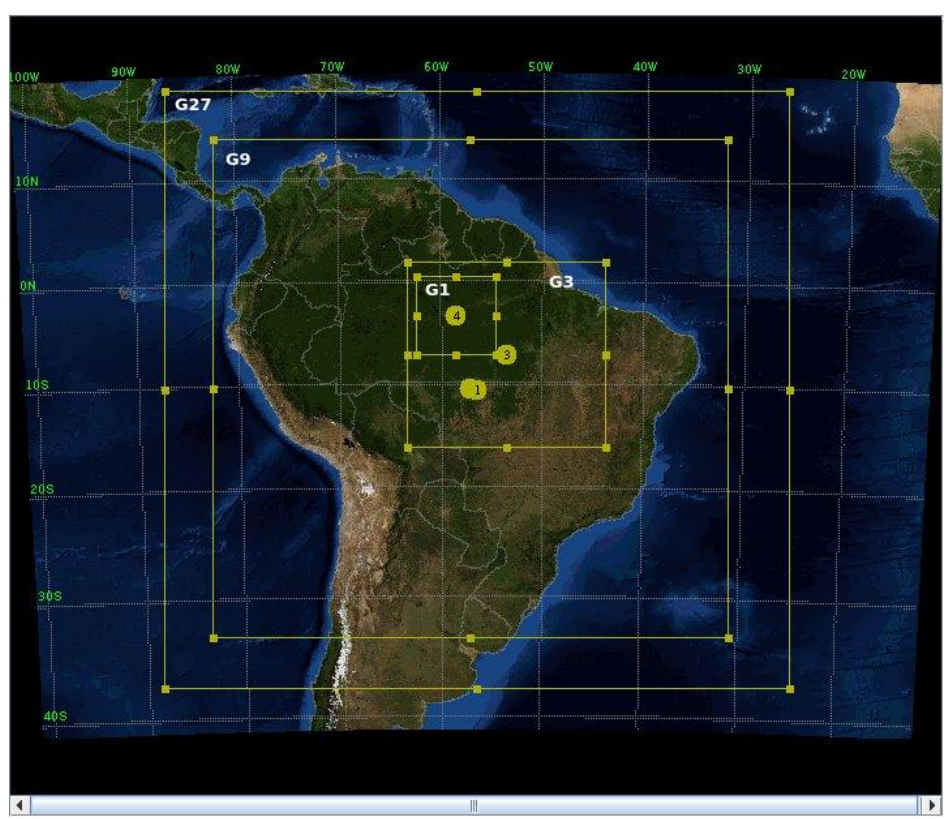

Figure 3.3: The four grid domains used to run the Control Run.

\subsection{Control Run Experiment}

The control run experiment is defined using the nested grids presented in Fig. 3.3 , where the grid spacing is defined in section 3.8 where is found the basic characteristics. The specific physical parameterizations including the planetary boundary layer, microphysical, cumulus, terrain surface model and radiation are described in Table 3.2

The experiment is initialized at 0000 UTC at September 07 ${ }^{\text {th }}, 2014$ for D01, D02 and D03, and at 1200 UTC September 08 ${ }^{\text {th }}, 2014$ for D04. The physics parameterizations used in the four experiments are shown in Table 3.2. More attention will be given for the twomoment parameterization schemes, i.e. for Morrison and Milbrandt schemes. Another run using only the Kessler warm parameterization scheme is made to evidence the differences between this warm phase scheme with the mixed-phase schemes (Lin, Morrison, Milbrandt and WSM6). 
Table 3.2 - Physical characteristics of the Control Run

\begin{tabular}{|c|c|}
\hline Number of Vertical Levels & 65 \\
\hline Model Top & $50 \mathrm{hPa}$ \\
\hline Large domain time step & $60 \mathrm{~s}$ \\
\hline Downscaling ratio & 3 \\
\hline Domain Numbers & 4 \\
\hline Cumulus & Multi Scale Kain-Fritsch (Zheng et al., 2016) ${ }^{1}$ \\
\hline \multirow[t]{2}{*}{ Microphysics } & Milbrandt (Milbrandt and Yau, 2005) , Purdue Lin , bSM6 c \\
\hline & and Morrison ${ }^{\mathrm{d}}$ \\
\hline Long-Wave Radiation & RRTMG \\
\hline Short-Wave Radiation & RRTMG \\
\hline Surface Layer Model & MM5 Similarity \\
\hline Land Surface Model & Five Layer Thermal Diffusion \\
\hline Planetary Boundary Layer & Yonsei University Scheme \\
\hline
\end{tabular}

${ }^{a}$ Control Model Run

b Second parameterization scheme tested.

c Third parameterization scheme tested.

d Fourth parameterization scheme tested.

${ }^{1}$ Used in grids d01, d02 and d03.

\subsection{Cold Pools identification}

SL are phenomena that present cold pools at the front-inflow as important physical feature responsible for propagating all the system. Thus, it is necessary to investigate the cold pools associated with the SL flow. This identification can be made following the steps used by (Klingle et al., 1987) using one, and the only available Doppler radar. However, this method can be sometimes mistaken because radars not always present good data when the cloud systems approach very close to the radar (due to cloud clusters). So, a modified procedure is applied in this work, following the modification used by (Abreu, 2016; Lopes, 2017) and proposed by (Feng et al., 2015), which is presented in the sequence.

This manner of identifying cold pools functions by defining a grid box of a limited area inside the WRF simulation domain, and calculating the temperature and water vapor 
mixing ratio at $2 \mathrm{~m}$ anomalies inside this grid. Feng et al. (2015) used a $100 \mathrm{~km} \mathrm{X} 100$ $\mathrm{km}$ grid box spacing area and Abreu (2016) used a $50 \mathrm{~km}$ X $50 \mathrm{~km}$ grid box spacing area and in this work, the area was defined as a $20 \mathrm{~km} \mathrm{X} 20 \mathrm{~km}$ grid spacing box so the local temperature variations can be more precisely caught by this process.

\subsection{Errors Calculations}

Numerical weather forecasting always presents errors. The sources of errors are several, including numerical truncation, the lack of information such as a low number of weather observations in space and/or time for a better specification of the initial condition, and numerical grid spatial scales which may not be in the same time and spatial scale of the real meteorological systems, among others.

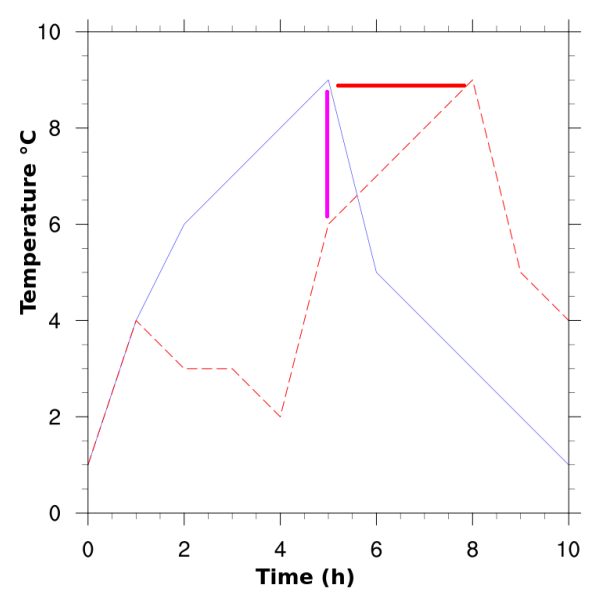

Figure 3.4: Example of amplitude and phase errors in numerical simulations.

Because of the undulating essence of variables distribution in space (and solutions of the model equations), the errors in numerical weather outputs appear as phase and amplitude errors. This can be visualized with the help of Fig. 3.4, where the pink line shows "the size" of the amplitude error, and the red line shows "the size" of the phase error between two curves. Hence, some metrics for calculating errors are presented in this work to quantify the skill of the WRF model simulations.

The Mean Error (ME), or BIAS, is calculated by the equation 3.6. This measure does not bring information about the model accuracy because some negative and positive values may be canceled. However, it shows the existence of systematic errors in simulations. 


$$
M E=B I A S=\sum_{i=1}^{N} \frac{X_{s i m}-X_{o b s}}{N}
$$

where $X_{o b s}$ is the observation value, $X_{\text {sim }}$ is the simulated value and $N$ is the number of observations.

The Mean Squared Error (MSE) measures the average of the squares of the errors, that is, the difference between the simulation and what is observed given by the equation 3.7 . It is always positive and values closer to zero show better simulations.

$$
M S E=\frac{1}{N} \sum_{i=1}^{N}\left(X_{s i m}-X_{o b s}\right)^{2}
$$

The Root Mean Square Error (RMSE) is similar to MSE, with the advantage of giving results in the same unity of the variable in the analysis. This error is given by the equation 3.8. Like the MSE, when RMSE is closer to zero, the simulation is better. Both of them, MES and RMSE, are affected by outliers, because its specific error is squared, and both of them are used to identify times when outliers occur.

$$
R M S E=\sqrt{\frac{1}{N} \sum_{i=1}^{N}\left(X_{\text {sim }}-X_{\text {obs }}\right)^{2}}
$$


Chapter 4

\section{Results and Discussion}

\subsection{Case study of September 08 ${ }^{\text {th }}, 2014$}

This case study was chosen due to the heavy rainfall observed through the radar reflectivity data from SIPAM over the region of Amazonas. Because of the several types of mesoscale convective systems observed in this day, it is considered an ideal case for indepth studies in the mesoscale scale. Also, this day presents a SL that was originated over the southeast of Pará during the Project GOAmazon observations, and not less important, this case was selected because the radar data are available, while in other cases that were previously selected, the radar measurements did not present data for the whole event.

\subsection{Synoptic Overview}

In this section, a general analysis overview will be given for introducing the synoptic aspects of this case study. To do so, the satellite images from GOES-13, GFS Analyzes, and Rawinsonde data will be shown to highlight its characteristics.

\subsection{GOES-13 Infrared Images}

The case study begins to form in the dawn of September $08^{\text {th }}, 2014$ as it can be viewed in Fig. 4.1 $\mathrm{ra}$ at 0100 UTC when three separate cells are present in the southern part of Pará assigned as cell number 1, 2 and 3. These cells reach up to $-50{ }^{\circ} \mathrm{C}$ and at 0330 UTC (see Fig. 4.1-b) cell 1 fades away as a new cell is formed behind cells number 2 and 3. Cell number 3 reaches up to $-70{ }^{\circ} \mathrm{C}$ which indicates that it is higher and more vertically extended. However, at 0430 UTC in Fig. 4.1. cell 3 loses intensity, reaching up to -60 
${ }^{\circ} \mathrm{C}$ as it becomes larger in the horizontal scale and cell number 4 disappears. This does not change a lot from Fig. 4.1 $\mathrm{c}$ to Fig. $4.1 \mathrm{fd}$, but cell 3 reaches up to $-70{ }^{\circ} \mathrm{C}$ in its inner portion which indicates that there must have been updrafts feeding the clouds. At 0700 UTC (Fig. 4.1-a) the cells become larger and they begin to look like an arc-shaped cell in Fig. 4.1-f.

As the time goes by, cell number 2 starts to be more vertically extended because its temperature reaches up to $-70{ }^{\circ} \mathrm{C}$ at 1000 (Fig. 4.2-a) and 1100 UTC (Fig. 4.2-b) as cell number 3 becomes tiny at every time step. At 1130 UTC cell number 2 becomes even larger while cell number 3 is still loosing horizontal and vertical extension while its top temperatures are warmer. A new cell is observed at 1200 UTC assigned as cell number 5, while cell number 2 is larger and cell number three is almost fading away.

At 1400 UTC (Fig. 4.2 -e) the cells merge together into a larger new cell assigned as cell number 6 which covers the eastern portion of Amazonas and the western portion of Pará. As the cell moves west, new cells are observed (7,8 and 9) in Fig. 4.2-f at the southeastern and northeastern parts of Amazonas. All cells are cold and this means that they are vertically large. However, some portions of cell number 6 also present less deep portions, reaching up to $-30{ }^{\circ} \mathrm{C}$ which may represent the stratiform regions of the system. At 1600 UTC, in Fig. 4.3-a the cells number 6 and 7 form a larger system assigned by the number 10 containing 3 main areas denoted as $\mathrm{A}, \mathrm{B}$, and $\mathrm{C}$ where the colder temperatures are sited. Also, there are two other cells denoted as 8 and 9 coming from northeast of Amazonas that grow larger at 1700 UTC in Fig. 4.3-b. Cells 8 and 10 reaches maturity at 1800 UTC where cells $10-\mathrm{A}, 10-\mathrm{B}$, and $10-\mathrm{C}$ reach up to $-80{ }^{\circ} \mathrm{C}$ at the top of the clouds in Fig. 4.3-c. At 1830 UTC (see Fig. 4.3-d) cells 8 and 9 are bounding together with the large cell 10 that also present SL chraracteristics with its convective and mature portions at regions $\mathrm{A}, \mathrm{B}$ and $\mathrm{C}$ and a stratiform band observed at the northeastern portion of region 10-A. The system is still moving to the west where it merges in a very large system over the eastern portion of Amazonas, denoted as 11 in Fig. 4.3 e where there are 2 colder regions and a stratiform region over its northeastern portion. 

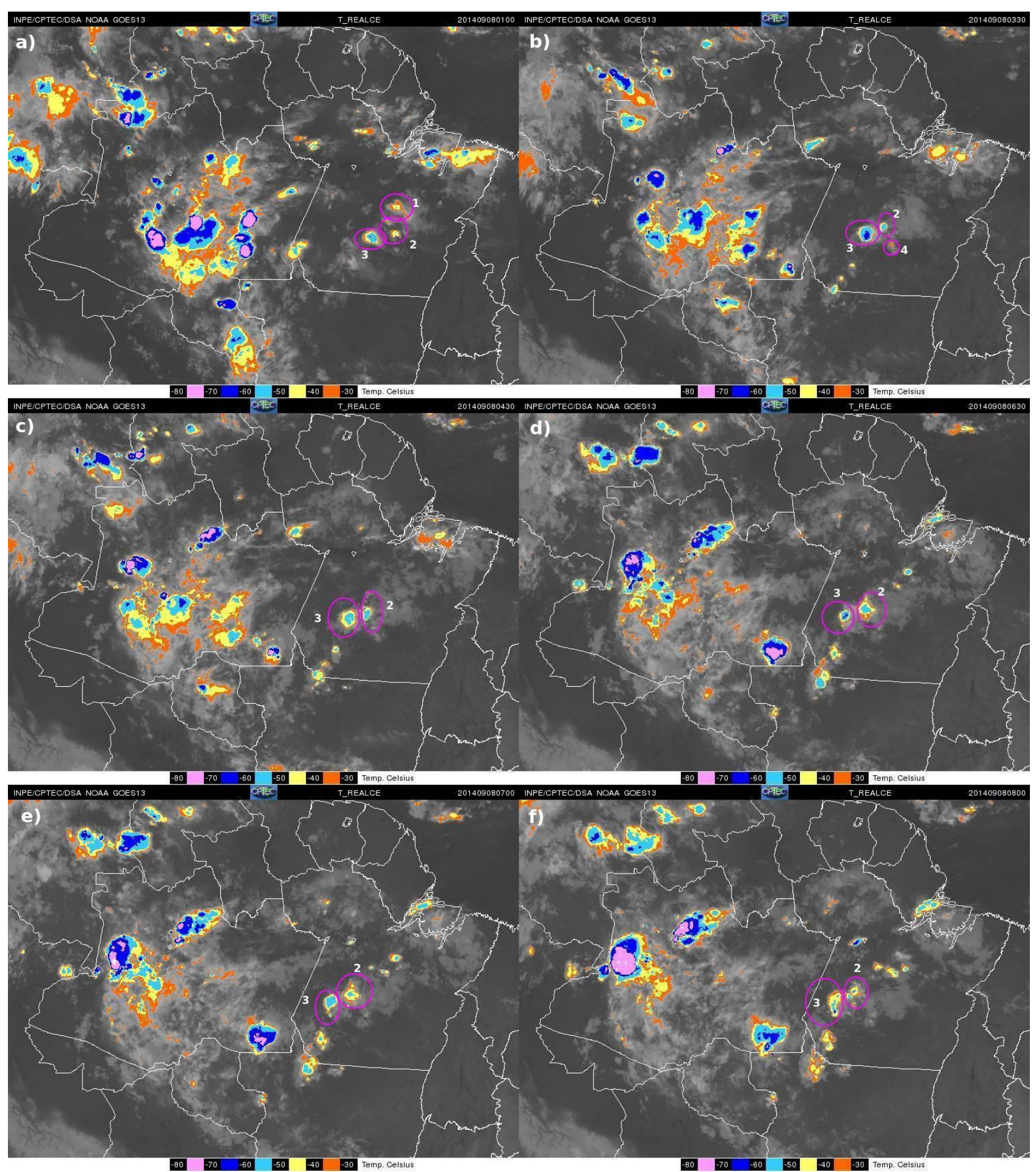

Figure 4.1: GOES 13 satellite temperature hilighted infrared images for September $08^{\text {th }}$ at a) 0100 UTC, b) 0330 UTC, c) 0430 UTC, d) 0630 UTC, e) 0700 UTC and f) 0800 UTC. 


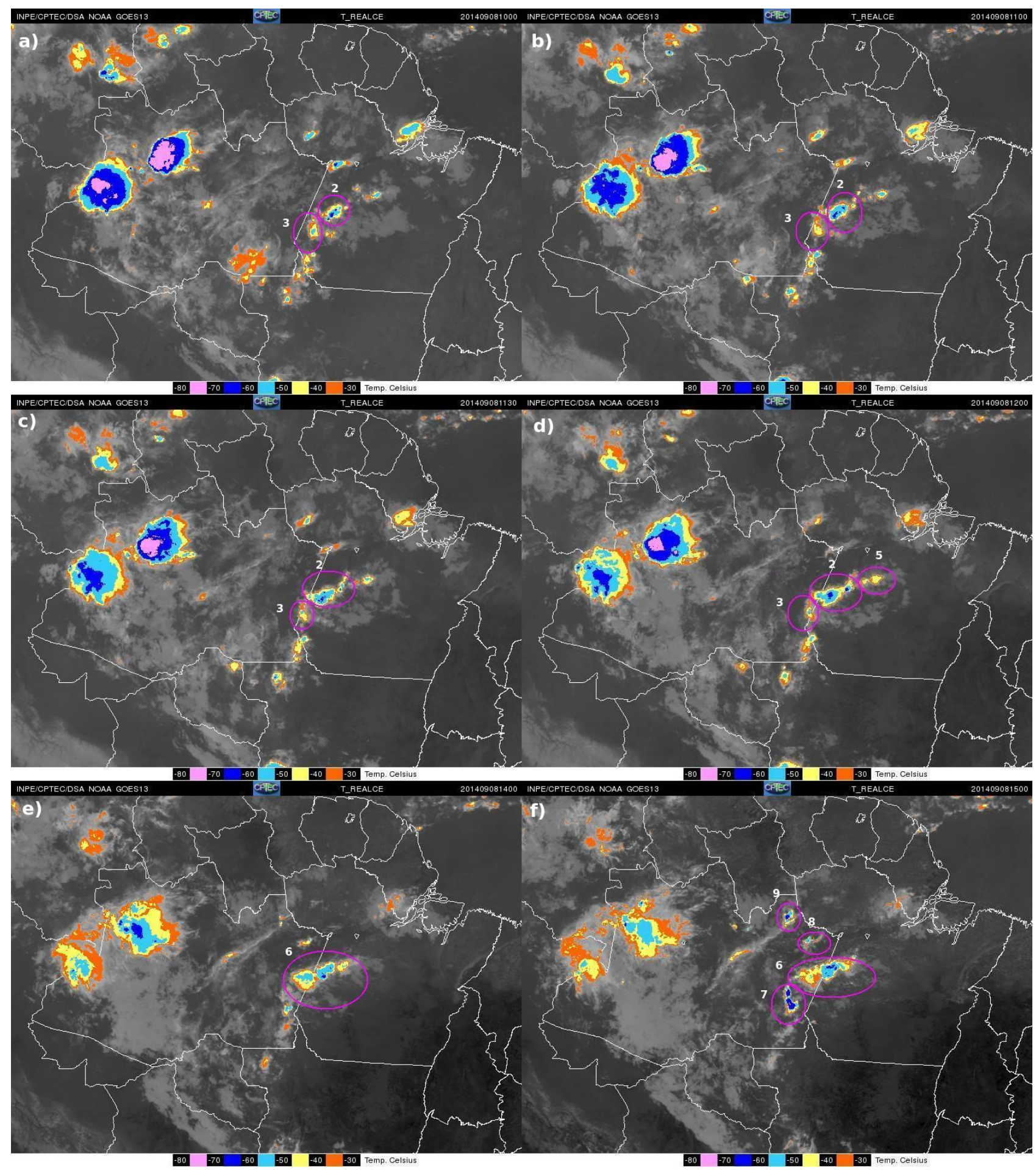

Figure 4.2: GOES 13 satellite temperature hilighted infrared images for September $08^{\text {th }}$ at a) 1000 UTC, b) 1100 UTC, c) 1130 UTC, d) 1200 UTC, e) 1400 UTC and f) 1500 UTC. 


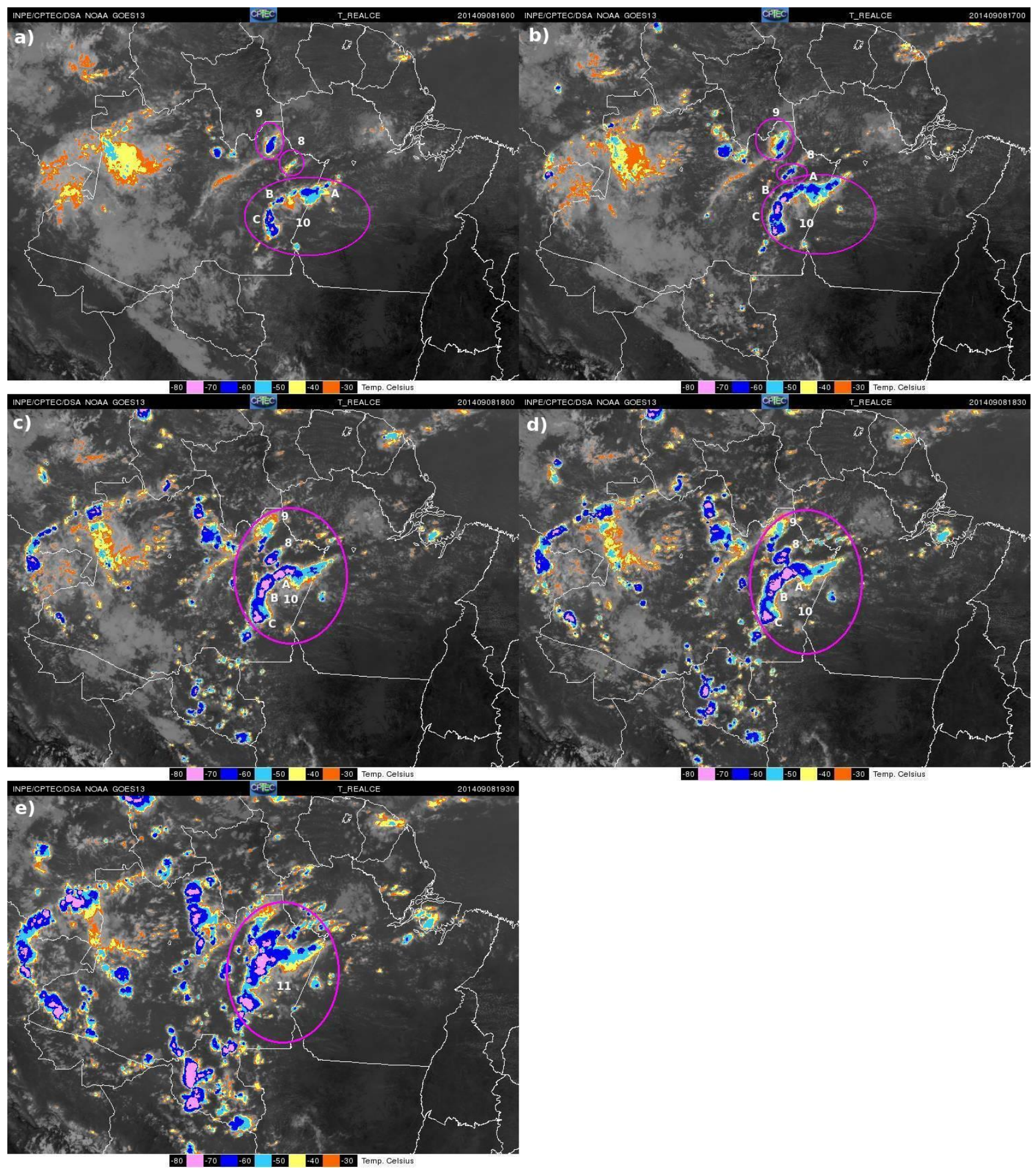

Figure 4.3: GOES 13 satellite temperature hilighted infrared images for September $08^{\text {th }}$ at a) 1600 UTC, b) 1700 UTC, c) 1800 UTC, d) 1830 UTC and e) 1930 UTC.

\subsection{GFS and Rawinsonde Analysis}

In this section, a synoptic overview with the aid of GFS Analysis and Rawinsonde data of the case is made to show the importance of the synoptic patterns on the formation of 
the observed convection. Fig. 4.6-a shows the sea level pressure and wind speed at $10 \mathrm{~m}$ for September 08 ${ }^{\text {th }}, 2014$ at 0000 UTC where it can be observed that the South American Subtropical High (SASH) is covering a large portion of eastern South America up to the southeastern portion of Tocantins and the whole portion of Goiás. At the southeastern region of Pará, the winds are mostly from the southeast and over the northeastern portion of Brazil, it is also observed that the winds are from northeast to the northern region of Pará. These winds over the southeastern region of Pará formed the convection observed in Fig. 4.1-a inside the pink circles. This pattern was also supported by the upper air circulation in Fig. 4.7 $\mathrm{fa}$ which is directed from southeast to the region of Tocantins and Pará and the high CAPE in Fig. 4.4 - a which reaches up to $3078 \mathrm{~J}$ and CINE of -24.8 J.

At 0600 UTC, the winds are still moving from southeast to the region of Tocantins in Fig. 4.6-c, also noted in Fig. 4.6-d. The upper air circulation pattern remains the same and the convection is now over the southwestern region of Pará, approaching the eastern region of Amazonas, as it can be noted in Fig. 4.1 -d. CAPE rises from 3078 to $3200.6 \mathrm{~J}$ (see Figs. 4.4 a and 4.4 -b which means that there is still high energy to form new cells. However CINE is negatively higher than it was at 0000 UTC, and falls to -48.7 J. At 1200 UTC, the winds are not only moving from southeast to the region of Amazonas, but they experience an apparent confluence over the region in the white circle in Fig. 4.6-e, which generates the convection observed in Fig. 4.2-b. It can be observed in Fig. 4.4-c that the region below $600 \mathrm{hPa}$ seems to be very moistened, mainly at the surface and between 600 and $700 \mathrm{hPa}$.

It is also observed that at $1500 \mathrm{UTC}$ the region below $600 \mathrm{hPa}$ becomes more moistened and the CAPE also rises up to $5301.8 \mathrm{~J}$, as seen in Fig. $4.4 \mathrm{~d}$, which is also one of the pieces of evidence that can show the convection growing over the pink circles in Fig. 4.2 f. This and the upper air circulation directed towards the region of interest (see Fig. 4.7-e) helped the system reach the Amazon region. Also, but not less important, the CAPE is still strong right before the event occurrence over Manacapuru and Manaus reaching up to $5061.9 \mathrm{~J}$ in Fig. 4.5 and the region below $600 \mathrm{hPa}$ shows some dryness when it is compared with the data presented in Fig. 4.4 d. 
a)

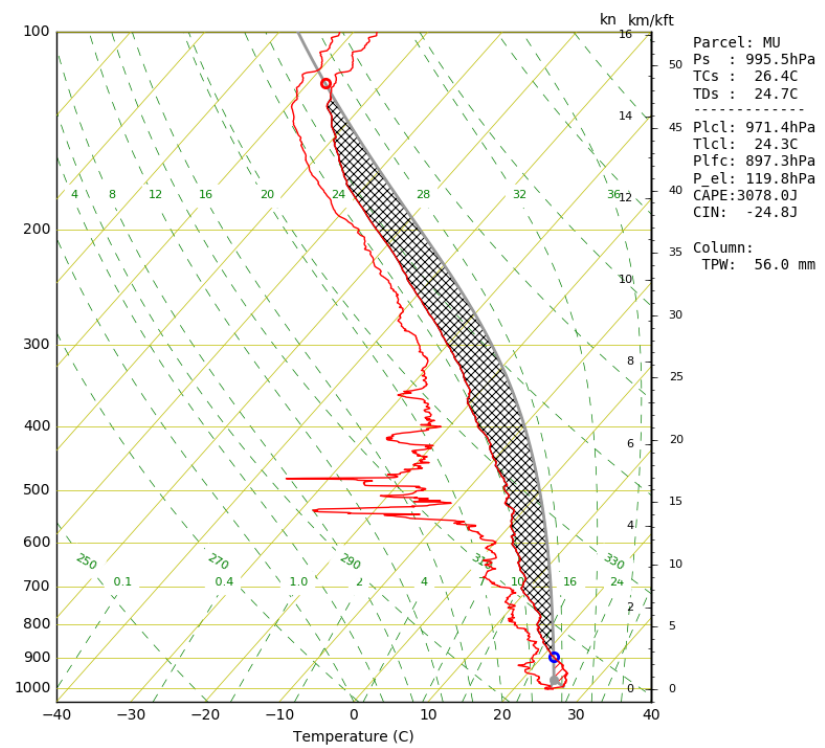

c)

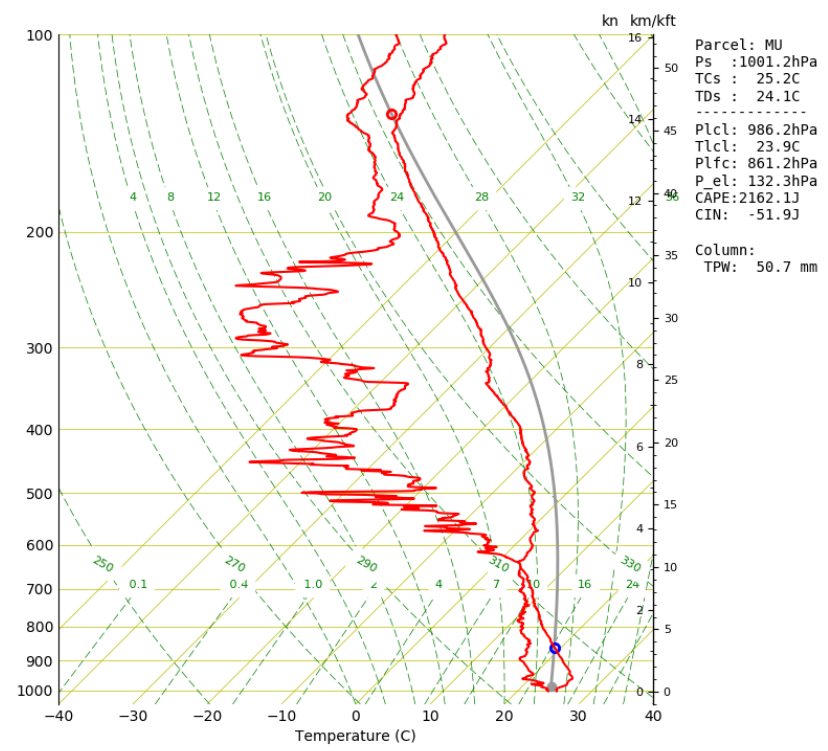

b)

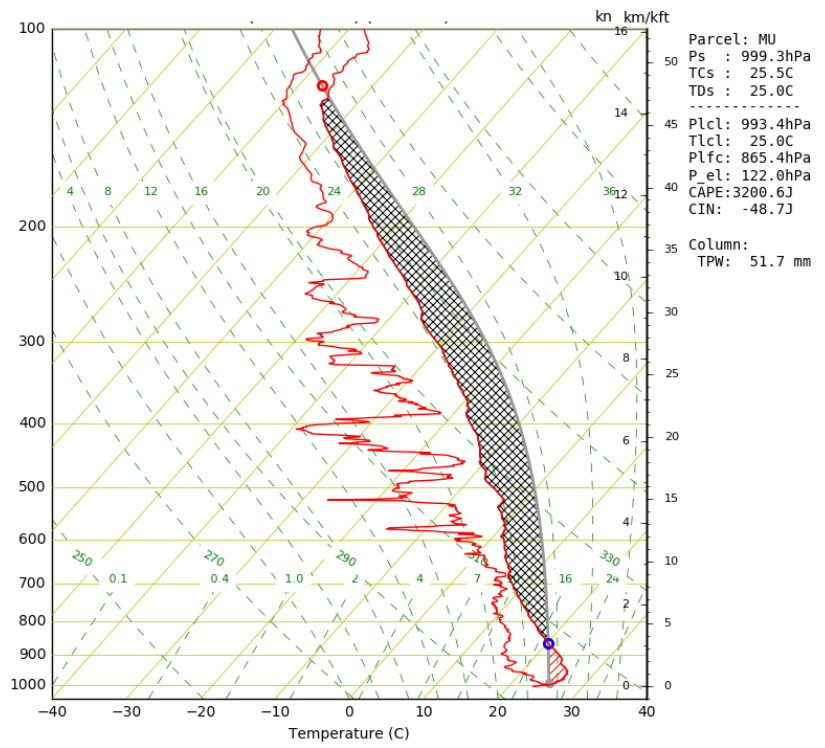

d)

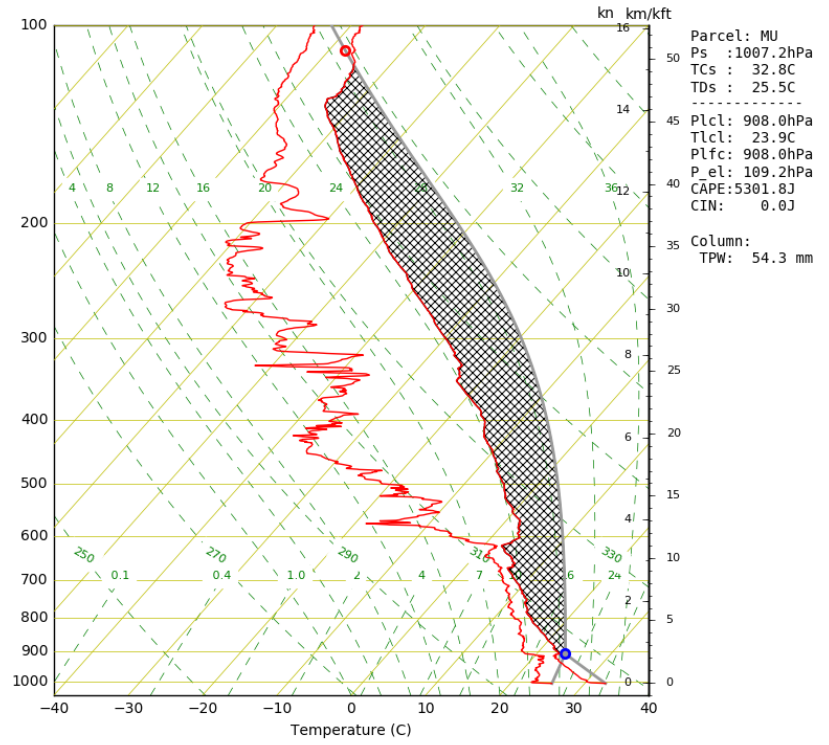

Figure 4.4: Rawinsonde data for September 08 ${ }^{\text {th }}$, 2014 at a) 0000 UTC, b) 0600 UTC, c) 1200 UTC and d) 1500 UTC. 


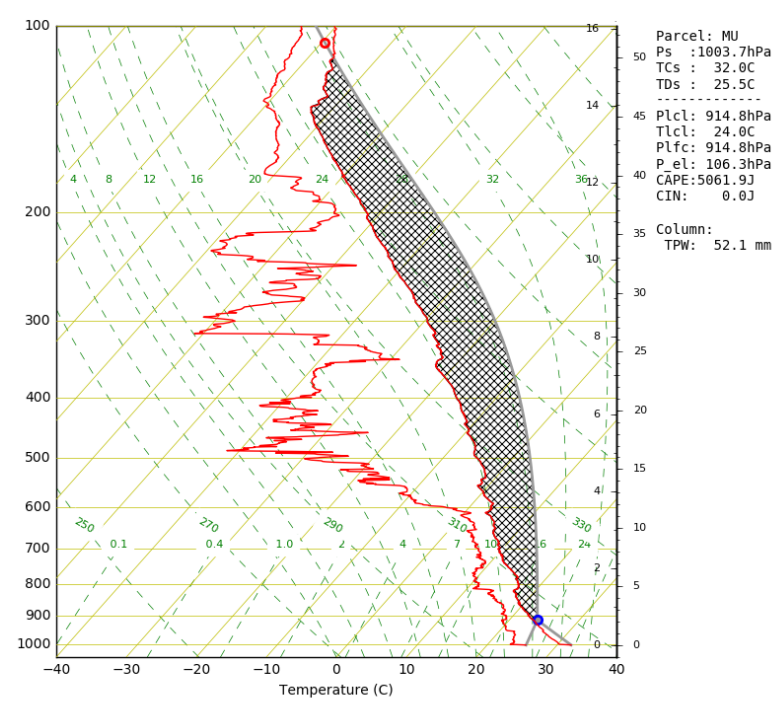

Figure 4.5: Rawinsonde data for September $08^{\text {th }}, 2014$ at 1700 UTC.

\subsection{Comparison between WRF $27 \mathrm{~km}$ Control Run Experiment and the GFS data}

In this subsection, the comparison between GFS and the WRF $27 \mathrm{~km}$ grid will be analyzed. This is a necessary step to show that WRF model simulations are capable of demonstrating the synoptic fields. Thus, the following analyzes will also serve as a model verification for the WRF $27 \mathrm{~km}$ grid. This is an adequate approach to make sure that the main synoptic features that may affect other scales of motion are well simulated.

Figure 4.6 shows the sea level pressure and the $10 \mathrm{~m}$ wind velocity fields for GFS (left) and WRF (right) models for September $8^{\text {th }} 0000$ UTC in the top, 0600 UTC in the middle and 1200 UTC in the bottom. With the help of the first time of simulation compared with the GFS analysis for September $8^{\text {th }}$ at 0000 UTC (see Figs. 4.6-a and b) it can be seen that the SASH is very well sited through the WRF $27 \mathrm{~km}$ control grid (CTL), and its intensity is also very well simulated. The South Pacific Subtropical High (SPSH) is also sited in the same location in comparison with GFS. It is important to point out that the SPSH is not fully seen because of the size of the WRF CTL domain. In dynamic terms, if the sea level pressure is well simulated, it is not expected that any problem will be found when one checks the wind speed and direction at the same level. This is what can be noted here when one checks the positioning of the Intertropical Convergence Zone 
(ITCZ). Its positioning along the latitude and longitude coordinates are perfectly sited and the simulated winds have the same magnitude of the GFS analysis at the same time. The winds outside of the ITCZ follow the isobars and its direction, even that it is not perfectly simulated, particularly over the regions with strong heating, show remarkable skill when qualitatively compared to the GFS analysis. Same observations can be made for September $8^{\text {th }}$ at 0600 UTC (see Figs. 4.6-c and d) and 1200 UTC (see Figs. 4.6 - and f) with two slight differences over the northwestern South America sea level pressure.

These characteristics can also be seen by checking the wind speed and streamlines at $250 \mathrm{hPa}$. The streamlines and wind velocity speed at $250 \mathrm{hPa}$ order shown in Fig. 4.7 follows the same order as Fig. 4.6. At the top at 0000 UTC (Figs. 4.7 a and b), it is noted that the main simulated flow patterns are very similar with the GFS analysis. For example, the $\mathrm{BH}$ is positioned over the same region in the simulation in comparison with the analysis. To the right of the $\mathrm{BH}$, there is a very large through that can be seen in both simulated and analysis fields, and also the flow patterns over the northeast South America are very well simulated. Qualitatively, therefore, it can be inferred that the model runs show some distinctions in comparison to the analysis. The main difference is related with the jet stream velocity intensity which is around 40 to $55 \mathrm{~m} \mathrm{~s}^{-1}$ in the GFS analysis and around 40 to $50 \mathrm{~m} \mathrm{~s}^{-1}$ in the simulated field. Also, there is a break in the jet stream around $55^{\circ} \mathrm{W}$ which does not exist in the GFS analysis. At 0600 UTC (Figs. 4.7 f and d) it can be noted that the simulated jet stream break is not in the same latitude and longitude grid interval of the GFS analysis but, in general, and looking to the 1200 UTC figure (Figs. 4.7-e and f) both analysis and run, it can be noted that WRF shows good skill compared to the synoptic conditions as it can be seen in Table 4.8 where the calculated errors with respect to the rawinsonde data are very low. Such results indicate that the $27 \mathrm{~km}$ grid run can be used to nest grids with higher horizontal spatial resolution to predict variables such as those coming from the microphysical parameterizations, among others of interest like deep cumulus convection. 
a)

$20 S$

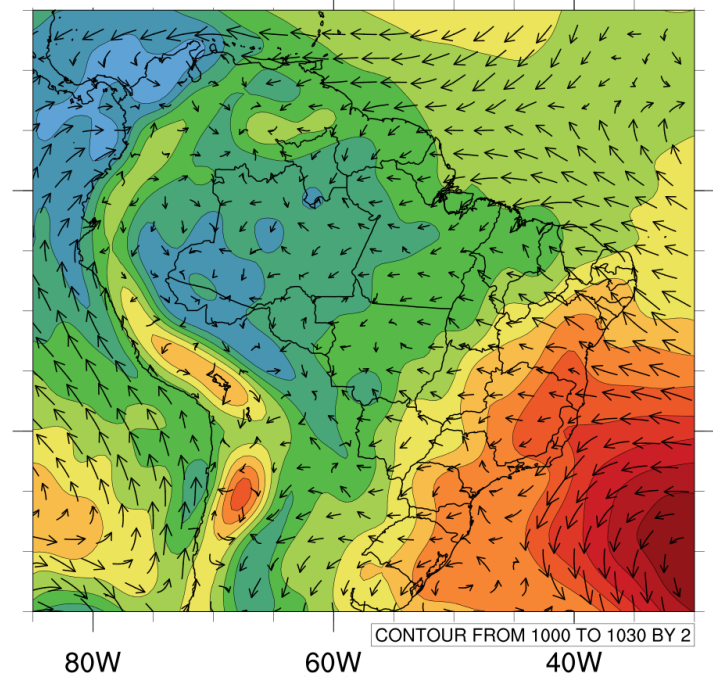

c)

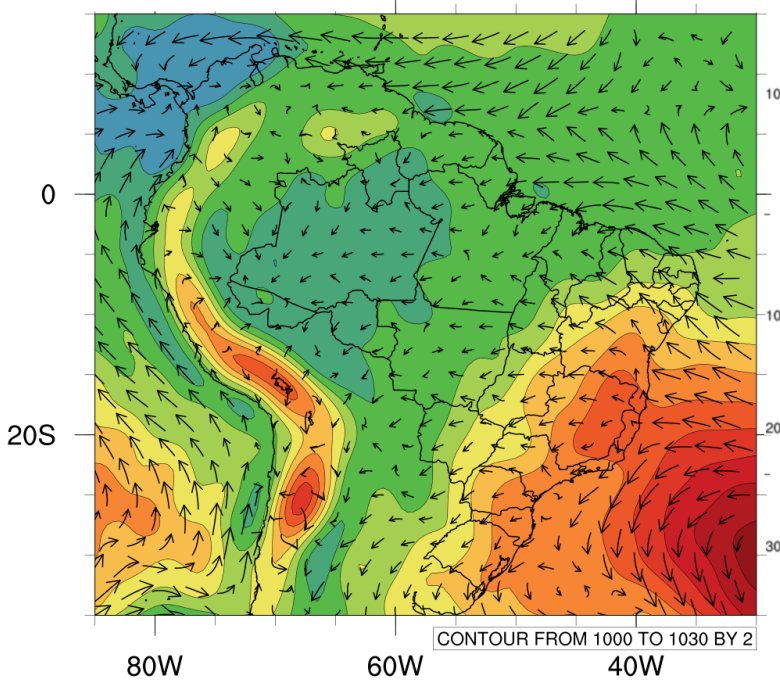

e)

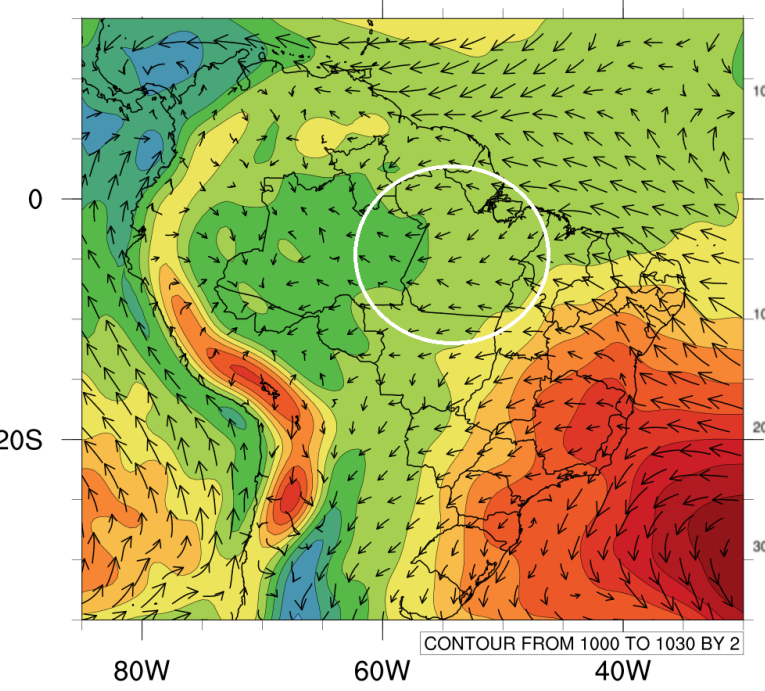

b)

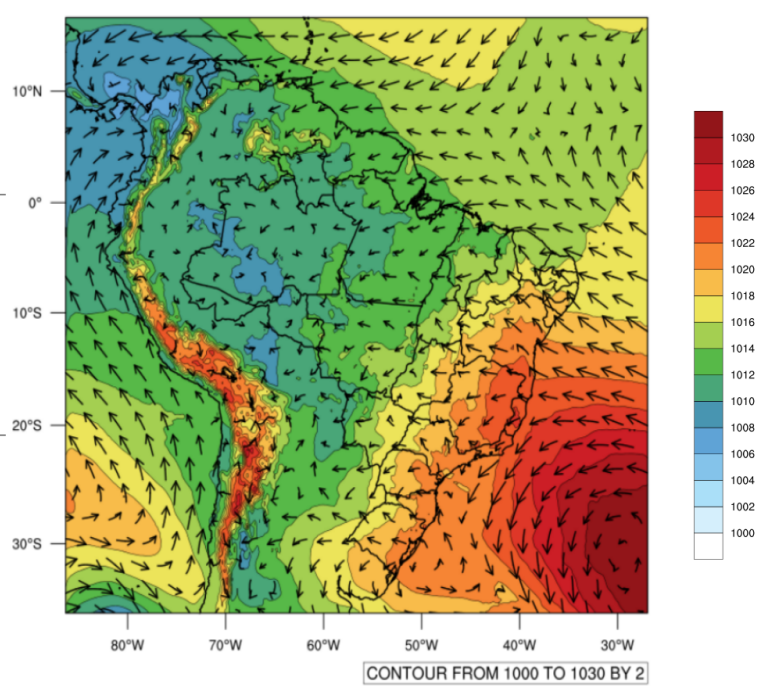

d)

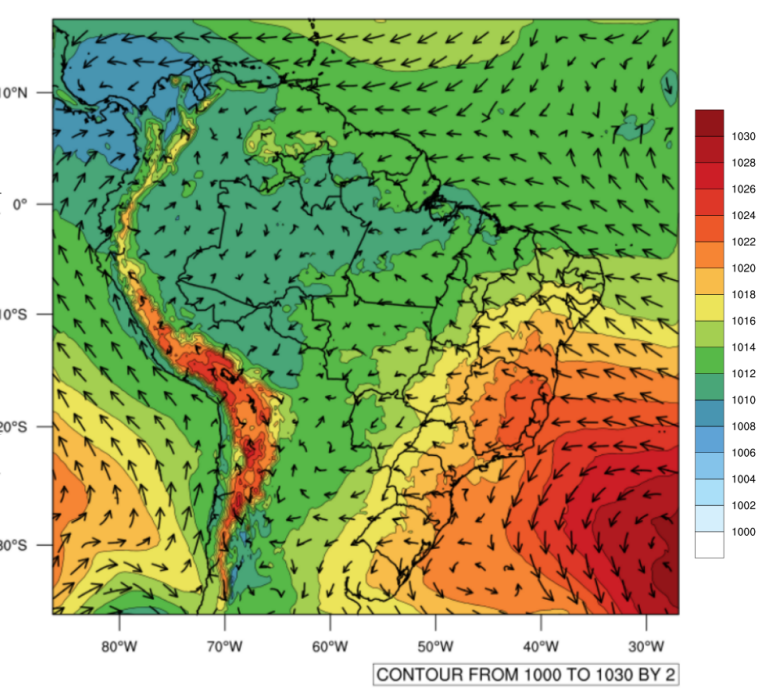

f)

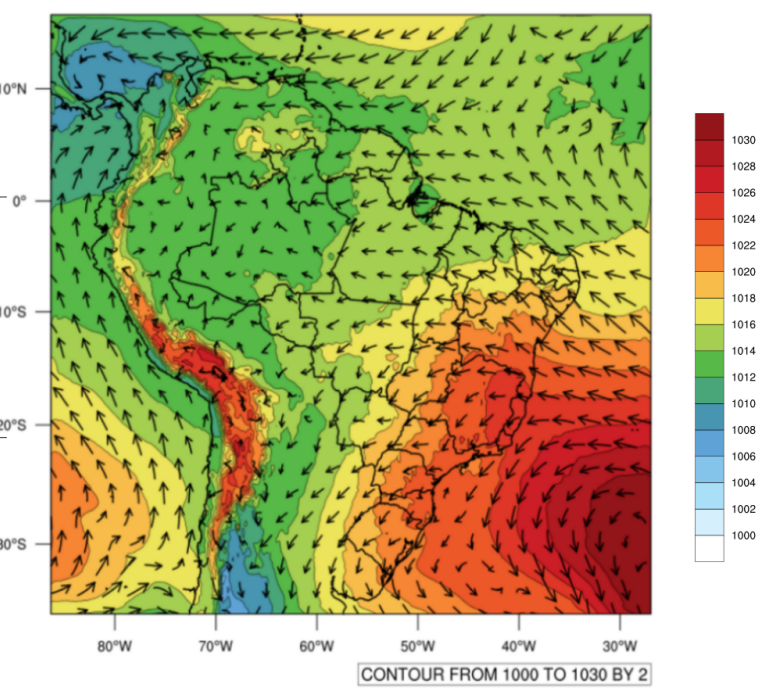

Figure 4.6: Sea Level Pressure and Wind at $10 \mathrm{~m}$ from GFS (left: a, c and e) and WRF (right: b, d and f) models at $250 \mathrm{hPa}$ for September $8^{\text {th }}$ at $0000 \mathrm{UTC}$ (top), $0600 \mathrm{UTC}$ (middle) and 1200 UTC (bottom). 

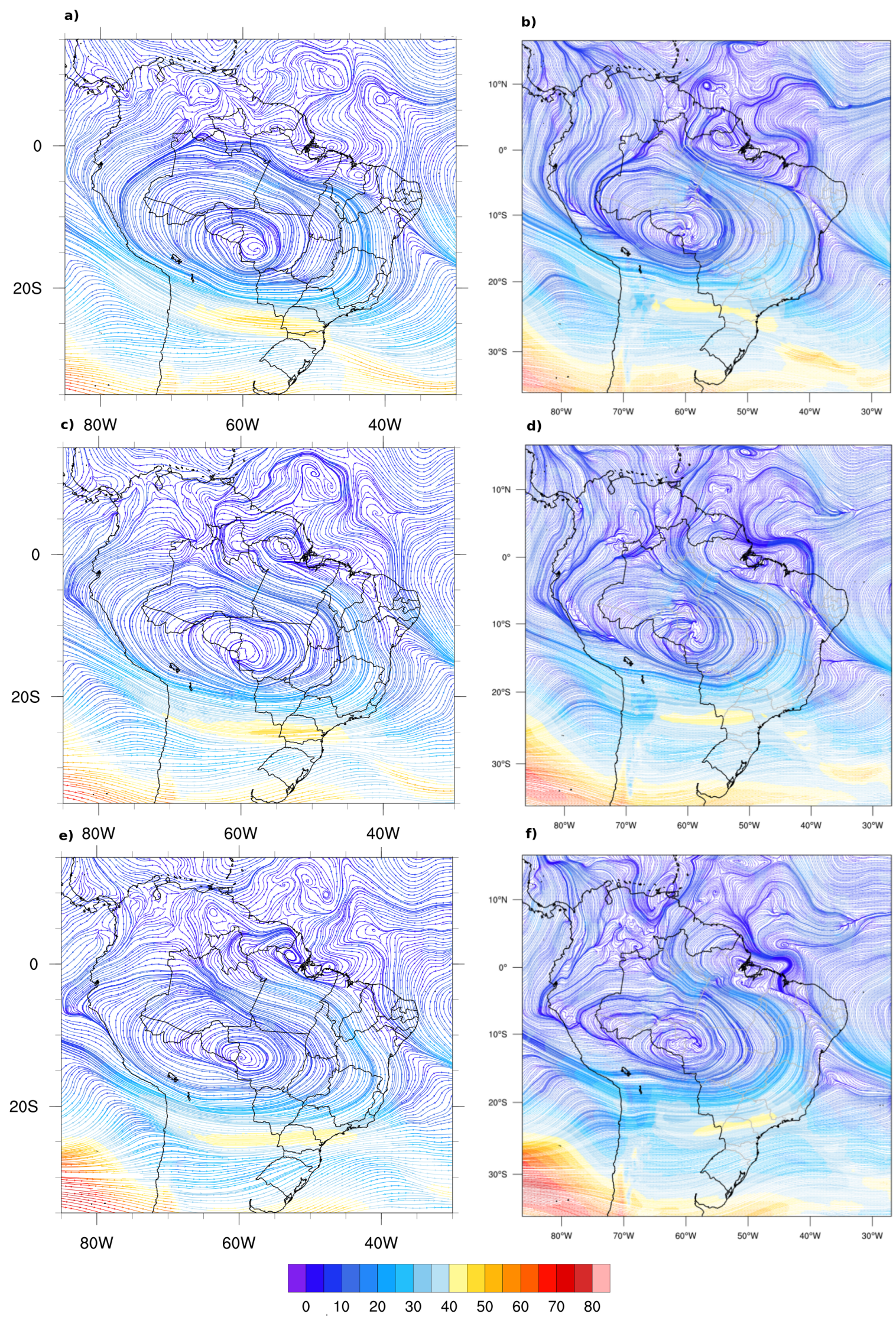

Figure 4.7: Streamlines and Wind Velocity from GFS (left: a, c and e) and WRF(right: b, $\mathrm{d}$ and f) models at $250 \mathrm{hPa}$ for September $8^{\text {th }}$ at $0000 \mathrm{UTC}$ (top), $0600 \mathrm{UTC}$ (middle) and 1200 UTC (bottom). 


\subsection{Analysis of the $9 \mathrm{~km}$ and $3 \mathrm{~km}$ Grids}

In this section the WRF, D02 and D03 rain rates will be shown and its results are compared with the system positioning and system intensity shown in Figs. 4.1, 4.2 and 4.3 .

The D02 grid shown in Fig. 4.8 displays the rain rate for the $9 \mathrm{~km}$ grid simulation for Milbrandt parameterization scheme. In Fig. 4.8 a at 0800 UTC, when the system is approaching the region of interest, the rain rates over the eastern portion of Pará indicate the systems assigned as 2 and 3 sited over Fig. 4.1-f. One slight difference that can be noted between both is that the simulated system is positioned more vertically than it is observed in the satellite image at 0800 UTC. However, the simulated system intensity seems to be highly correlated with the system intensity over Fig. 4.1 f. In Fig. 4.8-b it is also noted that the simulated system positioning is more vertically inclined than it appears in the satellite image in Fig. 4.2-b. Though, the model simulation shows the system position closest to the border of Amazonas and Pará as well as it is sited more to the north than it is in Fig. 4.2-b. The systems assigned in Fig. 4.2-b intensity is also well simulated in Fig. 4.8-b. At 1500 UTC, when the system starts to get more intense in Fig. 4.3-c, the simulation in Fig. 4.8-c shows less intense rain rates. The system intensity is not highly correlated with the observation but it must be considered that the systems positioning and the systems $6,7,8$ and 9 are present in Fig. 4.8 c. 

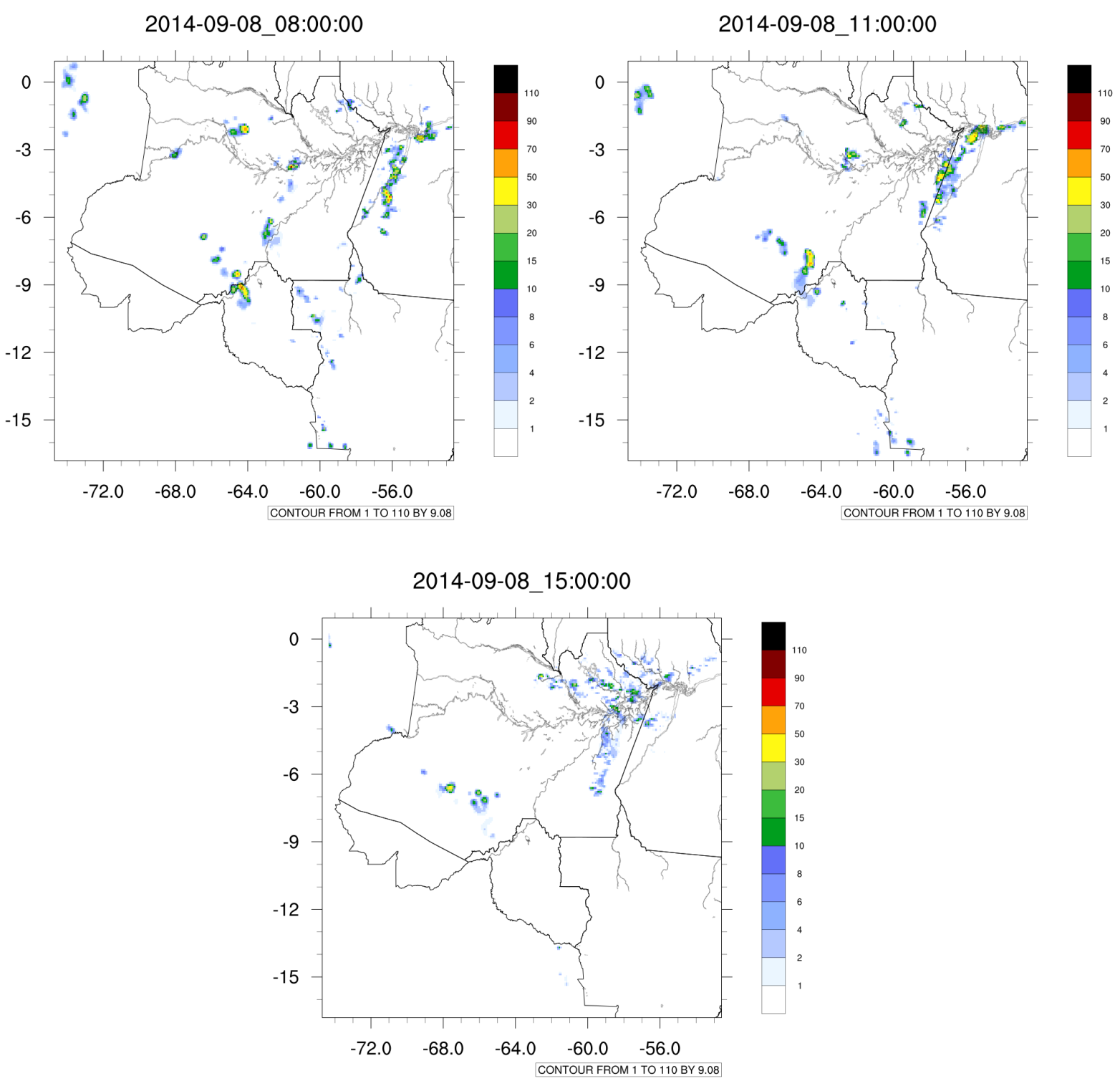

Figure 4.8: WRF rain rate $\left(\mathrm{mm} \mathrm{h}^{-1}\right)$ at a) $\left.0800 \mathrm{UTC}, \mathrm{b}\right) 1100 \mathrm{UTC}$ and c) $1500 \mathrm{UTC}$ for the Milbrandt parameterization scheme inside domain D02.

Domain D03 shows the $3 \mathrm{~km}$ grid simulation results and the rain rates for the Milbrandt are shown in Fig. 4.9. At 0800 UTC, the systems assigned as 3 and 2 in Fig. 4.1ff are more precisely simulated in Fig. 4.9-a which is resultant from the increase in the horizontal resolution (Mass et al., 2002). Despite that, the simulated systems are still sited more to the north than in Fig. 4.1 f, but the convective regions are fairly better correlated than for D02. In Fig. 4.9-b the systems already trespass the border between Amazonas and Pará which indicates that the system speed propagation for the simulation is advancing in time faster than in the reality. 

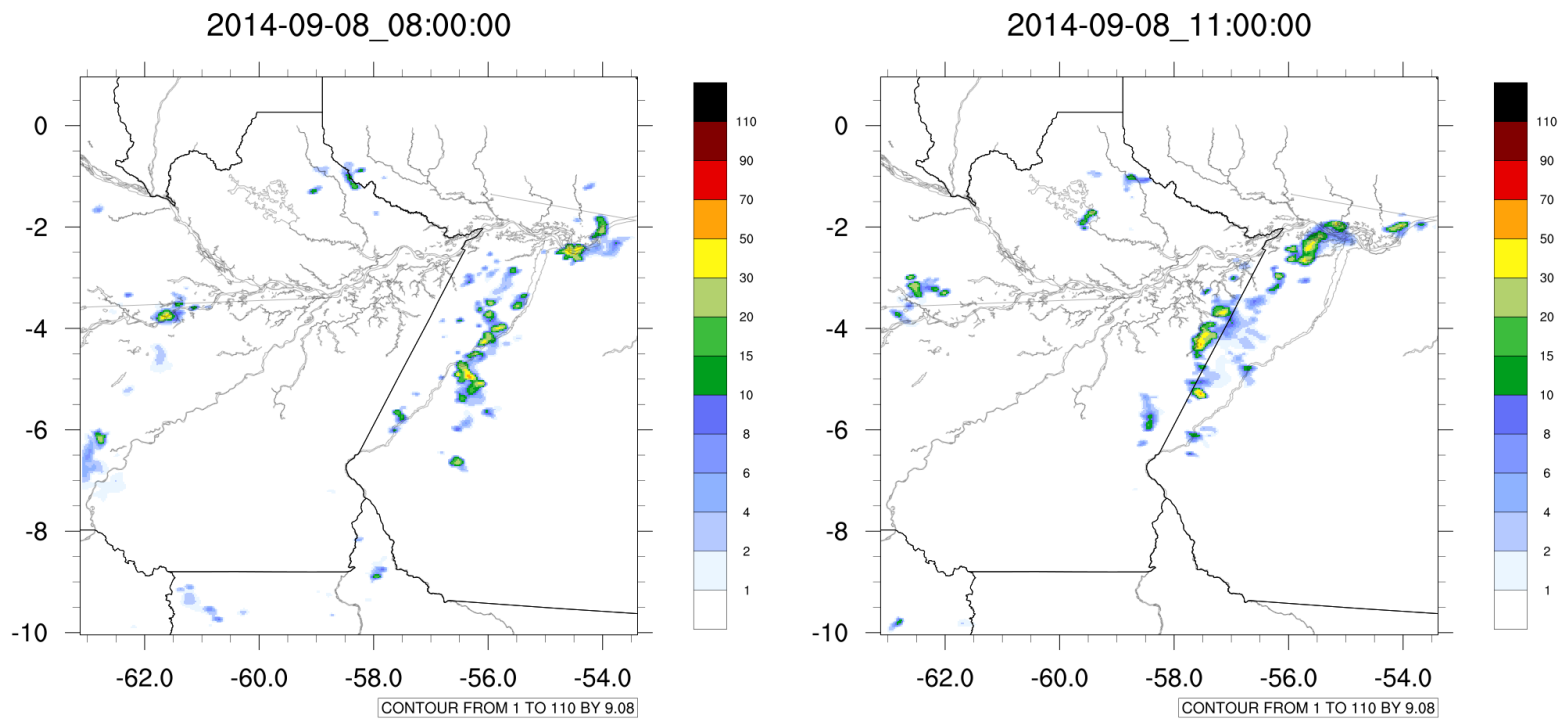

2014-09-08_15:00:00

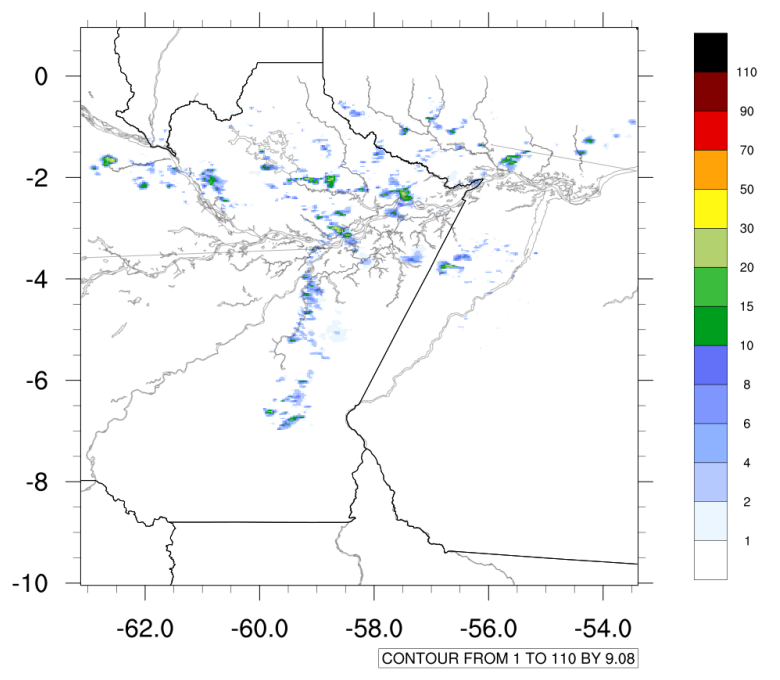

Figure 4.9: WRF rain rate $\left(\mathrm{mm} \mathrm{h}^{-1}\right)$ at a) $\left.0800 \mathrm{UTC}, \mathrm{b}\right) 1100 \mathrm{UTC}$ and c) 1500 UTC for the Milbrandt parameterization scheme inside domain D03.

\subsection{Mesoscale Overview}

The radar reflectivity and radial velocity data are displayed in Fig. 4.11 and Fig. 4.12 from 1630 to 1900 UTC, respectively.

Through the analysis of the radar reflectivity data it can be seen that there are several cells in the radar range (see Fig. 4.11 -a) which show reflectivity ranging from 20 to 30 $\mathrm{dBz}$ in the regions that present stratiform precipitation mostly covering the surroundings of the cells. There are also convective regions that show reflectivity ranging from 30 to $60 \mathrm{dBz}$ where the radar radial velocity reaches up to $-14 \mathrm{~m} \mathrm{~s}^{-1}$ in Fig. 4.12 -a indicating 
that the system is moving towards the radar. This also shows that the system preferential wind motion of the southeastern portion of the system, denoted by the red line in Fig. $4.11 \mathrm{r}$, is southeast, while in the northeastern portion, it is northeast, as seen in Fig. 4.11 $\mathrm{a}$ assigned by the pink straight lines. As it can be seen in Fig. 4.10, however, it may be confirmed that the preferential wind motion is southeast. This hodograph was generated by the winds retrieved from the rawinsonde data for 1500 UTC and it shows that there is low-level wind shear, that is highly associated with the SL formation (Rotunno et al., 1988).

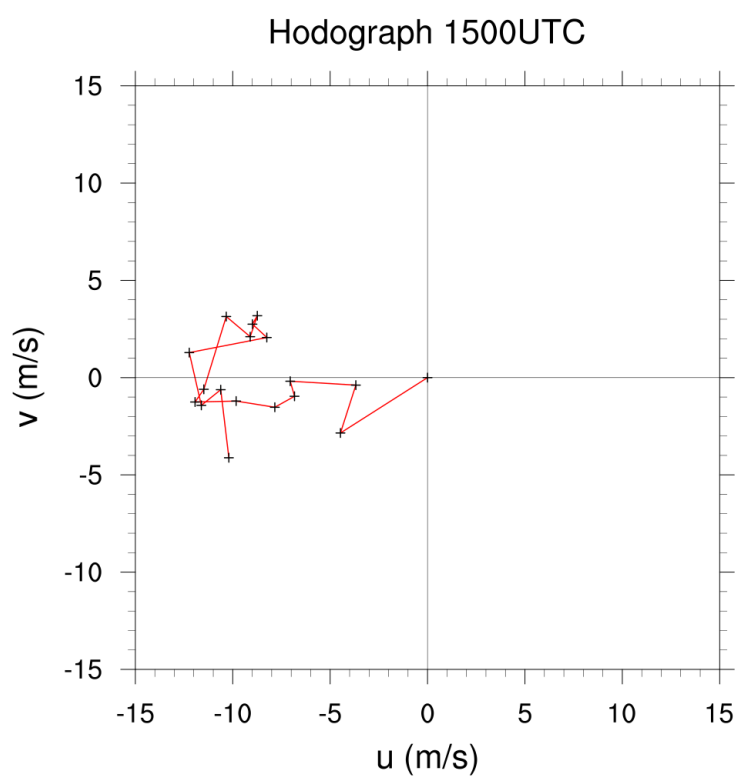

Figure 4.10: Hodograph for September $08^{\text {th }}, 2014$ at 1500 UTC.

At 1700 UTC, the cells are still moving towards the region of the radar, as it can be seen in Fig. 4.11 b, with more intense winds over some regions reaching up to 14 and $16 \mathrm{~m} \mathrm{~s}^{-1}$ in the more intense parts. The radar reflectivity does not vary too much, but there are three cores that present reflectivity between 50 and $60 \mathrm{dBz}$, which is very high in this case $($ Houze Jr, 1997). At 1730 in Fig. 4.11 c the cells appear closer to the radar location, so it can be seen that the system looks like a SL, with some leading cumulonimbus clouds at the front line and stratiform parts at the rear part of the system, like those presented by Markowski and Richardson (2011). Also, the winds close inside the black circled area present both approach and departure from the radar indicating that there is a clockwise motion. This is associated with the mesolow at the front of the SL like in Fig. 2.6 assigned by Markowski and Richardson (2011) as pre-squall mesolow. This 
counterclockwise motion is more evident at 1800 UTC in Fig. 4.12 d, where the mesolow gets closer to the radar. Thus, the radar reflectivity response to the clockwise motion is evident by stronger reflectivity ranging from 50 to $60 \mathrm{dBz}$ at $59.4^{\circ} \mathrm{W}$ and $3.8^{\circ} \mathrm{S}$.

The northeastern part of the system assigned as cell number 8 in Fig. 4.3 $\mathrm{d}$ is also displayed in Fig. 4.11 fe at 1830 UTC. The system presents clockwise motion which also represents the mesolow associated with the front of the system in Fig. 4.12 -e. It also presents convective regions with intense reflectivity cores ranging from 30 to $60 \mathrm{dBz}$ and stratiform regions around the surroundings of the system with reflectivities below $30 \mathrm{dBz}$. Also, at 1900 UTC in Fig. 4.12 f the system presents more intense clockwise motion in the radar surroundings area which makes the reflectivity to become more intense with more cores ranging from 40 to $60 \mathrm{dBz}$ in Fig. 4.11-f which means that there are more intense updraft regions right in the region of the mesolow. 
a)

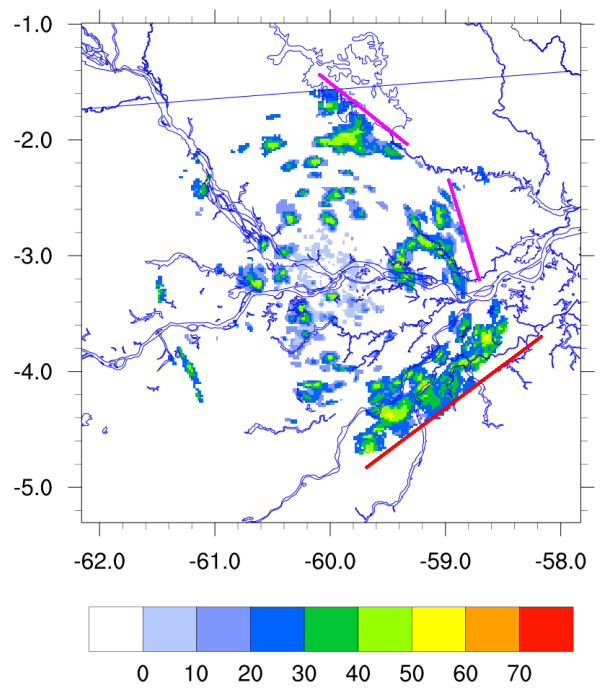

c)

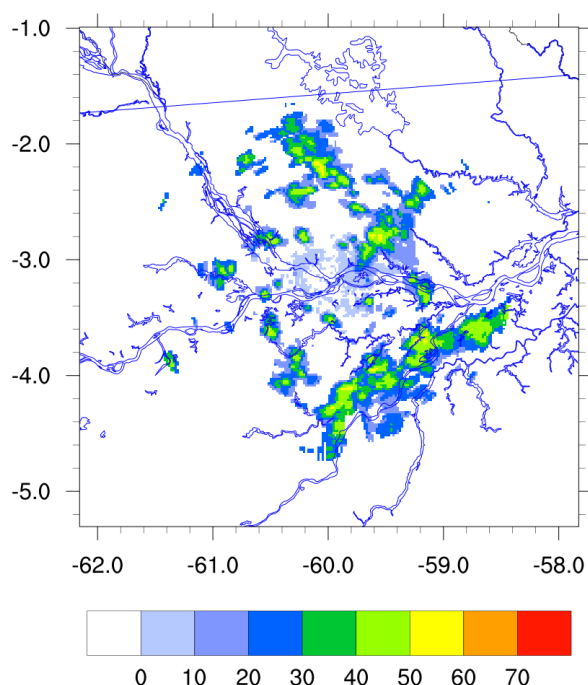

e)

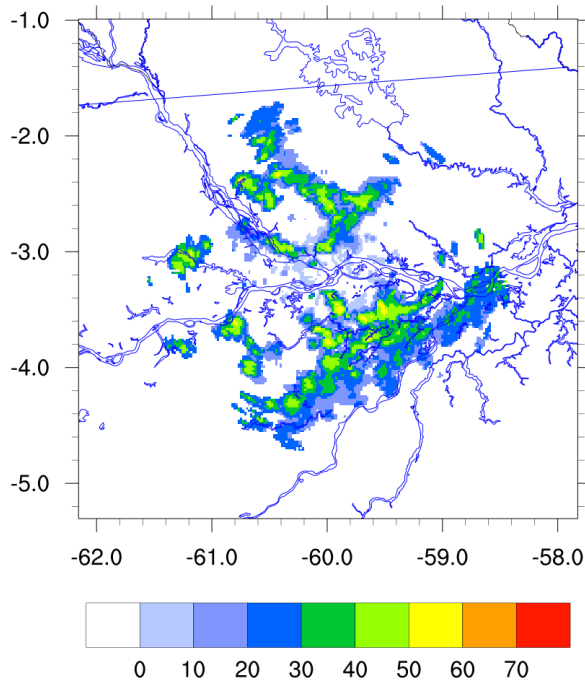

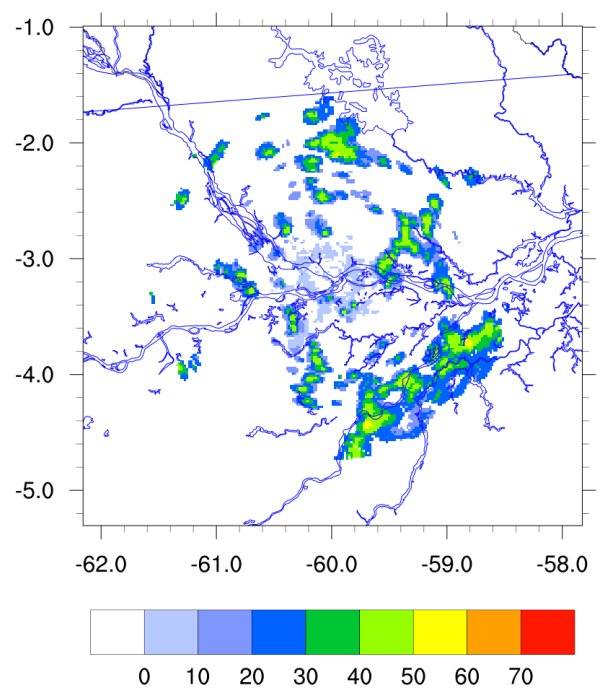

d)

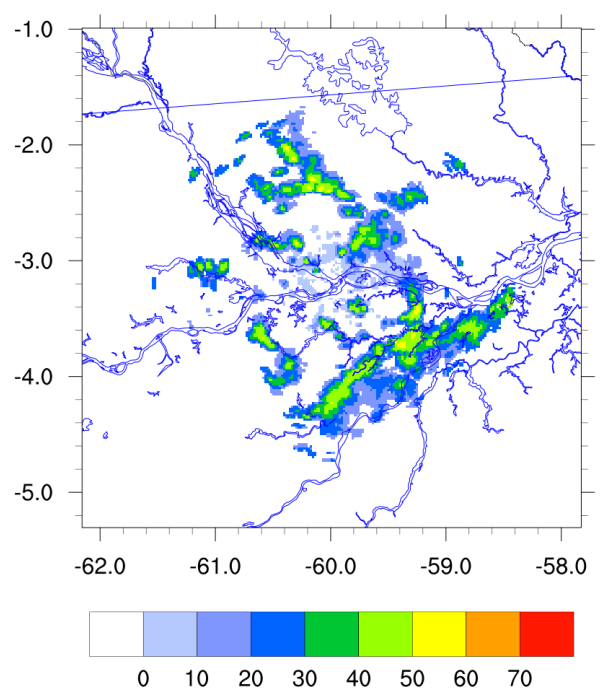

f)

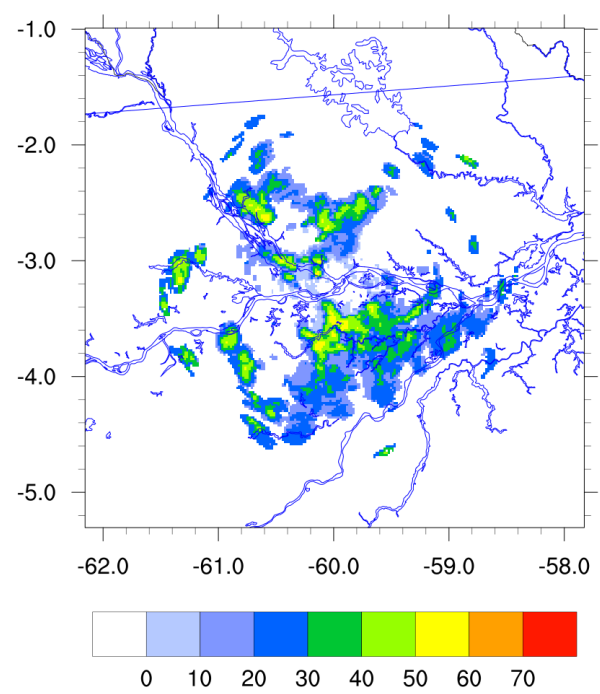

Figure 4.11: Radar reflectivity data (dBz) for September $08^{\text {th }}, 2014$ at a) 1630 UTC, b) 1700 UTC, c) 1730 UTC, d) 1800 UTC, e) 1830 UTC and f) 1900 UTC. 

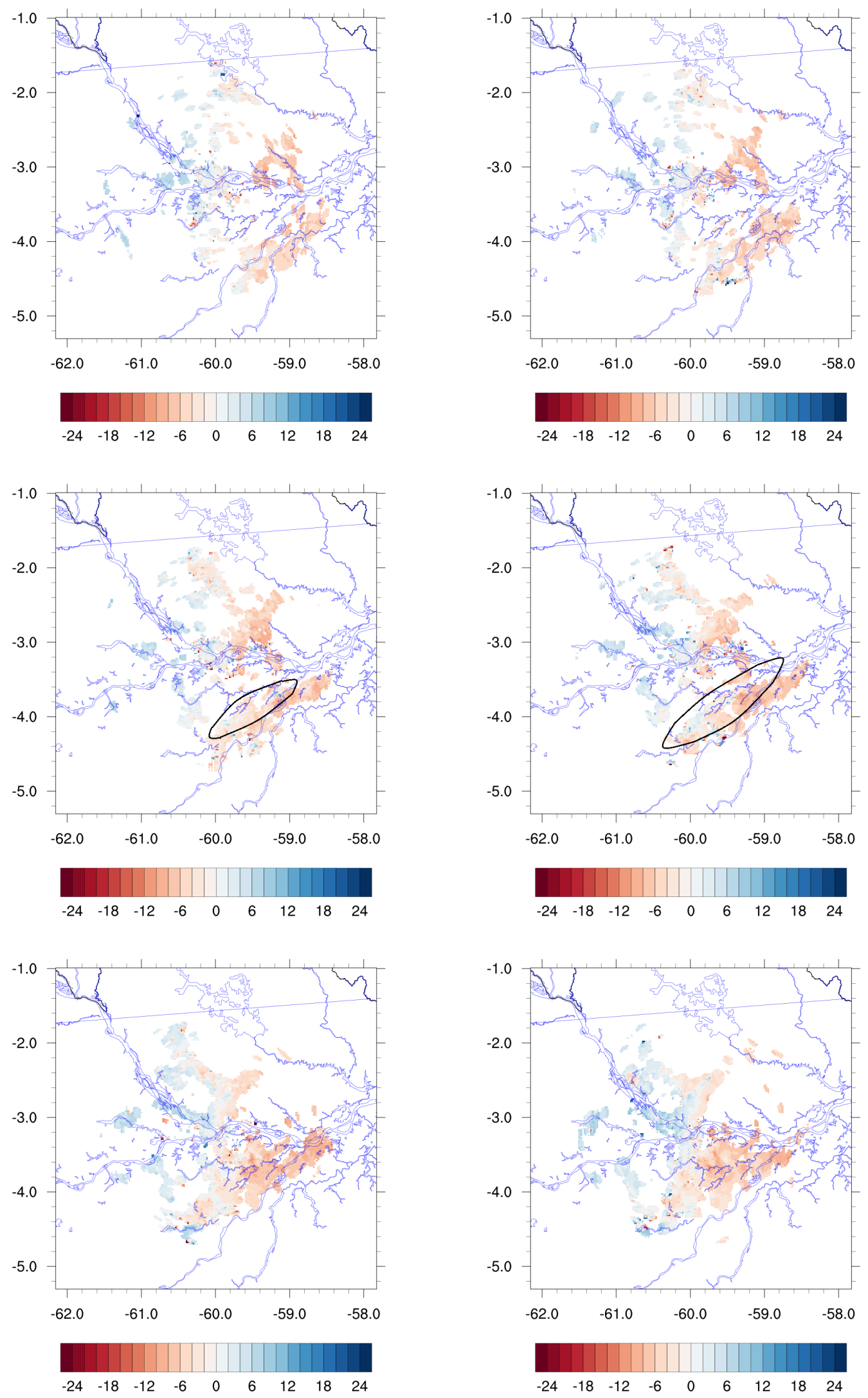

Figure 4.12: Radar radial velocity $\left(\mathrm{m} \mathrm{s}^{-1}\right)$ data for September $08^{\text {th }}, 2014$ at a) 1630 UTC, b) 1700 UTC, c) 1730 UTC, d) 1800 UTC, e) 1830 UTC and f) 1900 UTC. 


\subsection{Study of the WRF $1 \mathrm{~km}$ resolution grid errors}

In this section, the comparison among the WRF errors and WRF variables will be made with the help of the methods described in section 3.11 .

The following tables show the BIAS, RMSE and MSE for the Temperature (T), Dew Point Temperature $\left(\mathrm{T}_{d}\right)$ and Wind Speed (WSPD) for the larger $(27 \mathrm{~km})$ and thinner (1 km) domains for the same latitude and longitude points where the soundings were launched. The data used for this calculations are the WRF simulated data presented for September $08^{\text {th }}, 2014$ at 1500 UTC. Table 4.8 shows the aforementioned errors in table4.8-a for the Purdue Lin parameterization scheme, Table 4.8 $\mathrm{b}$ for the Milbrandt parameterization scheme, Table 4.8 c for Morrison parameterization scheme, and table 4.8 . d for the WSM6 parameterization scheme.

In a quick look in the tables, one can say that the most accurate results are presented by the Milbrandt parameterization scheme. In the overall, for the wind speed, it is the right affirmative, once its BIAS is $67 \%$ (for D01) and $74 \%$ (for D04) lower than the ones found for the Lin scheme. Also, it is lower than the ones presented in the other parameterization schemes. However, it can be noted that the other errors calculated with the variables herein that the Morrison scheme is the parameterization scheme that presents the worst errors. Another thing that can be mentioned is that the other schemes (Milbrandt, WSM6 and Lin) present very close errors to $\mathrm{T}$ and $\mathrm{T}_{d}$ but there is no significant gain in using higher horizontal resolution. This low difference may be associated with the vertical resolution that does not change for all simulations. These errors were calculated for a grid point inside the domains of the simulations. So, for a better representativeness, the correlation was calculated between the sum, in a defined area, of the radar rain rate and the model rain rate.

The sum of the radar and model rain rates were calculated for the level of $2.5 \mathrm{~km}$ above ground for 4 specific regions represented in Fig. 3.2. The sum is the total of all grid points in each box. Results are shown in Fig. 4.13. From these results, it can be noted that the model runs for all of the parameterization schemes used in this case can simulate the peaks of the precipitation, with one only exception for the southern box 4.13 a for the Milbrandt parameterization scheme, which does not show any precipitation for the southern region of the radar radius. These errors follow the errors presented in Fig. 3.4, where it is possible 
to see amplitude and phase errors. It can be seen that, in the overall, the model runs are simulating the accumulated precipitation. To show this quantitatively, the correlation between the radar and WRF total precipitation is hereafter presented.

The correlations are shown in Table 4.6. It is possible to note that the higher correlations between the radar data and model simulations are the ones presented in the eastern box, which is bigger and presents higher accumulated precipitation values not only in the observation but also in the simulations. In a quick look, it is pointed out that the better results are presented for the WSM6 parameterization because it presents very good correlations for the northeastern and eastern boxes. It may not show the best correlations for the northwestern and southern boxes, which are better correlated with Morrison scheme results but it is the only one that presents values closer to 1 when compared to Lin and Milbrandt schemes for all the boxes. Secondly, Morrison scheme also displays good correlations with one exception that is the northeastern box.

Table 4.1 - Variables errors for domain 1 and 4 for September 08 ${ }^{\text {th }}, 2014$ at 1500 UTC.

\begin{tabular}{llll}
\multicolumn{5}{c}{ Table 4.2 - a) } & Purdue Lin \\
\hline Variable & $\mathrm{T}$ & $\mathrm{T}_{d}$ & $\mathrm{WSPD}$ \\
Bias D01 & 1.329 & 5.544 & -2.852 \\
Bias D04 & 1.462 & 5.421 & -2.544 \\
RMSE D01 & 8.815 & 9.028 & 4.166 \\
RMSE D04 & 8.868 & 9.419 & 3.891 \\
MSE D01 & 77.706 & 81.522 & 17.361 \\
MSE D04 & 78.644 & 88.720 & 15.1413 \\
\hline \multicolumn{5}{c}{ Table 4.4- c) Morrison } \\
\hline Variable & $\mathrm{T}$ & $\mathrm{T}_{d}$ & $\mathrm{WSPD}$ \\
Bias D01 & 1.144 & 8.137 & -3.157 \\
Bias D04 & 1.501 & 6.469 & -2.744 \\
RMSE D01 & 8.830 & 11.642 & 5.182 \\
RMSE D04 & 8.875 & 9.723 & 4.796 \\
MSE D01 & 77.984 & 135.541 & 26.860 \\
MSE D04 & 78.768 & 94.552 & 23.005 \\
\hline
\end{tabular}

\begin{tabular}{llll}
\multicolumn{5}{c}{ Table 4.3 - b) Milbrandt } \\
\hline Variable & $\mathrm{T}$ & $\mathrm{T}_{d}$ & $\mathrm{WSPD}$ \\
Bias D01 & 1.548 & 5.586 & -1.917 \\
Bias D04 & 1.594 & 5.330 & -1.892 \\
RMSE D01 & 9.008 & 9.017 & 3.658 \\
RMSE D04 & 9.012 & 9.226 & 3.6733 \\
MSE D01 & 81.147 & 81.323 & 13.388 \\
MSE D04 & 81.224 & 85.131 & 13.493 \\
\hline \multicolumn{5}{c}{ Table 4.5- d) WSM6 } \\
\hline Variable & $\mathrm{T}$ & $\mathrm{T}$ \\
Bias D01 & 1.142 & 5.610 & $\mathrm{WSPD}$ \\
Bias D04 & 1.580 & 5.271 & -2.386 \\
RMSE D01 & 8.842 & 9.447 & 4.027 \\
RMSE D04 & 8.996 & 9.474 & 4.254 \\
MSE D01 & 78.187 & 89.248 & 16.218 \\
MSE D04 & 80.939 & 89.767 & 18.097 \\
\hline
\end{tabular}




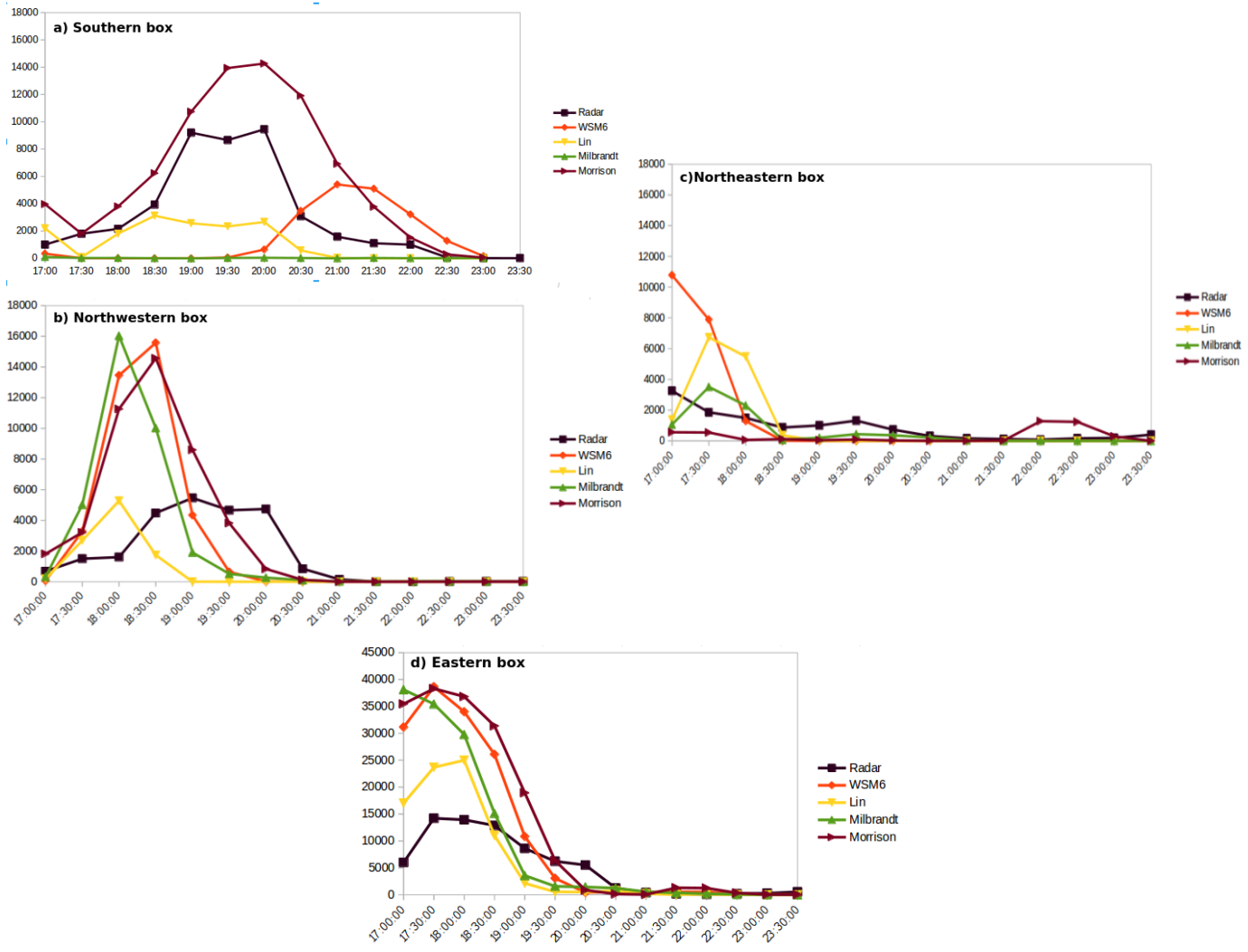

Figure 4.13: WRF and radar sum for the rain rates for September 08 ${ }^{\text {th }}, 2014$ for the a) Southern, b) Norwestern, c) Northeastern and d) Eastern boxes around the radar radius.

Table 4.6 - Radar data correlations with the WRF simulations for the sum of the rain rates boxes in September $08^{\text {th }}$, 2014 from 1700 UTC to 2330 UTC.

\begin{tabular}{lllll}
\hline Parameterization & WSM6 & Lin & Milbrandt & Morrison \\
Southern Box & -0.52 & 0.09 & -0.18 & 0.53 \\
Northwestern Box & 0.39 & 0.05 & 0.22 & 0.6 \\
Northeastern Box & 0.87 & 0.53 & 0.62 & -0.01 \\
Eastern Box & 0.86 & 0.82 & 0.72 & 0.88 \\
\hline
\end{tabular}

\subsection{System Lifecycle, Evolution and Propagation}

In this section, the system lifecycle, evolution, and propagation will be shown with the aid of 3 different points of view: the satellite derived rain rate from $\mathrm{CMORPH}$, the radar data and WRF simulations for the inner domain with $1 \mathrm{~km}$ resolution. Figures 4.14 and 4.15 show the CMORPH and radar rain rate and Figures 4.16, 4.17, 4.19, 4.20 display the rain rate in $\mathrm{mm} \mathrm{h}^{-1} \mathrm{WRF}$ simulations for 1700, 1730, 1800, 1830, 1900, 1930 and 2000 UTC for the 4 different parameterization schemes. Note that the region of interest lies in 
the middle of the boxes chosen in Fig. 3.2 .

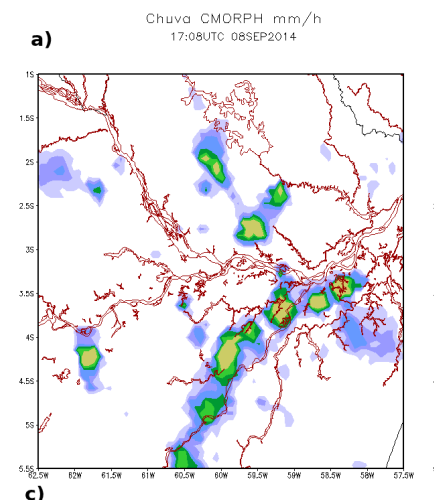

b) Chuva CMORPH mm/h
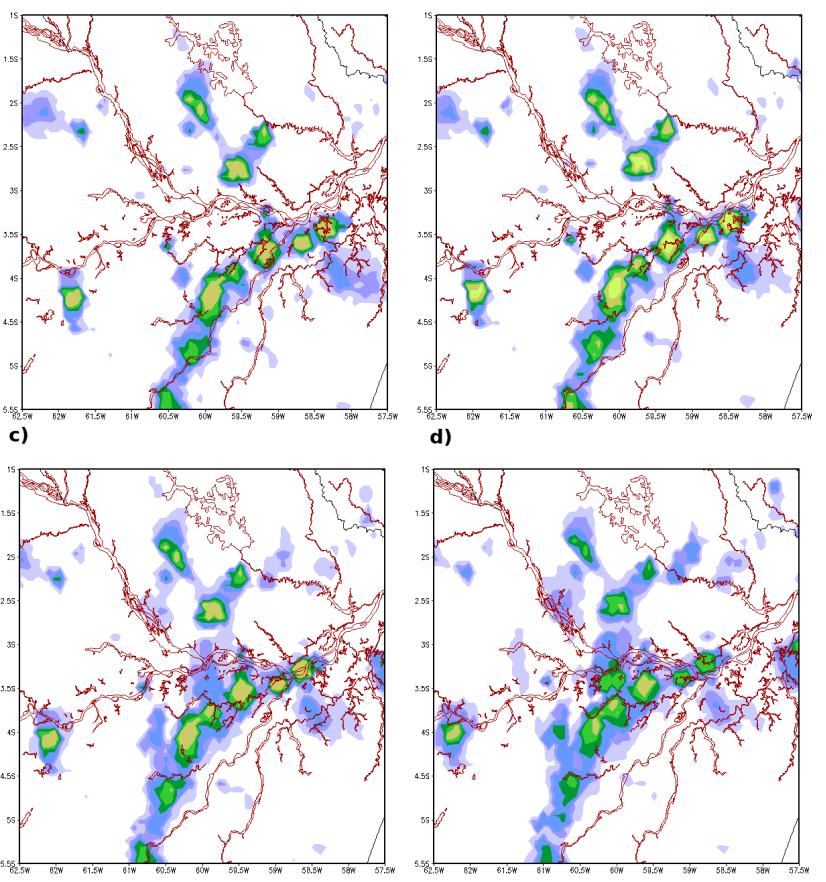

e)

f)
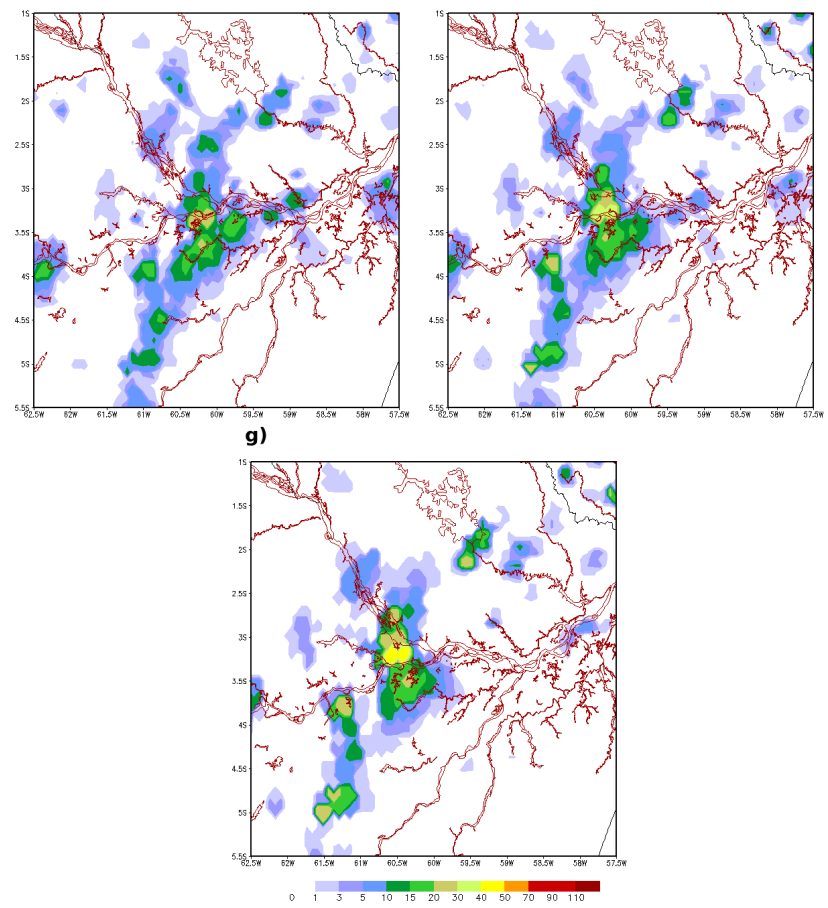

Figure 4.14: CMORPH rain rate $\left(\mathrm{mm} \mathrm{h}^{-1}\right)$ at a) $\left.1700 \mathrm{UTC}, \mathrm{b}\right) 1730 \mathrm{UTC}$, c) $1800 \mathrm{UTC}$, d) 1830 UTC, e) 1900 UTC, f) 1930 UTC and g) 2000 UTC. 

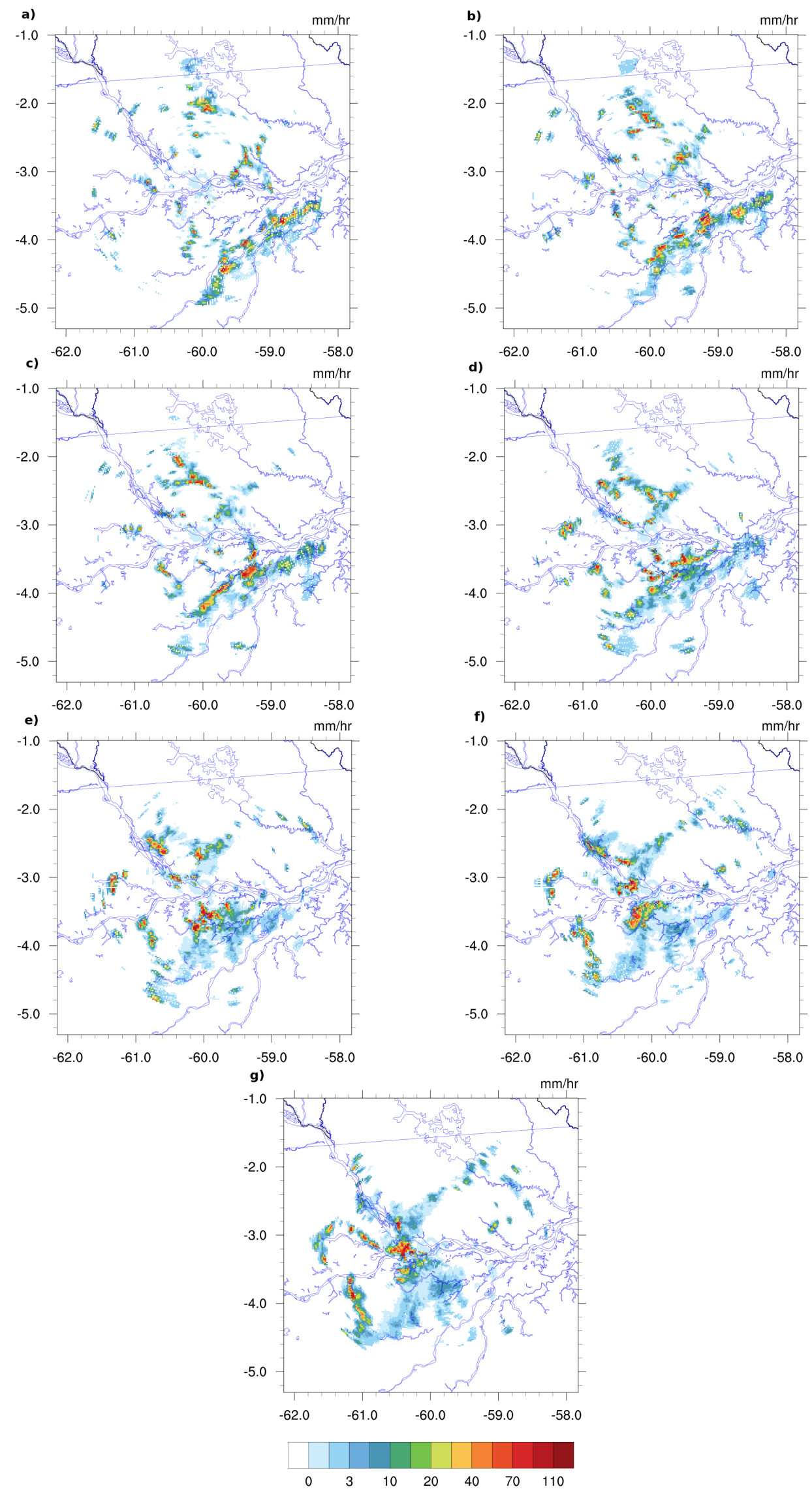

Figure 4.15: Radar rain rate $\left(\mathrm{mm} \mathrm{h}^{-1}\right)$ at a) $\left.\left.\left.1700 \mathrm{UTC}, \mathrm{b}\right) 1730 \mathrm{UTC}, \mathrm{c}\right) 1800 \mathrm{UTC}, \mathrm{d}\right)$ 1830 UTC, e) 1900 UTC, f) 1930 UTC and g) 2000 UTC. 
In Fig. 4.16, which comprises the timespan in between 1700 and 2000 UTC, the most important time period in which the convection is more intense in the region of Manacapuru and Manaus are shown. The analysis of Fig. 4.16, which is in the inner region of the $27 \mathrm{~km}$ CTL run, shows that the CMORPH rain rate data at 1700 UTC presents a similar pattern to the one seen in the satellite imagery of Fig. $4.3 \mathrm{~b}$, due to the fact that the CMORPH precipitation estimative merges infrared and microwave satellite data. The radar data for the same time strongly correlates with the CMORPH information. However, the WRF results for the same time do not show any precipitation to the southernmost part of the system. In this situation, the correlation between the radar data and the simulated data for this event reaches only -0.18 in the southern box of Fig. 3.2, as shown in Table 4.6. Through this analysis, it can be inferred that the precipitation for the southern region is initially underestimated. It is seen that the system displayed by the CMORPH and radar images show predominantly southeasterly winds, but WRF simulation for this parameterization shows winds that are apparently preferentially from the east, inferred from the system inclination. Moreover, to deny this apparent point of view, one can see that checking vertical velocities and the wind speed in the bottom of Fig. 4.21, the wind is directed from the southeast as well.

The initiation of the system is seen over the southwestern region of Pará State, as it was mentioned previously and pointed out in the circled areas inside Fig. 4.2. It reaches its maximum intensity at 1930 UTC, when the system is already in the region of interest. At this moment, the precipitation rate ranges from 40 to $50 \mathrm{~mm} \mathrm{~h}^{-1}$ at $60.5^{\circ} \mathrm{W}$ and 3.25 ${ }^{\circ} \mathrm{S}$, which is presented earlier when it is checked in WRF simulation for the Milbrandt parameterization scheme (at 1730 UTC) at the northeast of the region of Manacapuru. On the other hand, through the radar rain rates, it is observed that the values are higher than what was retrieved by the satellite derived data and is even higher than the WRF simulation for this scheme for all times displayed throughout the whole period in Fig. 4.16. Until now this parameterization scheme does not properly simulate the rain field in the northwestern and southern portion of the region of interest. Nonetheless, it shows high correlations with the rain rates in the eastern and northeastern portions of the system, reaching 0.72 and 0.62 , respectively. To verify that, it is necessary to take a look and compare CMORPH and radar rain rates in Fig. 4.16 d with WRF rain rate for the same time. It is seen that the rain rate over the southern region of the system studied is very 
lower when it is presented by the simulated WRF rain rate fields in this parameterization experiment.

The rain rates for CMORPH, radar, and WRF for the Purdue Lin scheme can be visualized in Fig. 4.17. For this parameterization scheme, it can be seen that even though it does simulate the precipitation seen in the radar rain rate for the southern box observed in Fig, 4.13, the correlation obtained and showed in Table 4.6 for this region is only 0.09 . This has left an intriguing question because if it does represents the radar curve, but does not catch its peaks or phase the correlation must have had been bigger. Thus, to make sure that this tiny but very large error in the correlation for the southern box would not be representative, the correlation was calculated again for the timespan ranging from 1730 UTC to 2330 UTC, and the new results are shown in Table 4.7. The new calculations made possible to stress out that the correlation is largely affected by points off the curve. The new correlation rises from 0.09 to 0.81 , which indicates that the model simulation for this scheme can be an useful predictor. For the other parameterization schemes, this new calculations did not make a large difference, but it can be noted that Morrison scheme rises its correlation by 0.05 , which does not seem to be a large difference. However, it makes a large difference in representing variables such as precipitation, which is the toughest one in meteorology. Notwithstanding, this tiny change in the computations of the correlation between the rain rates makes the Purdue Lin scheme the best one in the simulation of the rain over the southern region in comparison with the other parameterization schemes. This is even more evident when comparing the rain rate fields for Lin (Fig. 4.17), Morrison (Fig. 4.20), Milbrandt (Fig. 4.16) and WSM6 (Fig. 4.19) schemes with the available observed data.

Table 4.7 - Radar data correlations with the WRF simulations for the sum of the rain rates boxes in September $08^{\text {th }}, 2014$ from 1730 UTC to 2330 UTC.

\begin{tabular}{lllll}
\hline Parameterization & WSM6 & Lin & Milbrandt & Morrison \\
Southern Box & -0.50 & 0.81 & -0.10 & 0.58 \\
\hline
\end{tabular}



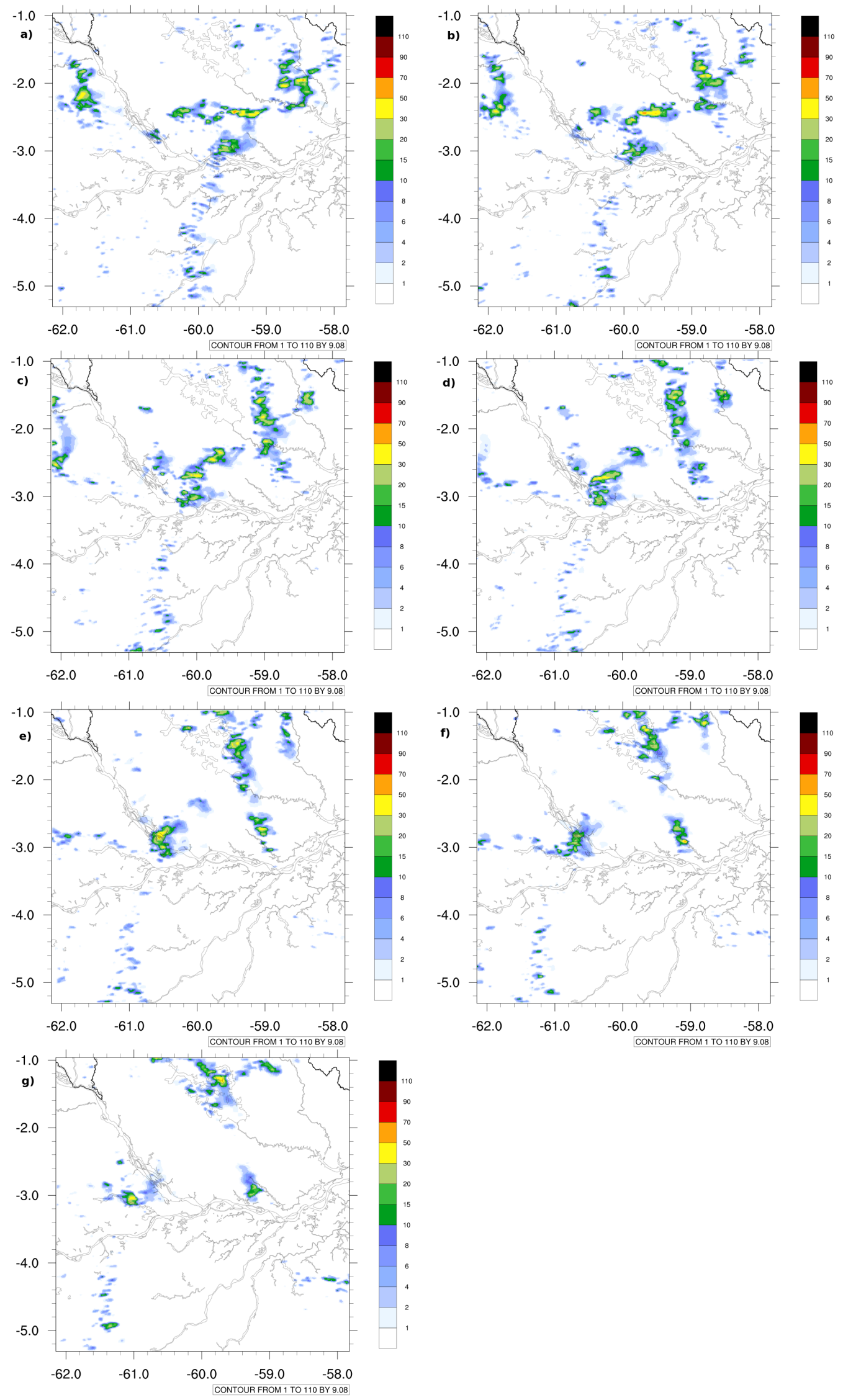

Figure 4.16: WRF rain rate $\left(\mathrm{mm} \mathrm{h}^{-1}\right)$ at a) $\left.\left.\left.1700 \mathrm{UTC}, \mathrm{b}\right) 1730 \mathrm{UTC}, \mathrm{c}\right) 1800 \mathrm{UTC}, \mathrm{d}\right)$ 1830 UTC, e) 1900 UTC, f) 1930 UTC and g) 2000 UTC for the Milbrandt parameterization scheme. 
From another point of view, looking Fig. 4.17, and comparing WRF simulation with CMORPH and also the radar rain rates, there is a slight difference between the meteorological system horizontal inclination over the region. The system is diagonally inclined when it is viewed from the CMORPH rain rates, but its inclination is not very well simulated by WRF in this parameterization scheme, which may have been caused by some differences in the wind simulations.

Since the radar rain rates shown in Fig. 4.17 are the same as in Fig. 4.16 it is noted that the radar rain rates are very intense, reaching up to $110 \mathrm{~mm} \mathrm{~h}^{-1}$, which represents large amounts of rain. This may be associated with the time between each radar volume scan, which is made each $12 \mathrm{~min}$, and for CMORPH and WRF simulations, with results each 30 min in both cases. On the other hand, both CMORPH and WRF simulations reach a maximum of 40 and $50 \mathrm{~mm} \mathrm{~h}^{-1}$. CMORPH and WRF values seem to be more feasible because the total accumulated rainfall that was measured in the GOAmazon automatic station reached up to $57.4 \mathrm{~mm}$ by the end of the day. So it may indicate that the ZR relationship adopted herein may have overestimated the rain over the region.

The WRF simulation in the Purdue Lin case shows some spurious precipitation systems to the north and northeast of Manacapuru, not observed in the real data. Another problem that can be noted here is that the system rain rate happens earlier than it was observed. This can be seen in Fig. 4.13-b where there is a phase error which is close to the one explained in Fig. 3.4 in the simulated WRF results and the radar rain rate curve. This is not a singularity that can only be viewed in this parameterization scheme but can also be observed through the other parameterization schemes in Fig. 4.13-b and Fig. 4.13-a. This shows that WSM6 scheme may reach close values with the radar rain rate, but there is a difference of approximately 3 hours in the start of precipitation.

The WSM6 parameterization scheme, which is the one that shows the highest correlations with the radar rain rate data, also presents some amplitude and phase errors in this case. If the data in the graphic presented in Fig. 4.13 a for this parameterization scheme were manually displaced to the left, the graphic would be like the one shown in Fig. 4.18. 

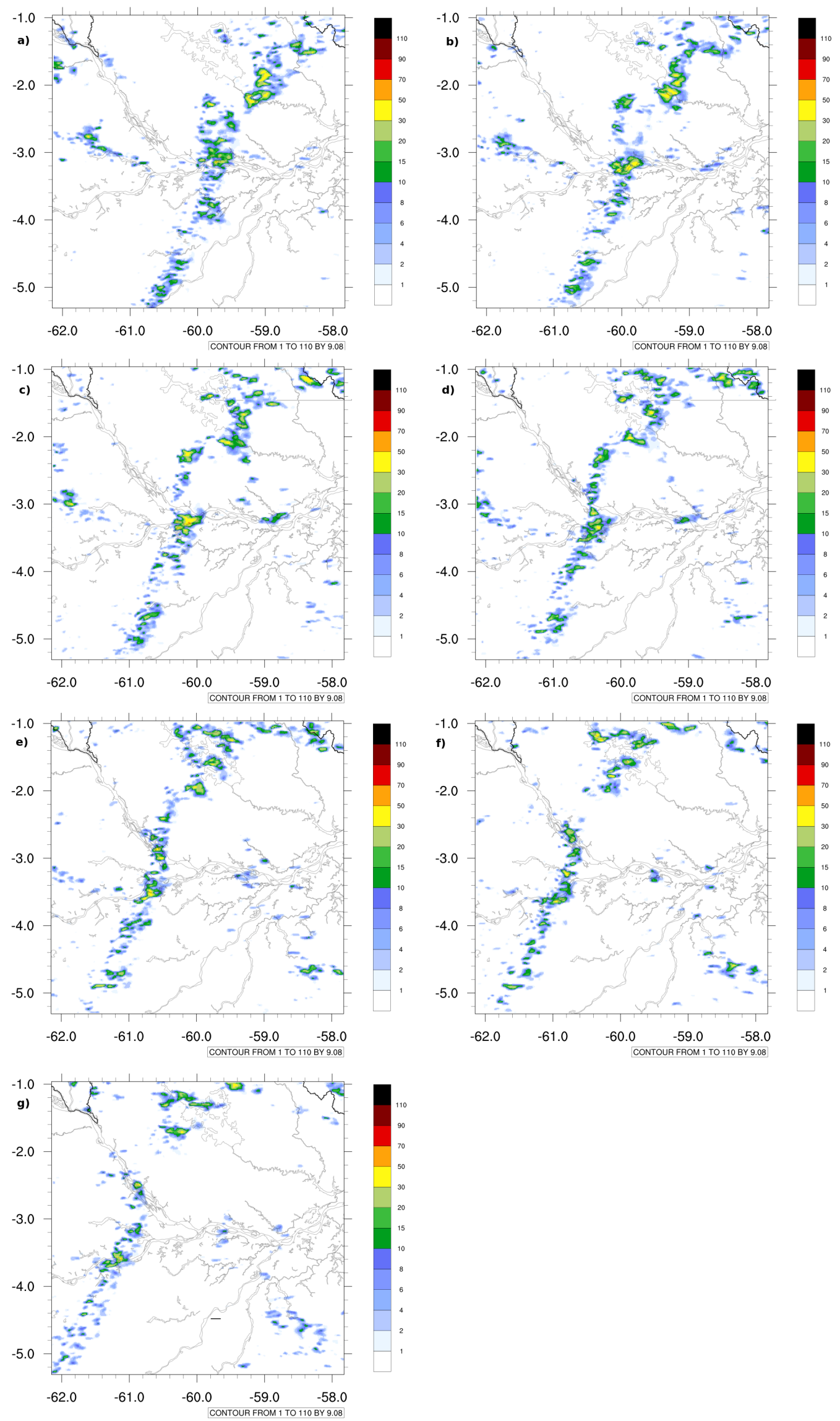

Figure 4.17: WRF rain rate $\left(\mathrm{mm} \mathrm{h}^{-1}\right)$ at a) 1700 UTC, b) 1730 UTC, c) 1800 UTC, d) 1830 UTC, e) 1900 UTC, f) 1930 UTC and g) 2000 UTC for the Purdue Lin parameterization scheme. 
This phase shift caused in the rain rate would not make the simulation to be perfect but would turn the correlation to be 0.9 . The same could not be done for the Morrison scheme over the same region because the specific problem that caused the correlation to be 0.53 in the southern box was that the rain rates in this scheme reached higher values than the ones obtained by the radar. So, the amplitude error viewed in Morrison scheme affects the correlation as much as points off the curve.

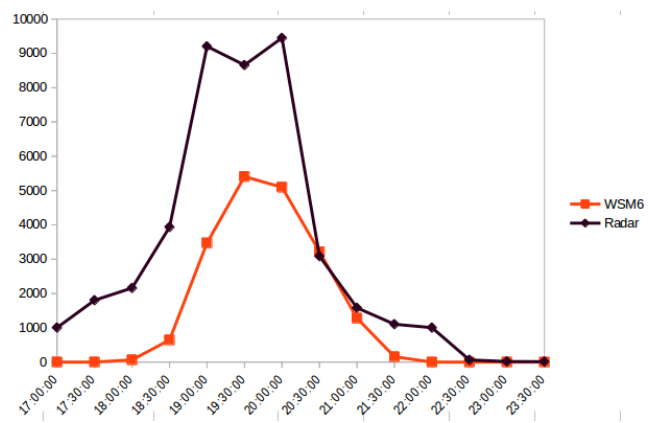

Figure 4.18: Rain rate $\left(\mathrm{mm} \mathrm{h}^{-1}\right)$ sum for the southern box of the radar and the WRF modified rain rate for WSM6 parameterization scheme.

Contrasting this parameterization scheme with the other ones, it can be noted that the rain rates for Milbrandt, Morrison, and Lin also show some phase differences with the radar and CMORPH. Spatially, looking at Figs. 4.16, 4.17, 4.19 and 4.20 all the parameterization schemes show phase errors associated with the rain rates over the region inside the inner domain (D01). Such things happen because the model parameterizations schemes are not sufficient to remove all the errors that can be present in atmospheric model simulations. One important thing to mention is that the global models do not provide information in the same spatial and time resolution as the mesoscale convective systems occur. This can be a crucial subject when mesoscale or even finer meteorological systems are simulated by regional meteorological models.

In Fig. 4.20 the rain rates for CMORPH, radar and WRF simulation for Morrison scheme are shown. This parameterization scheme showed the highest correlation for the eastern and northwestern region (see Table 4.6). Its values reach 0.88 and 0.6 , respectively which are strongly correlated to the radar data. However, the northeastern box shows the weakest correlation with the observed rain rates. This is associated with the fact that the other parameterization schemes used in this case demonstrated lesser phase errors when compared with Morrison scheme. 

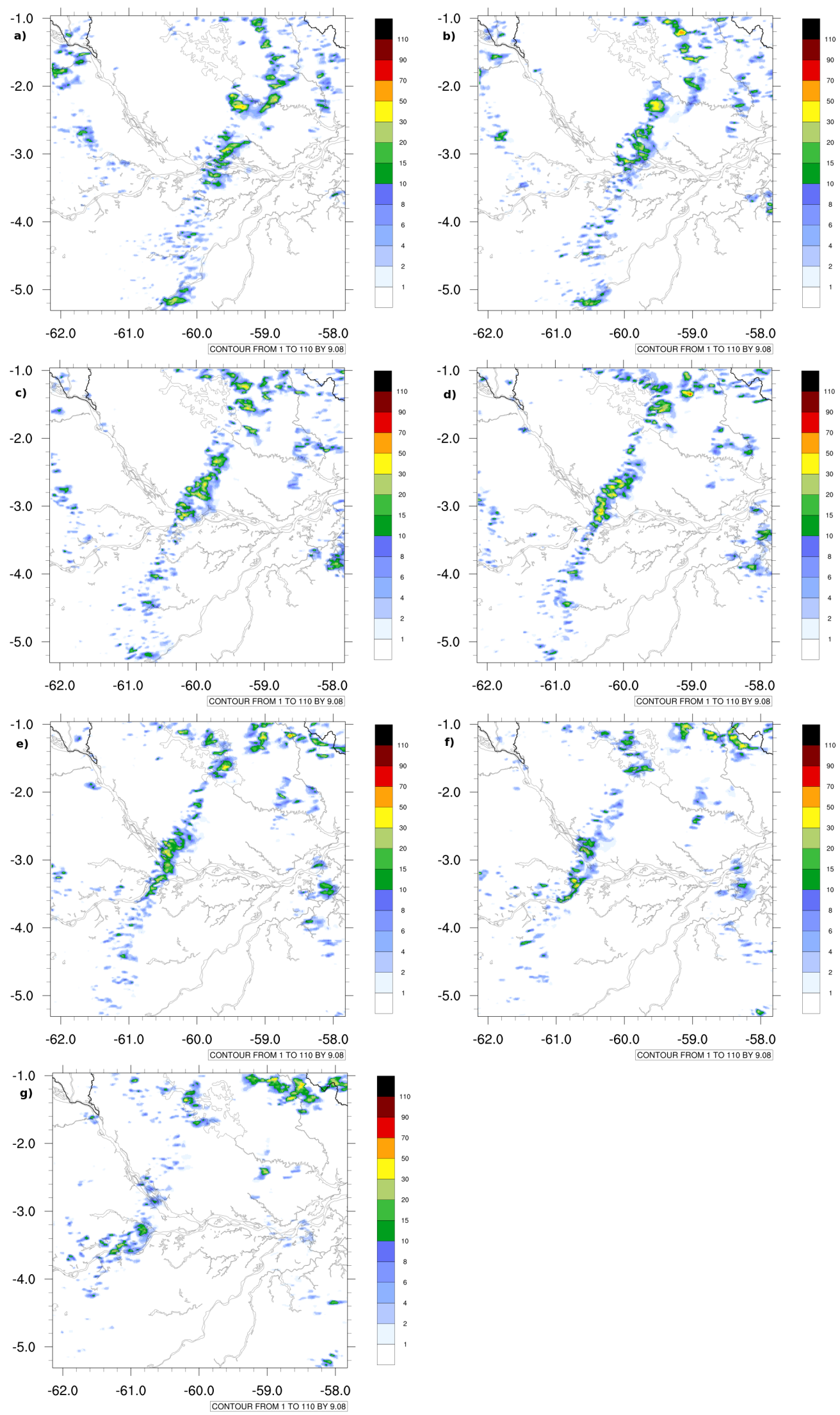

Figure 4.19: WRF rain rate $\left(\mathrm{mm} \mathrm{h}^{-1}\right)$ at a) $\left.\left.\left.1700 \mathrm{UTC}, \mathrm{b}\right) 1730 \mathrm{UTC}, \mathrm{c}\right) 1800 \mathrm{UTC}, \mathrm{d}\right) 1830$ UTC, e) 1900 UTC, f) 1930 UTC and g) 2000 UTC for the WSM6 parameterization scheme. 
Also, the system positioning was not well simulated by WRF in this case. Moreover, this scheme showed correlation of 0.53 in the southern box which is also the highest among other schemes used here. Initially, it can be noted that the problems that mostly affected the parameterization schemes from showing better correlations with the observed data were associated with the system positioning which is a phase difference. This result may point out that there may be a need of adopting another methodology to initiate the model run such as data assimilation.

This parameterization scheme also simulated spurious rain rate fields, but differently, from WSM6 simulation, it showed such errors in the northeastern and eastern region of Manaus and Manacapuru. However, observing 4.20 it is seen that the rain rate fields are showing similar results to the satellite and radar observations over the region of interest. This is the motive that has led the correlations between this parameterization scheme and the observed data to reach values closer to 1, except for the northeastern box that reached only -0.01 .

In the overall, not accounting the phase and amplitude errors, WRF simulation for this region is a strong tool to determine whether there is a strong severe weather happening or not. In the sequence, it should be checked if microphysical quantities and other physical characteristics are also well simulated by the model. 

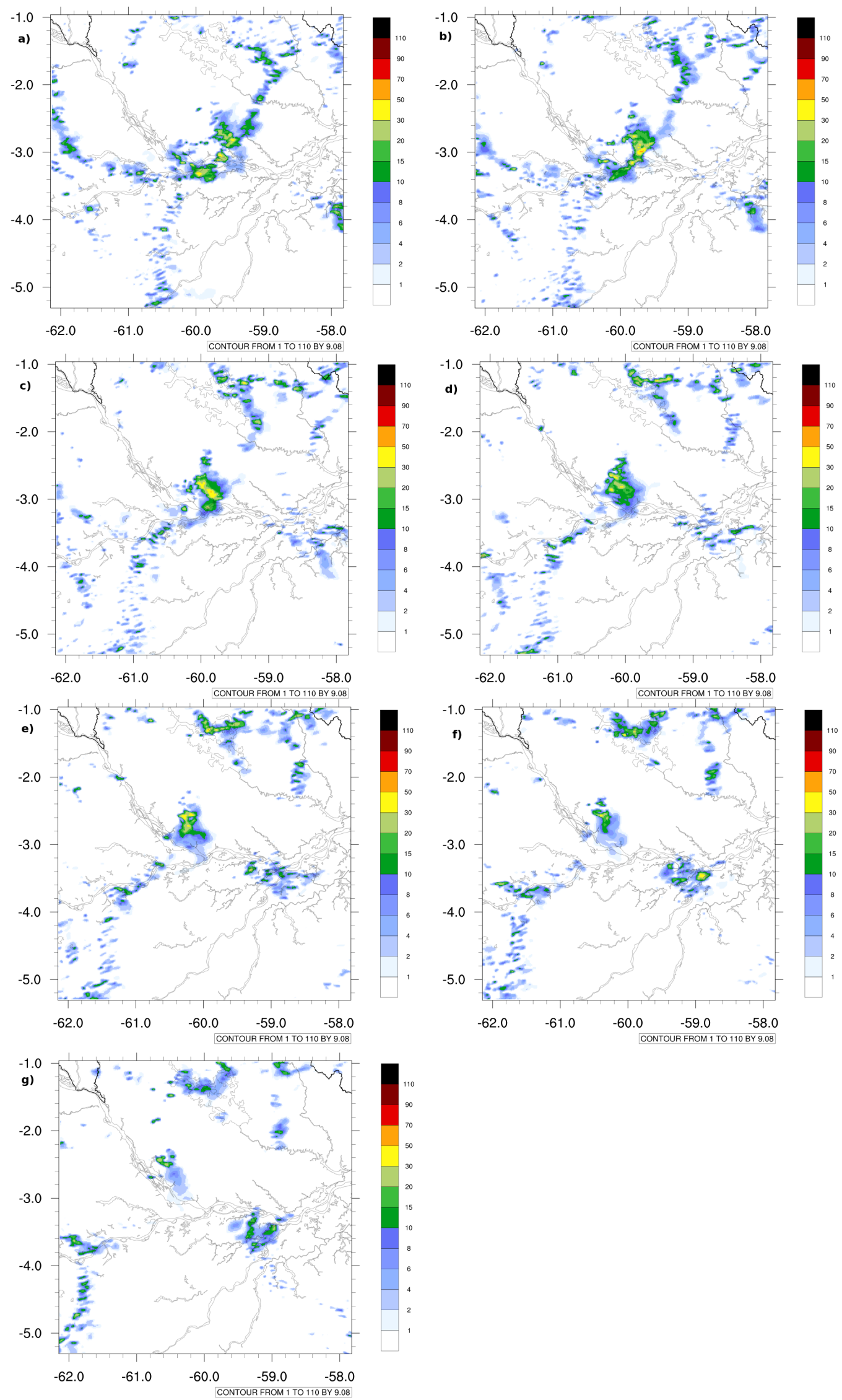

Figure 4.20: WRF rain rate $\left(\mathrm{mm} \mathrm{h}^{-1}\right)$ at a) $\left.\left.\left.1700 \mathrm{UTC}, \mathrm{b}\right) 1730 \mathrm{UTC}, \mathrm{c}\right) 1800 \mathrm{UTC}, \mathrm{d}\right)$ 1830 UTC, e) 1900 UTC, f) 1930 UTC and g) 2000 UTC for the Morrison parameterization scheme. 


\subsection{Cold Pool and CAPE Analysis}

The cold pool analysis (see Section 3.10) is shown in Fig. 4.21 where the mean temperature inside the thinner domain with a box of $20 \mathrm{~km}$ was calculated and the perturbations temperatures were extracted and plotted together with the precipitation (Figs. 4.21 -a and 4.21 -b). The same was applied for the $2 \mathrm{~m}$ water vapor mixing ratio (Figs. 4.21-c and 4.21 d). Also, the wind velocities and the vertical velocities are demonstrated for the case study in Figs. 4.21 fe and $4.21 \mathrm{f}$.

Analyzing the perturbation temperature at 1500 UTC in Figs. Figs. 4.21 a and 4.21 b, it is noted that there is a long and thin high warm perturbation temperature between 59 and $60^{\circ} \mathrm{W}$. So, it can be inferred that the perturbation temperature differences is the leading trail that drives the system in the preferential wind motion, which is southeast, where the cells are in development (see 4.2 e). These warm perturbation temperature observed in both Figs. 4.21 - a and 4.21 b reaching up to $3{ }^{\circ} \mathrm{C}$, between 59 and $60{ }^{\circ} \mathrm{W}$, contra-balances with the cold perturbations temperatures at the rear of the system positioned between 59 and $60{ }^{\circ} \mathrm{W}$, which is the region where there is heavy rain. The cold perturbation temperatures are not as intense as the warm perturbations, but it clearly denotes the region where there is upward vertical motion (front of the system) and downward vertical motion (rear of the system). This can be observed in Figs. 4.21 fe and 4.21 f where there is a long thin dark green line positioned between 59 and $60^{\circ} \mathrm{W}$ indicating the region presenting upward motion and at the rear of the system there are several dark green and dark brown cores representing upward and downward motion, respectively. Thus, it is noted that the system is triggered by temperature gradients which make possible the formation of new convective cells and also the system propagation.

A further investigation using the perturbations in the water vapor mixing ratio (middle of Fig. 4.21) at 1500 UTC shows that there are also high perturbations in this field at the same region of the warm perturbation temperatures. This rise in the mixing ratio stills moves towards the region of interest (see Fig. 4.21-d) observed as a line shaped pattern which reaches the region of Manaus and Manacapuru at approximately 1730 UTC (not shown here). Another important aspect that is noted in this section is that the ice plays a key role in the southernmost part of the system. 
a)
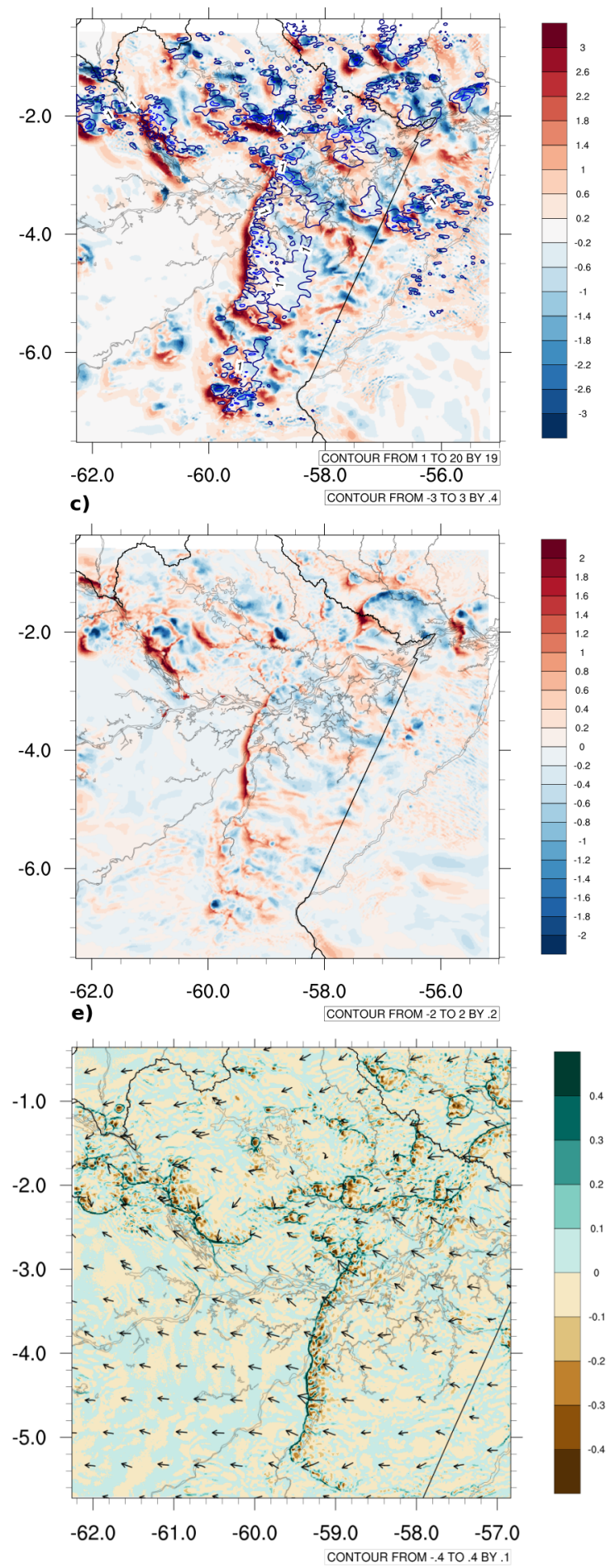

b) 2014-09-08 16:30:00
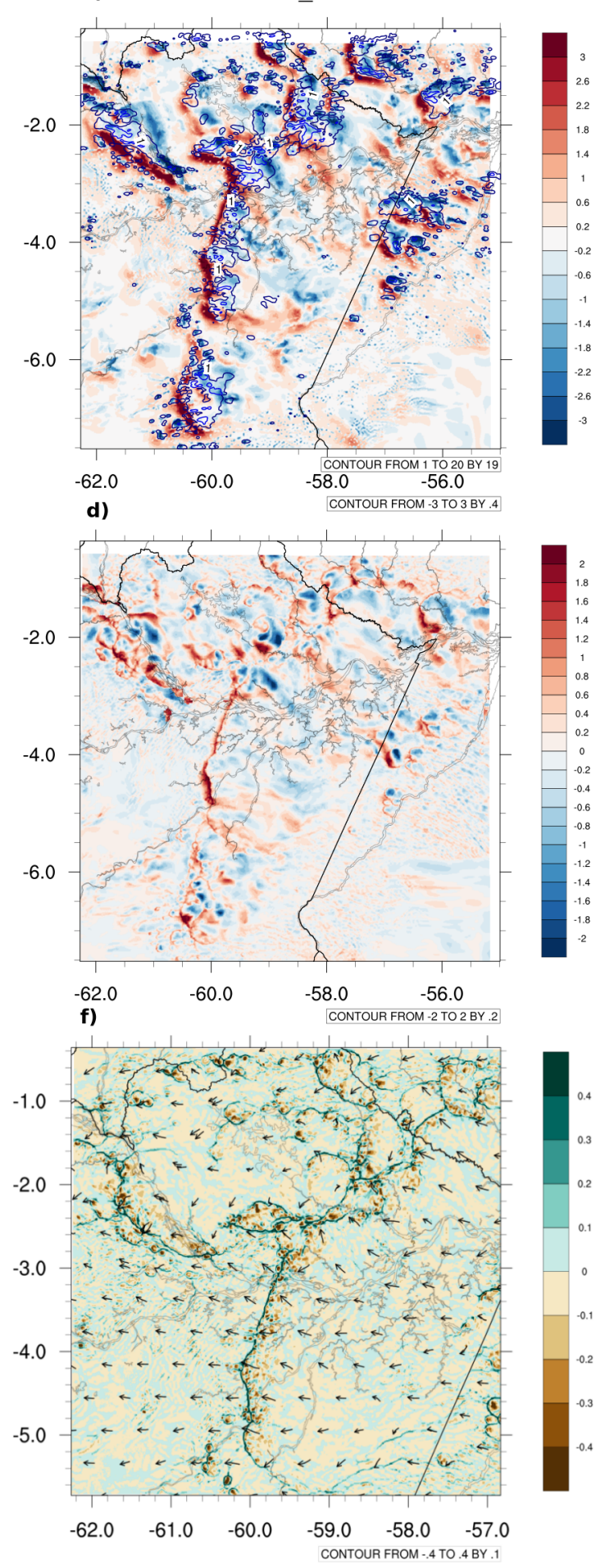

Figure 4.21: Temperature at $2 \mathrm{~m}$ anomalies and the rain rate $\left(\mathrm{mm} \mathrm{h}^{-1}\right)$ at a) $1500 \mathrm{UTC}$ and b) 1630 UTC, water vapor mixing ratio at $2 \mathrm{~m}$ anomalies c)1500 UTC and d)1630 UTC and vertical velocity at $200 \mathrm{~m}$ and wind speed at e)1500 UTC and f)1630 UTC.

The ice role can be tested through a model run that was made with the same parameterization schemes, but the microphysics, to determine if the ice was or was not important in the formation of the cold and warm perturbation temperatures in this case. The micro- 
physics used in this test was the Kessler parameterization scheme, which does not include ice (i.e. only for warm clouds). This run was then compared to the control grid test. Figs. 4.22 -a and 4.22 -b show the cold and warm perturbation temperatures with the rain rates for 1 and $20 \mathrm{~mm} \mathrm{~h}^{-1}$ at 1500 and 1600 UTC, respectively.

At 1500 UTC it is noted that the system displayed in Fig. 4.22-a does not show a high correlation compared with the one formed and presented in Fig. 4.21-a. However, it is seen that the warm temperatures presented by the Milbrandt parameterization scheme are simulated between approximately 60.5 and $59.5^{\circ} \mathrm{W}$ for the Kessler scheme in Fig. 4.22 -a. The warm temperatures anomalies coverage is not as large as the one presented in Fig. 4.21 -a, which makes the system not as organized as it really is when it is checked in Fig. 4.3 b. Also, when the system in Fig. 4.22 b is compared with the satellite image in Fig. 4.23 at 1630 , it is possible to infer that this parameterization scheme is generating larger precipitating cells over $4{ }^{\circ} \mathrm{S}$ which do not depend exclusively on the perturbations temperatures because its intensity is not as strong as the one observed in Fig. 4.21 b.
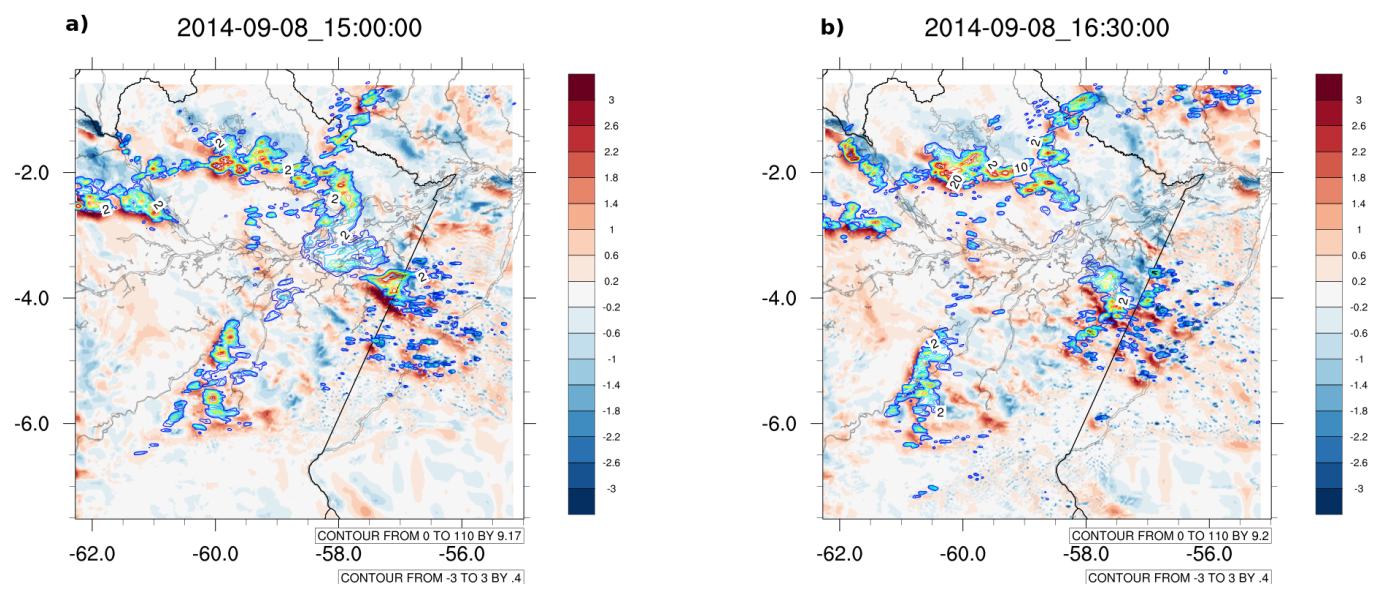

Figure 4.22: Perturbation temperature at $2 \mathrm{~m}$ for a) 1500 UTC and b) 1630 UTC for the simulation for Kessler scheme. 


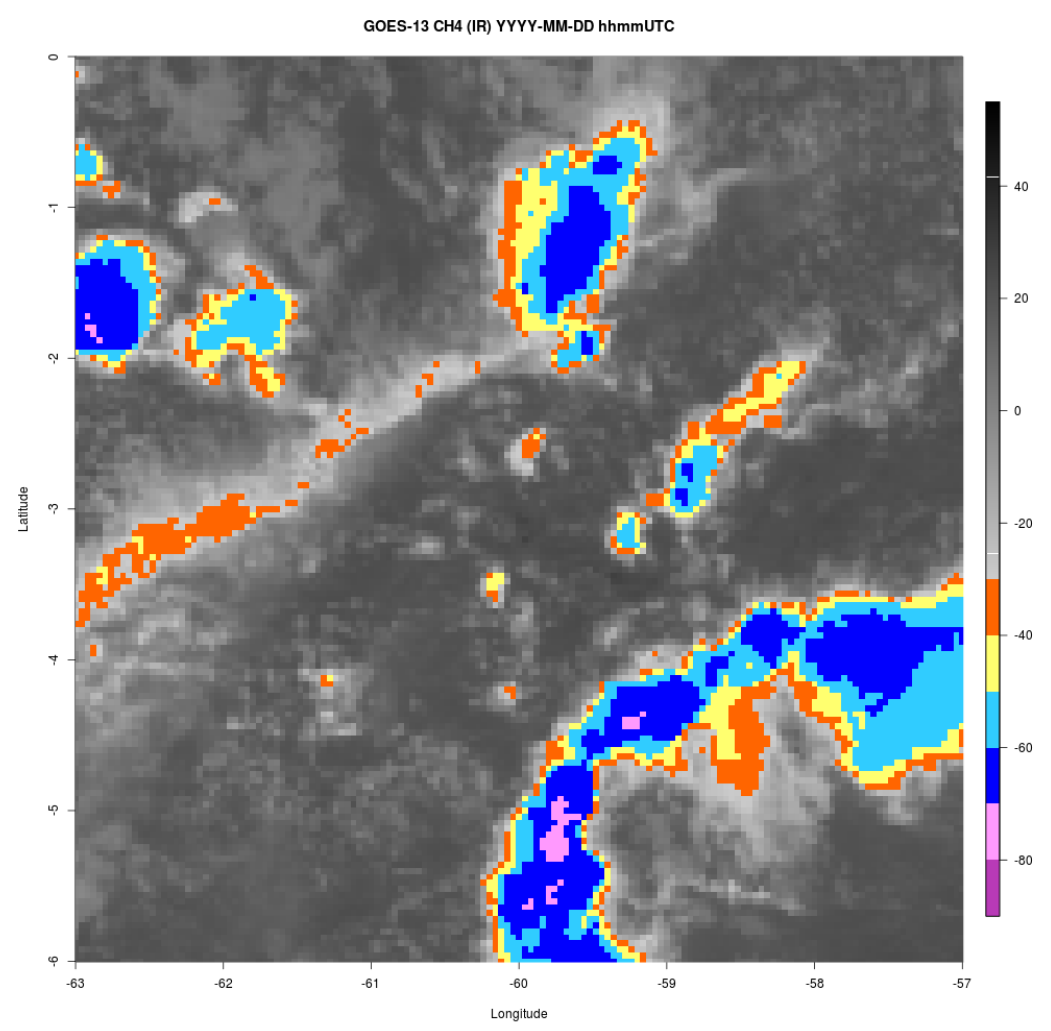

Figure 4.23: GOES-13 satellite infrared highlighted image of the northern part of Brazil at September $08^{\text {th }}, 2014$ at 1630 UTC.

Fig. 4.24 displays the WRF perturbation potential temperatures from 1500 to 1900 UTC for Milbrandt and Morrison parameterization schemes. Through the perturbations potential temperatures, it is possible to identify the region where cold pools are sited within the domain. Regions of negative perturbation temperatures are the regions where the cold pools are over the box D04 and it can be inferred that both parameterization schemes show similar results. It can be seen that the cold pools observed at 1500 UTC (Figs. 4.24-a and $4.24 \mathrm{~b}$ ) are larger in horizontal extension for the Morrison parameterization scheme, showing cold pool fraction of 0.44 , while the Milbrandt parameterization scheme shows 0.38 (see Table 4.8). This is consistent with the tests showed by Morrison and Milbrandt (2010) which presents cold pool fractions higher for the Morrison parameterization scheme in contrast with Milbrandt. Also, there are regions where the perturbations of potential temperatures are lower, as shown by Morrison in Fig. 4.24 b, where the minimum perturbation potential temperatures reach up to the $-4 \mathrm{~K}$. Also, the colder $\theta^{\prime}$ at the forward flank are also simulated by Morrison at $59^{\circ} \mathrm{W}$ and $3.5^{\circ} \mathrm{S}$ and at the rear flank are simulated in Milbrandt parameterization schemes. The perturbation potential temperature minimal 
is reduced at 1700 UTC in Figs. 4.24 $\mathrm{c}$ and $4.24 \mathrm{~d}$ because both parameterizations show smaller cold pools which is associated with the decay of the system. The Milbrandt parameterization scheme displays higher $\theta^{\prime}$ at the forward flank region where the heaviest precipitation is located (see Figs. 4.20-a and 4.16-a), while the Morrison scheme shows lower $\theta$ ' at the rear flank. At 1900 UTC, in $4.24 \mathrm{f}$ it can be seen that the more intense cold pool is showed at the center of the domain which is larger and more intense than the one presented in Fig. 4.24 e. This is also associated with the fact that the more intense rainfall region is for Morrison scheme located in 4.20 e. The system in Figs. 4.24 e and $4.24 \mathrm{f}$ tend to form the same pattern as the one shown in Fig. 4.3-e which is more latitudinally extended.

Table 4.8 - Cold Pool fraction for September 08 ${ }^{\text {th }}, 2014$ from 1500 UTC to 1900 UTC.

\begin{tabular}{lll}
\hline Cold Pool Fraction & Morrison & Milbrandt \\
1500 UTC & 0.44 & 0.38 \\
1700 UTC & 0.28 & 0.1 \\
1900 UTC & 0.13 & 0.1 \\
\hline
\end{tabular}

The cold pool fraction is associated with the number of clouds over the region. In this case, for example, the Top of the Atmosphere (TOA) outgoing longwave radiation (OLR) is showing low values reaching up to $100 \mathrm{~W} \mathrm{~m}^{-2}$ in some regions where the clouds are more vertically extended and the radiation emitted from the surface to the atmosphere is lower in Fig. 4.25. It can be seen that at 1500 UTC the TOA-OLR is lower for the Morrison parameterization scheme which indicates that the convection formed by this scheme is much more intense than for Milbrandt. Also, the regions that show lower TOA-OLR are much larger for Morrison scheme because there is more convection when the latent heat flux is observed (not shown here) which generates more vertically extended clouds. It is stressed out that since this scheme generates more convection, it does also show more precipitation values near the surface as it was already seen in Fig. 4.13-a and is also corroborated by Morrison and Milbrandt (2010). Morrison and Milbrandt (2010) shows that this fact is associated in part with a larger flux of frozen condensate into the melting layer from above, which can be seen in Fig. 4.36-b.

At 1700 UTC in Fig. 4.25 c and 4.25 d it is more evident that the TOA-OLR is also showing low values for Morrison than it is for Milbrandt over some regions, but 
Milbrandt also shows some regions where TOA-OLR is lower than Morrison. Thus, the large differences are not encountered in the amplitude but in the area of lower OLR values which is much larger for Morrison because it generates more convection over the region. This pattern remains the same at 1900 UTC where the OLR lower values cores are still simulated in the Morrison scheme in Fig. 4.25-f which may be associated with the large system seen in Fig. 4.3 e. The pattern presented in Fig. 4.3 -e is very similar to the one showed in Fig. 4.25-f. 
2014-09-08_15:00:00

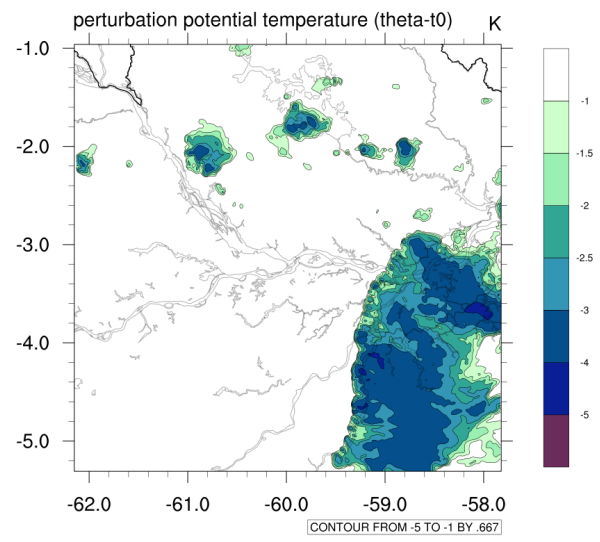

2014-09-08_17:00:00

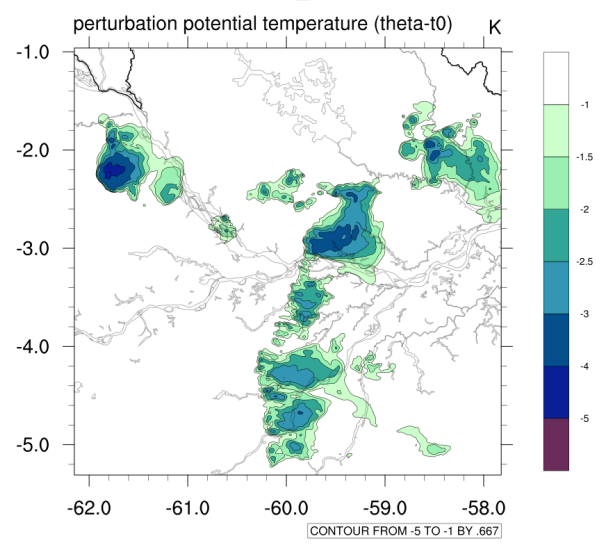

2014-09-08 19:00:00

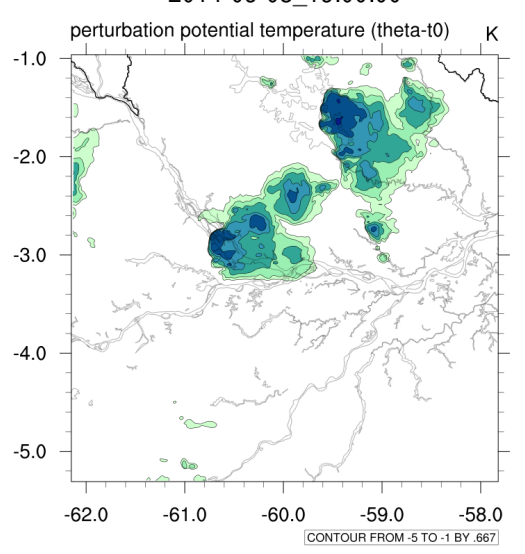

2014-09-08_15:00:00

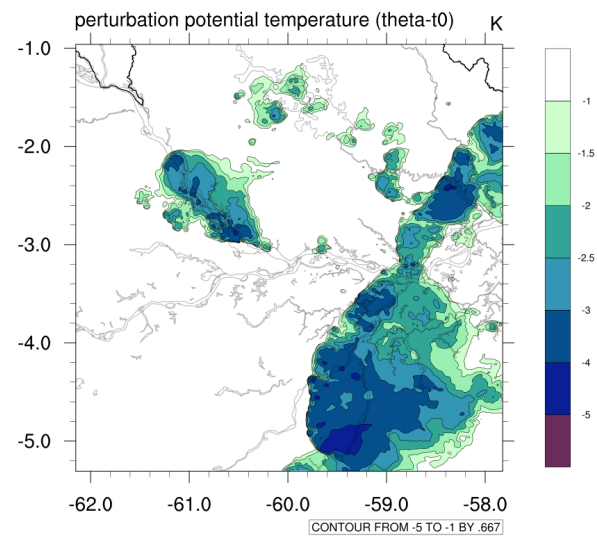

2014-09-08_17:00:00

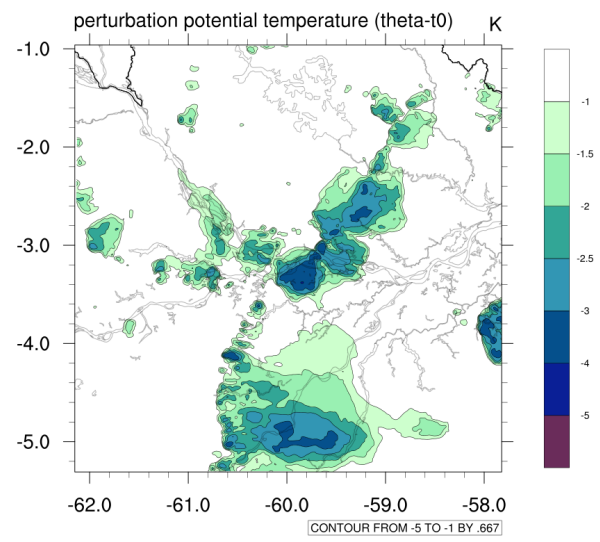

2014-09-08 19:00:00

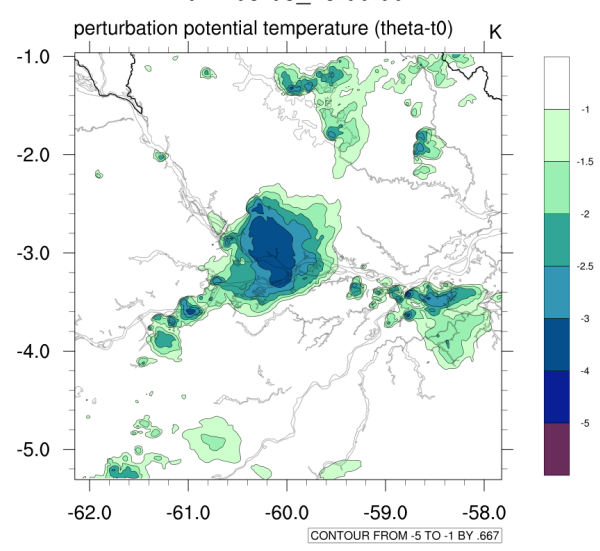

Figure 4.24: WRF perturbation potential temperature fields in the surface for September $08^{\text {th }}$ at a) 1500 UTC, c) 1700 UTC, e) 1900 UTC for Milbrandt and b) 1500 UTC, d) 1700 UTC and f) 1900 UTC for Morrison parameterization schemes. 

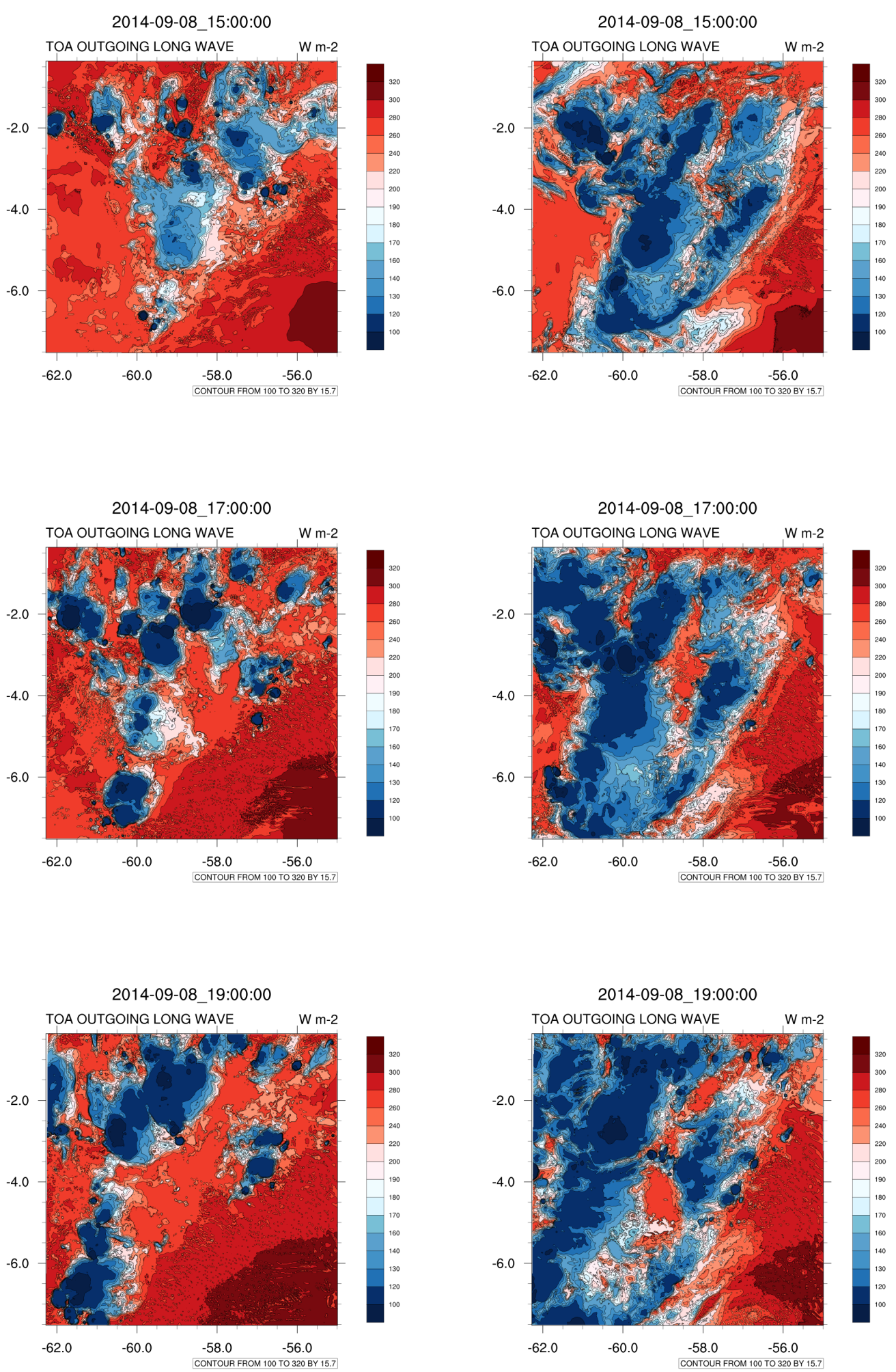

Figure 4.25: WRF outgoing longwave radiation fields for September $08^{\text {th }}$ at a) 1500 UTC, c) 1700 UTC, e) 1900 UTC for Milbrandt and b) 1500 UTC, d) 1700 UTC and f) 1900 UTC for Morrison parameterization schemes. 
The WRF simulated Convective Available Potential Energy (CAPE) and Convective Inhibition (CIN) are demonstrated in Fig. 4.26. The interesting part of these variables is that CAPE is constantly high in 4.26-a, reaching up to $3000 \mathrm{~J} \mathrm{~kg}^{-1}$ over the most intense regions. CAPE is very low when the system is crossing over some region where the system is located (see the blue-yellow-green region) and as a consequence of that, when CAPE is consumed by convection, CIN tends to rise. This is very different than it was first observed by (Abreu, 2016) where CAPE only rises close to a place where the convection is about to form and falls right afterwards.

In Fig. 4.26-b it is seen the same pattern where CAPE is high over most parts of the region and falls right where the convection is formed. CAPE falls because of the cooling caused by the system rainfall. This is also observed for the next hours in Fig. 4.26 c and $4.26+\mathrm{d}$.
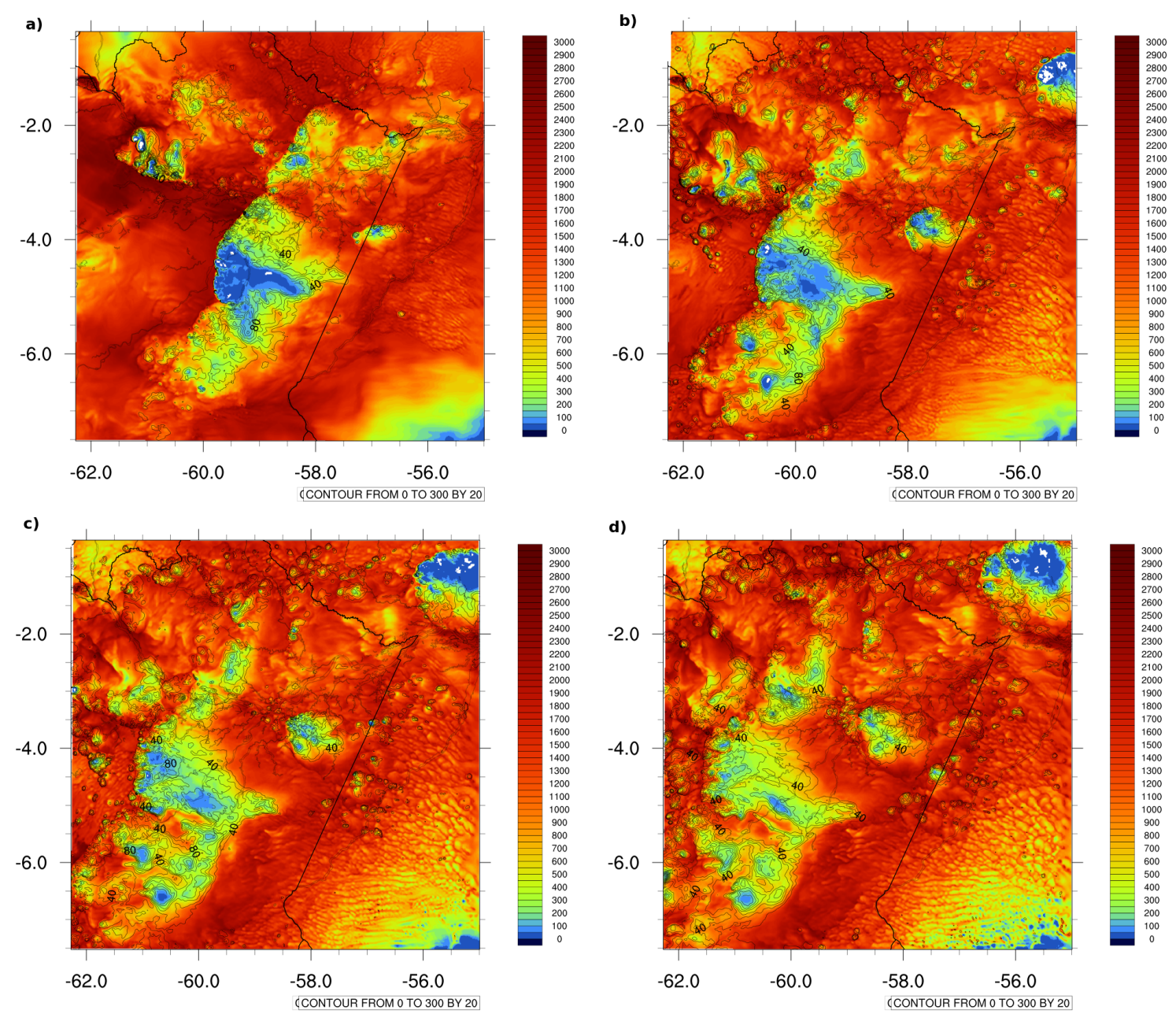

Figure 4.26: WRF simulated CAPE (shades) and CIN (contoured) for September 08 $8^{\text {th }}, 2014$ at a) 1500 UTC, b) 1700 UTC c) 1800 UTC and d) 1900 UTC for Milbrandt parameterization scheme for D04. 


\subsection{Microphysical Vertical Cross-Sections Analysis of the $1 \mathrm{~km}$ Resolution Grid}

This section demonstrates the microphysical variables for all the experiments made through the case study. The cloud water, snow, rain, ice, and graupel were vertically summed to generate the microphysical variables vertical cross-sections at $3.1927^{\circ} \mathrm{S}$ between 60.45 and $59.55^{\circ} \mathrm{W}$. The graphics are displayed in Figs. 4.27, 4.28, 4.29 and 4.30 showing the microphysics and the isotherms of $0,-20$ and $-40{ }^{\circ} \mathrm{C}$.

Fig. 4.27 shows the cross-sections referent to the Milbrandt parameterization scheme between 1530 and 1800 UTC. Fig. 4.27 a shows that no significant cells are observed in the whole horizontal extension, but there is already a sign showing that the convection is starting to form in the rising cells in the cross-section. At 1600 UTC in Fig. 4.27. b the cells over the region at approximately $800 \mathrm{hPa}$.

At 1630 UTC one can see in Fig. 4.27 f that the cells that started forming in Fig. 4.27 $\mathrm{b}$ are now in development and trespass the level of $800 \mathrm{hPa}$ and reach up to $500 \mathrm{hPa}$ between 60 and $59.65^{\circ} \mathrm{W}$. The highest cell that is presented in Fig. 4.27. reaches the level of almost $400 \mathrm{hPa}$ is displayed between 59.75 and $59.65^{\circ} \mathrm{W}$. This cell contains up to $4 \mathrm{~g} \mathrm{~kg}^{-1}$ in its maximum intensity. Right at $1700 \mathrm{UTC}$ in $4.27 \mathrm{-d}$ it is possible to note that the cell over 59.75 and $59.65^{\circ} \mathrm{W}$ presents the anvil shaped cloud. This cell causes heavy rainfall over 59.95 and $59.8^{\circ} \mathrm{W}$ because the mixing ratio is high close to the surface.

In Fig. 4.27 e, at $1730 \mathrm{UTC}$, the cell positioned over $59.9^{\circ} \mathrm{W}$ in Fig. 4.27-d has larger anvil shaped cloud characteristic of a cumulonimbus at the eastern portion of the system that is now over $60.0^{\circ} \mathrm{W}$. The microphysical quantities are now lower in the inner portion of the cell and are ranging from 2 to $2.8 \mathrm{~g} \mathrm{~kg}^{-1}$. At $1800 \mathrm{UTC}$ in Fig. $4.27 \mathrm{f}$ the anvil shape is even more evident but it is possible to note that the single cell system starts to lose intensity. Then, it is evident that the microphysical quantities are now lower which is related to Fig. 4.16-c when the system starts to fade over this latitude.

The Milbrandt parameterization scheme is the only one used in this case study that includes the hail mixing ratio separately from graupel mixing ratio. It presented strong correlations in some portions of the system when compared with the radar data at Table 4.6, but at the southern box it presented a very low correlation which may be associated with the fact that the microphysics representation in this parameterization scheme threats 
ice differently from others, but this can be further discussed later. This might have some sort of influence in the representation of the aspects of the clouds in this scheme.

In Fig. 4.28 the longitudinal cross-sections for Purdue Lin parameterization scheme are shown from 1530 to 1800 UTC. At 1530 UTC there are two regions showing the presence of cells. One over $60.35^{\circ} \mathrm{W}$ and another four between 60.1 and $59.6^{\circ} \mathrm{W}$. In this case, the cells start to get more intense at 1630 UTC (see Fig. 4.28 c) due to the increase of the microphysical quantities and the low-level updrafts (Fig. 4.21f) over the region comprehended between 60 and $59.85^{\circ} \mathrm{W}$ that are lower at 1530 UTC. Looking at Fig. 4.28 - it is noted that the cell between 59.85 and $59.8^{\circ} \mathrm{W}$ is getting more and more intense and rapidly changes at $1700 \mathrm{UTC}$ the cells begin to gain vertical extension. However, they gain vertical extension and around $600 \mathrm{hPa}$ the hydrometeor quantity increases from 2.8 up to $4 \mathrm{~g} \mathrm{~kg}^{-1}$. So, as the cells begin to be more vertically extended, this also means that there is convergence in the surface (see Fig. 4.21-e) where the vertical wind speed is more intense over the region of interest.

At 1730 UTC (Fig. 4.28-e) it is seen that the cells are even more intense, forming three convective cores with large amounts in the total microphysical particles, reaching up to 4 $\mathrm{g} \mathrm{kg}^{-1}$. They extend from the surface because there is rain occurring over the region, up to the level of $100 \mathrm{hPa}$ which is extremely vertically large. Another thing that may be pointed out here is that the hydrometeor concentration reaches up to $4 \mathrm{~g} \mathrm{~kg}^{-1}$ in a large extension but mostly between 800 and $100 \mathrm{hPa}$. These cells are more intense than those observed in Fig. 4.27 fd which presents a single cell with this hydrometeor concentration. In this case, there are two cells: one over 59.95, and another one over $60.18{ }^{\circ} \mathrm{W}$. Right after that, at $1800 \mathrm{UTC}$ the cell over $59.95^{\circ} \mathrm{W}$ joins together with the cell over 60.18 and becomes a larger cell which has a large vertical extension but the total microphysical particles concentration are lower. Thus, comparing this parameterization scheme with the Milbrandt scheme, it can be noted that the Purdue Lin scheme generates more cells and more vigorous cells when compared with the total microphysical particle concentration.

In Fig. 4.29 are displayed the total microphysical particles quantities for the WSM6 parameterization scheme. In Fig. 4.29 a it is seen that at the beginning of the simulation there are tiny cells compared with the other parameterization schemes. At 1600 UTC the cells presented in Fig. 4.29-a are showing more intense cores of microphysical particles reaching up to $1.2 \mathrm{~g} \mathrm{~kg}^{-1}$. At 1600 UTC the cells are vertically stretched between 60.25 

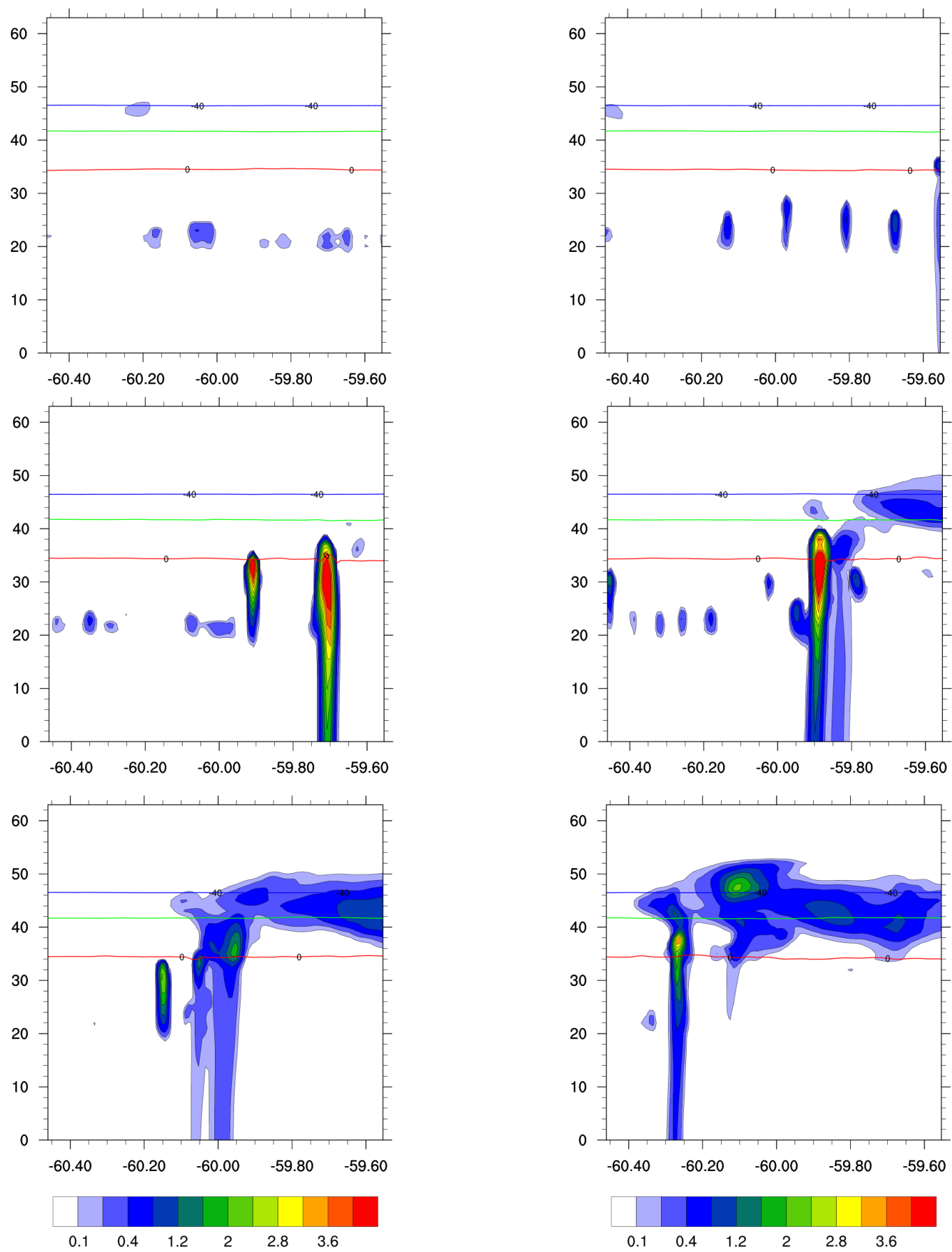

Figure 4.27: Total microphysical particles (cloud water, snow, ice, rain and graupel mixing ratio $\mathrm{g} \mathrm{kg}^{-1}$ ) in a longitudinal cross-section at a) $1530 \mathrm{UTC}$, b) $1600 \mathrm{UTC}$, c) $1630 \mathrm{UTC}$, d) 1700 UTC, e) 1730 UTC and f) 1800 UTC for the Milbrandt parameterization scheme between the surface and $50 \mathrm{hPa}$. 
and $60.1^{\circ} \mathrm{W}$ and also are presenting more intense cores of hydrometeor particles reaching up to $1.6 \mathrm{~g} \mathrm{~kg}^{-1}$. So, it is possible to check that the cells are getting more intense and more vigorous as the time goes by. This fact contributes to the generation of new cells like the ones observed between 59.75 and $59.55^{\circ} \mathrm{W}$ in Fig. 4.29. c which is associated with the system propagation of a SL.

These cells are more intense at 1700 UTC when they reach up to $4 \mathrm{~g} \mathrm{~kg}^{-1}$ in the total microphysical particles concentration in Fig. 4.29 d. It is also the time where the system is reaching maturity and begin to form the anvil shaped form when it is presented in Fig. 4.29 e in the large and intense cell presented between 60.2 and $59.8^{\circ} \mathrm{W}$. It is stressed out that the cell presented in this Fig. shows the mature part of the system and the stratiform region at the rear of the system which is also noted in Fig. 4.27 f fut is not that much evident in Fig. $4.28 \mathrm{f}$ because of the system horizontal extension presented for the Purdue Lin scheme. At 1800 UTC the system is more intense in the front of the system and its total microphysical particles reach up to $4 \mathrm{~g} \mathrm{~kg}^{-1}$. In comparison with the Purdue Lin and the Milbrandt scheme, the WSM6 scheme tends to present more intense and more vigorous cells than the ones presented in both presented earlier in Figs. 4.27 and 4.28 .

Fig. 4.30 shows the total microphysical particles properties in the longitudinal crosssection between 60.45 and $59.55^{\circ} \mathrm{W}$ between the surface and the level of $50 \mathrm{hPa}$. At 1530 UTC in Fig. 4.30-a this parameterization scheme already presents two cells above $200 \mathrm{hPa}$ with high hydrometeor concentration. At 1600 UTC, the cell is more concentrated between 600 and $200 \mathrm{hPa}$, indicating that the cells are rising in the atmosphere. At 1630 UTC the cell is larger in the horizontal extension and presents great amounts of hydrometeors (up to $4 \mathrm{~g} \mathrm{~kg}^{-1}$ ) in the core of the system. Over and between 60.1 and $59.75^{\circ} \mathrm{W}$ the cell presents large concentration in the total particles below $800 \mathrm{hPa}$ reaching up to $2.8 \mathrm{~g} \mathrm{~kg}^{-1}$.

Also in the western portion of the system, the cell presented in Fig. 4.30-d is vertically larger and presents a more intense core in the total particle concentration. The horizontal extension presented in Fig. 4.30 e is larger than any other in the already presented simulations at 1730 UTC as well as the core extension inside the system which trespasses the $-40{ }^{\circ} \mathrm{C}$. According to the literature (Yau and Rogers, 1996) between 0 and $-20{ }^{\circ} \mathrm{C}$ it coexists the water, supercooled water, ice and vapor and between -20 and $-40{ }^{\circ} \mathrm{C}$ water, supercooled water, and ice. This means that the cells observed in the simulations made in this case are referring to cold clouds. 

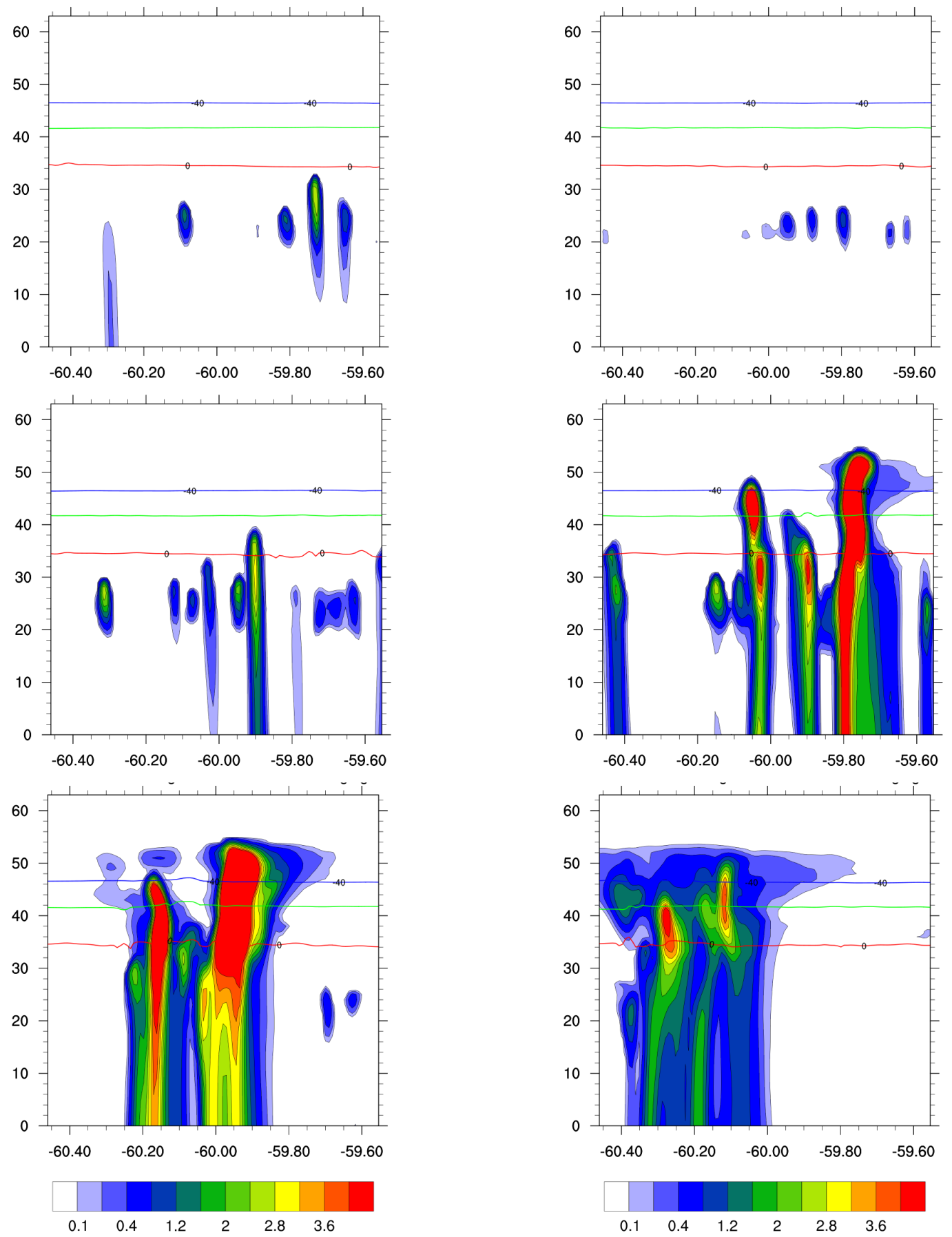

Figure 4.28: Total microphysical particles (cloud water, snow, ice, rain and graupel mixing ratio $\mathrm{g} \mathrm{kg}^{-1}$ ) in a longitudinal cross-section at a) $1530 \mathrm{UTC}$, b) $1600 \mathrm{UTC}$, c) $1630 \mathrm{UTC}$, d) 1700 UTC, e) 1730 UTC and f) 1800 UTC for the Purdue Lin parameterization scheme between the surface and $50 \mathrm{hPa}$. 

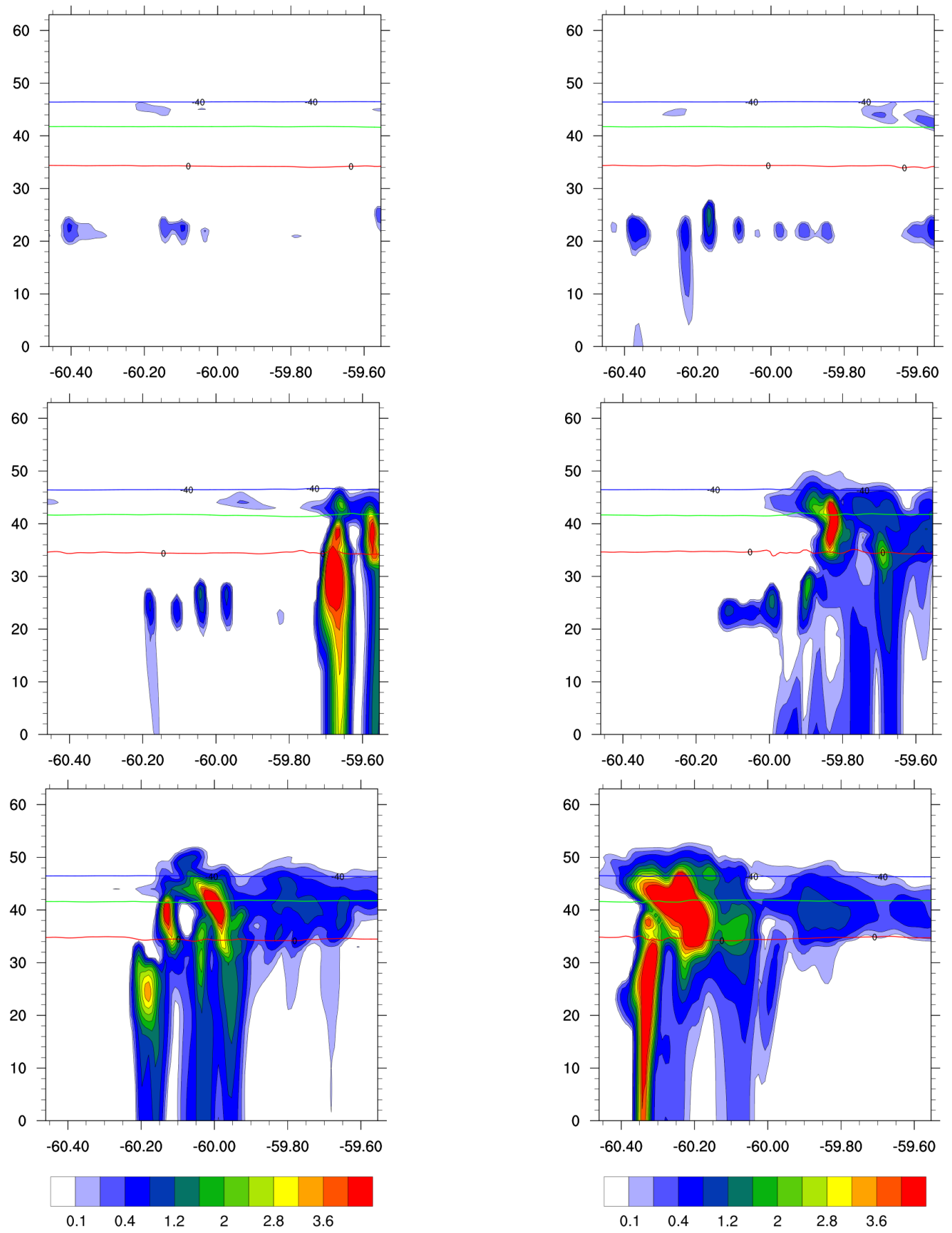

Figure 4.29: Total microphysical particles (cloud water, snow, ice, rain and graupel mixing ratio $\mathrm{g} \mathrm{kg}^{-1}$ ) in a longitudinal cross-section at a) 1530 UTC, b) 1600 UTC, c) 1630 UTC, d) 1700 UTC, e) 1730 UTC and f) 1800 UTC for the WSM6 parameterization scheme between the surface and $50 \mathrm{hPa}$. 
At 1700 UTC in Fig. 4.30-f it is noted that the system shows a decayment in the total particle concentration inside its inner core and it shows four cores reaching up to $4 \mathrm{~g} \mathrm{~kg}^{-1}$ between 60.4 and $59.8^{\circ} \mathrm{W}$. There is a new cell forming over $59.6^{\circ} \mathrm{W}$ and the whole system is large and more vigorous than the other ones presented for the other parameterization schemes. In this case, the system reaches approximately $100 \mathrm{~km}$ in the horizontal extension while for the Purdue Lin parameterization scheme it reaches the half of the horizontal extension.

In Fig. $4.30 \mathrm{f}$ it is seen that the system between 60.4 and $59.8^{\circ} \mathrm{W}$ in Fig. $4.30-\mathrm{f}$ begins to lose intensity but is still more intense than the other displayed for the other parameterizations. Thus, compared with the other parameterization schemes, Morrison is the one that generates the more vigorous and intense cells as the ones presented by the other simulations. 

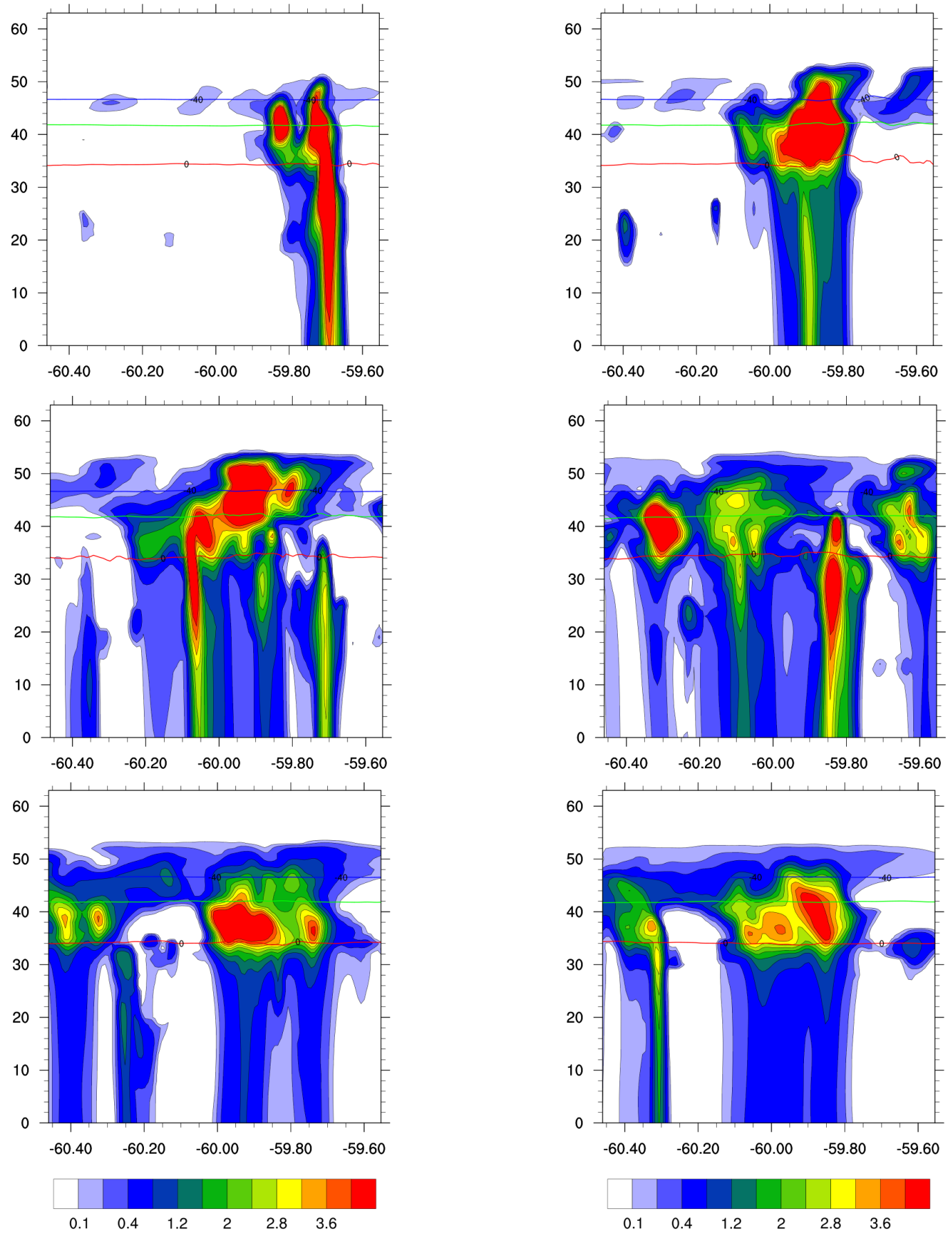

Figure 4.30: Total microphysical particles (cloud water, snow, ice, rain and graupel mixing ratio $\mathrm{g} \mathrm{kg}^{-1}$ ) in a longitudinal cross-section at a) $1530 \mathrm{UTC}$, b) $1600 \mathrm{UTC}$, c) $1630 \mathrm{UTC}$, d) 1700 UTC, e) 1730UTC and f) 1800 UTC for the Morrison parameterization scheme between the surface and $50 \mathrm{hPa}$.

\subsection{WRF Reflectivity, Vertical Velocity, and Microphysics Analysis}

In this section, WRF reflectivity, vertical velocity, and microphysics fields will be analyzed for the case study for both simulations with Morrison and Milbrandt parameterization 
schemes.

Fig. 4.31 shows the WRF reflectivity fields for September $08^{\text {th }}$ from 1630 to 1830 UTC for Milbrandt (left) and Morrison (right). Through these fields, it is possible to see that the reflectivity generated by Milbrandt at 1630 UTC in Fig. 4.31 a is similar to the one generated by Morrison in Fig. 4.31 b. Though, the Morrison parameterization scheme generates more trailing stratiform rainfall as it was already observed by Van Weverberg et al. (2012). Another important thing that can be noticed is that the system positioning is different from one to another. While the simulation for Milbrandt scheme system positioning is sited just at $60^{\circ} \mathrm{W}$, the simulation for Morrison scheme is sited between 60 and $61^{\circ} \mathrm{W}$. Also, the simulation for Morrison scheme is more southerly positioned than for the simulation for the Milbrandt scheme which indicates that the system is moving faster in the simulation for Morrison scheme. This fact may be associated with the low-level vertical velocity fields positioning in Figs. 4.32 -a and 4.32 $\mathrm{b}$ and the differences between the maximum wind vertical velocity which is similar for both cases, but between 1200 and 1400 UTC the simulation for Morrison scheme shows more intense maximum wind vertical velocity. Thus, this may have altered the system positioning like it was first seen in Morrison and Milbrandt (2010) results.

Fig. 4.35 shows the difference in the zonal wind speed for Morrison and Milbrandt. As it was already observed in Fig. 4.10, the winds are easterly directed which means that their values are negative. Thus, if the difference is positive, it means that the simulation for Morrison shows lower values compared with Milbrandt and the Milbrandt scheme shows more intense winds. If the difference is negative, then it happens the contrary.

The zonal wind speed is more intense for Milbrandt scheme at the rear (not shown) of the system below $700 \mathrm{hPa}$ in Fig. 4.35-a between 59.2 and $58.65^{\circ} \mathrm{W}$ which may have contributed for the system position difference for both schemes. While the zonal wind speed is more intense in the lower levels in Figs. 4.35-c and 4.35-e for the Morrison scheme, the zonal wind speed is more intense for the Milbrandt parameterization scheme at mid levels mostly between 400 and $600 \mathrm{hPa}$ between 59.2 and $58.65^{\circ} \mathrm{W}$. As it was already mentioned by Van Weverberg et al. (2012), the difference in the rear inflow jet may modify the vapor availability inside the cloud. In Fig. 4.35-b for example, the vapor mixing ratio difference between Morrison and Milbrandt scheme shows negative values between 400 and $600 \mathrm{hPa}$ which means that there is more air entraining inside the system and thus more 
water vapor available for the Milbrandt parameterization scheme. The evaporation was not computed, but the lower $\theta^{\prime}$ between 1600 and 1800 UTC in Fig. 4.34 and the negative water vapor mixing ratio between 400 and $600 \mathrm{hPa}$ from 1600 to $1800 \mathrm{UTC}$ indicates that the entraining caused evaporation inside the system and generated more intense cold pools for the Milbrandt scheme. Also, in Fig. 4.33 - a it can be seen that between 1600 and 1800 UTC the minimum vertical velocity is more intense for the Milbrandt parameterization scheme. All of these pieces of evidence show that the more intense winds for this scheme have caused more evaporation inside the system and this made the downward vertical motions more intense. However, the presence of more trailing stratiform regions for the Morrison scheme explain the higher rain rates in Fig. 4.20 than in Fig. 4.16.

At 1730 UTC in Figs. 4.31-c and 4.31-d it is seen that the Morrison parameterization scheme shows more intense cores when compared with the simulation for Milbrandt scheme. Both schemes show some phase difference with the radar reflectivity data shown in Fig. 4.11. c because the system is more intense and more developed in both schemes which would look more like the system presented in Fig. 4.11f. Both schemes are similar in the rain mixing ratio presented in the sum inside box 2 profile in Fig. $4.36 \mathrm{~b}$ showing up to $2.5 \mathrm{~kg}$ $\mathrm{kg}^{-1}$ for the same region. Also, both schemes present a linear relation with the number concentration for the same region (not shown) which is why both schemes present the same reflectivity intensity. The simulation for Milbrandt scheme shows more intense downdrafts in Fig. 4.33-a as well as more intense updrafts in Fig. 4.33-b from 1700 to 1830 UTC. The more intense downdrafts also cause the colder $\theta^{\prime}$ in Fig. 4.34 between 1630 and 1930 UTC. In Figs. 4.36-a it is noted that the mixing ratio generated in the simulation for Morrison scheme is larger for snow (qs), ice (qi), graupel/hail (denoted by qg) and rain (qr) but it shows lower cloud water mixing ratio (qc). This fact is explained by the larger trailing stratiform regions presented in Fig. 4.31-d compared with Fig. 4.31-c which contributed to the large difference in the sum for box 1 . Also as it was already explained by Morrison and Milbrandt (2010), the larger rain mixing ratio for Morrison scheme is in part due to the larger flux of frozen condensate above the melting layer. This cannot be shown here but there is a little evidence that the larger graupel/hail mixing ratio for this scheme may have melted/sublimated and changed into rain mixing ratio.

After, at 1830 UTC it is possible to see that the larger quantity of rain mixing ratio in the simulation for Morrison in Figs. 4.37-a, 4.37 -b and 4.37-d (solid lines) compared 
with the simulation for Milbrandt scheme (dashed lines) is also evident in the reflectivity fields in Fig. 4.31 f and Fig. 4.31-e. The reflectivity fields for the simulation made with Morrison scheme in Fig. 4.31 f show more intense reflectivity cores as well as for more intense regions of trailing stratiform rainfall (Van Weverberg et al., 2012). It is seen that this fact impacts the microphysical quantities simulated for both schemes. While the simulation for Morrison scheme shows higher mixing ratio values for rain, snow, ice and graupel on most of the regions presented in Figs. 4.36 and 4.37 (except for box 2 at 1700 and 1830 UTC), the simulation for Milbrandt scheme shows more water (q cloud) vapor mixing ratio for most of the areas at 1700 and 1830 UTC. It is viewed in Fig. 4.36-a that the simulation for Morrison scheme shows graupel mixing ratio close to $3 \mathrm{~kg} \mathrm{~kg}^{-1}$ while the simulation for Milbrandt scheme shows values close to $0.5 \mathrm{~kg} \mathrm{~kg}^{-1}$. This fact could be associated with the phase errors cited previously, but when the mixing ratios are summed for the whole inner domain (D04) it can be seen that the rain mixing ratio is really larger in Morrison simulation than for Milbrandt (see Figs. 4.38-a and 4.38-b). However, there is still the difference between cloud water for both schemes, i.e., Milbrandt scheme simulates more cloud water inside the domain. At 1830 UTC the Milbrandt parameterization scheme shows more graupel than Morrison, but the rain mixing ratio is still higher for Morrison. This may be associated with the larger ice mixing ratio observed between 400 and 100 $\mathrm{hPa}$ and with the larger concentrations for hail in the freezing level for Morrison scheme (Morrison and Milbrandt, 2010). Thus, if there is more hail for Morrison simulation, and more graupel in the Milbrandt simulation, there will be more rain mixing ratio for Morrison compared with Milbrandt explained by the fallout speed. However, the much larger concentrations of graupel/hail in Milbrandt scheme above the freezing level help to compensate for the fallout speed difference in rain mixing ratio in Fig. 4.36 b and 4.36-d (Morrison and Milbrandt, 2010). 

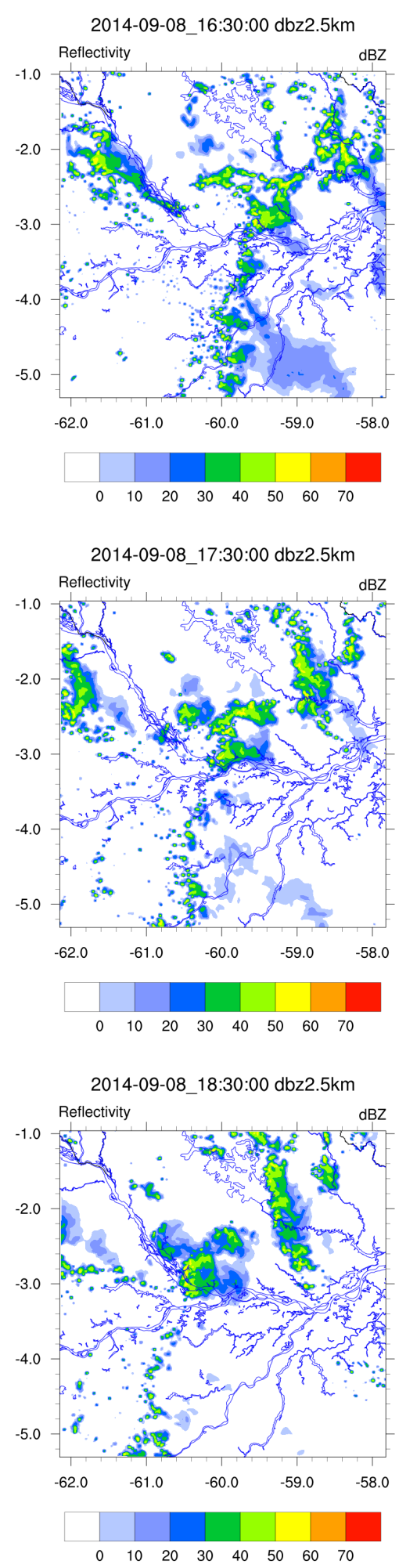

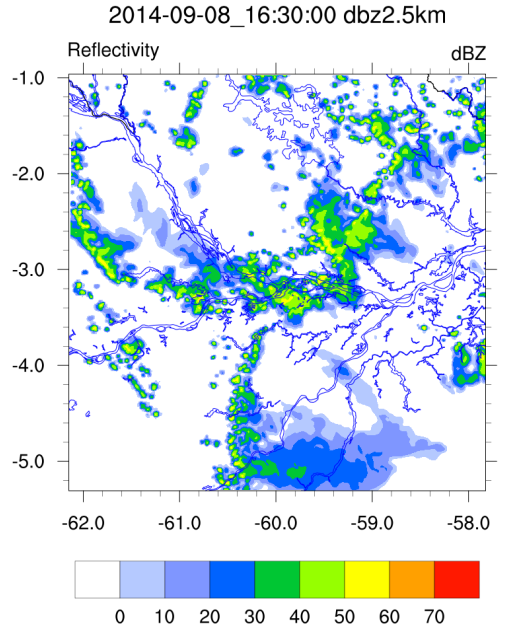

2014-09-08_17:30:00 dbz2.5km

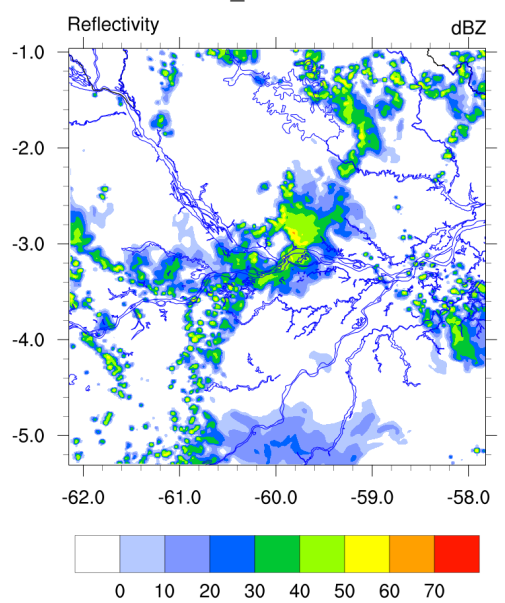

2014-09-08_18:30:00 dbz2.5km

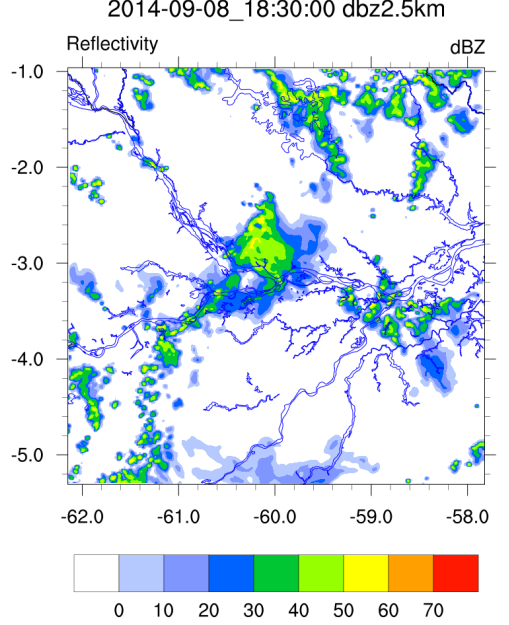

Figure 4.31: WRF reflectivity fields for September $08^{\text {th }}$ at a) 1630 UTC, c) 1730 UTC, e) 1830 UTC for Milbrandt and b) 1630 UTC, d) 1730 UTC and f) 1830 UTC for Morrison parameterization schemes at $2.5 \mathrm{~km}$ height. 

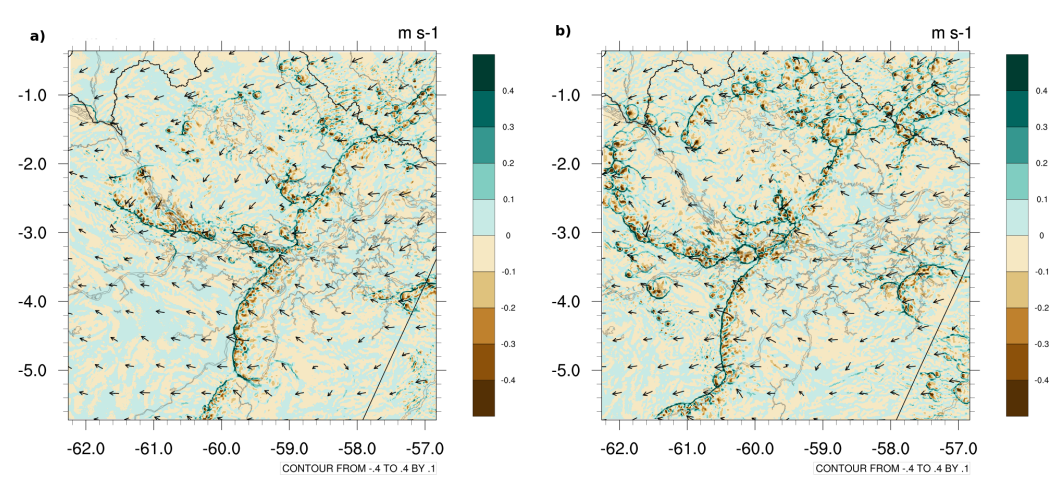

Figure 4.32: WRF vertical velocity fields for September $08^{\text {th }}$ for a) 1500 UTC and b) 1630 UTC for Morrison parameterization schemes at $0.2 \mathrm{~km}$ height.
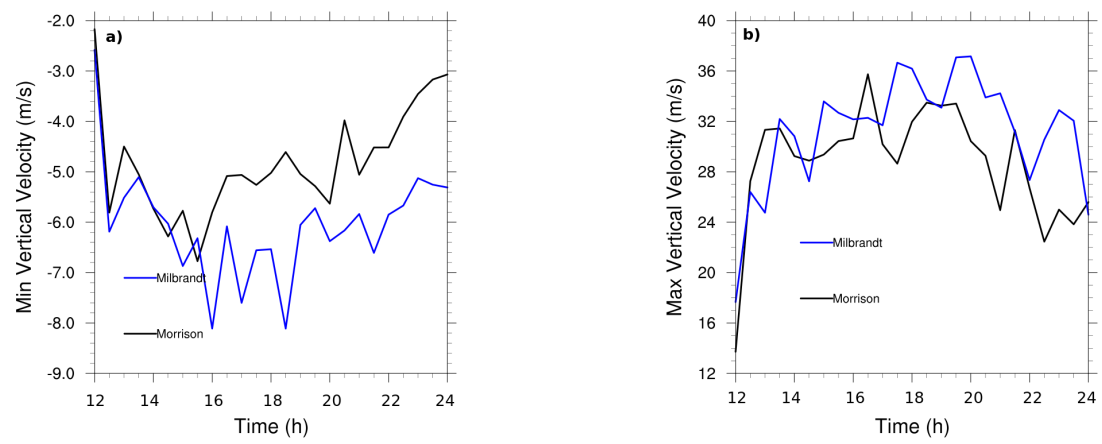

Figure 4.33: WRF a) minimum (below $3400 \mathrm{~m}$ ) to and b) maximum (at all levels) vertical velocities September $08^{\text {th }}$ from 1200 UTC to 0000 UTC.

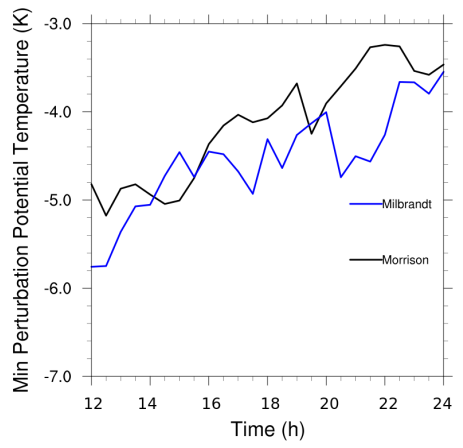

Figure 4.34: WRF minimum perturbation potential temperature at the surface for September $08^{\text {th }}$ from 1200 UTC to 0000 UTC. 


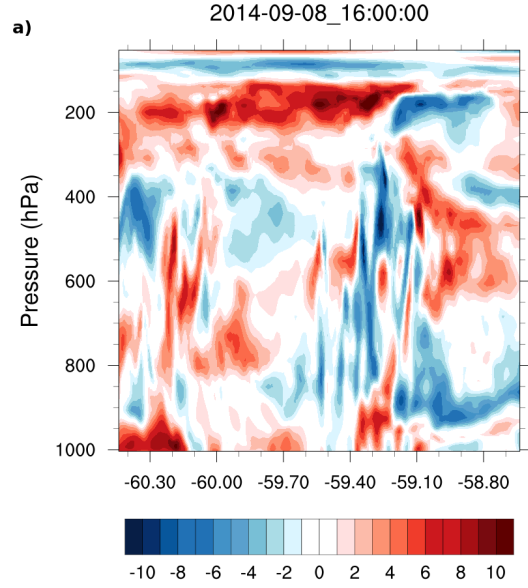

Wind $(\mathrm{m} / \mathrm{s})$

c)

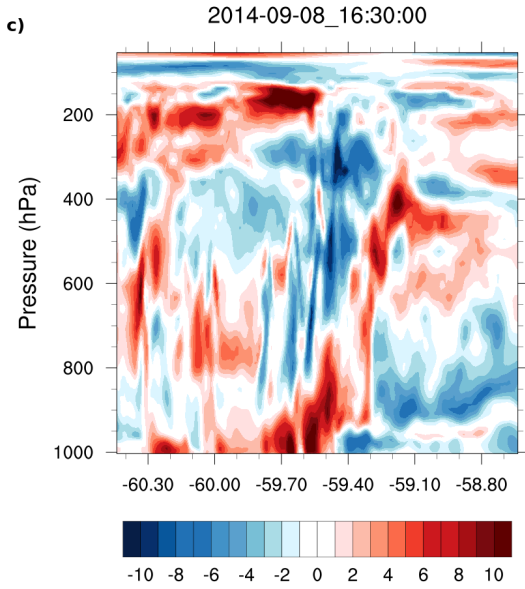

Wind $(\mathrm{m} / \mathrm{s})$

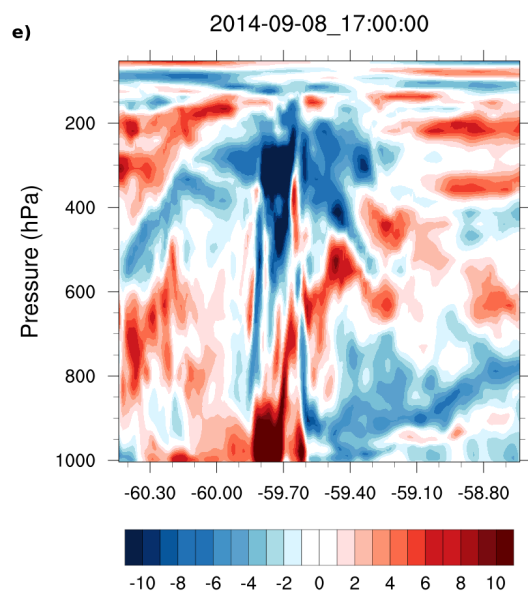

Wind $(\mathrm{m} / \mathrm{s})$

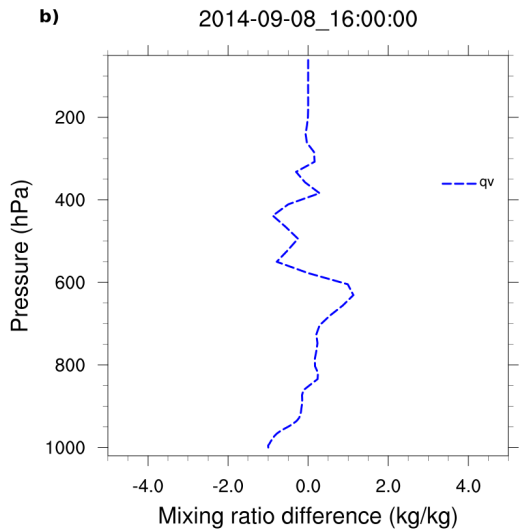

d)

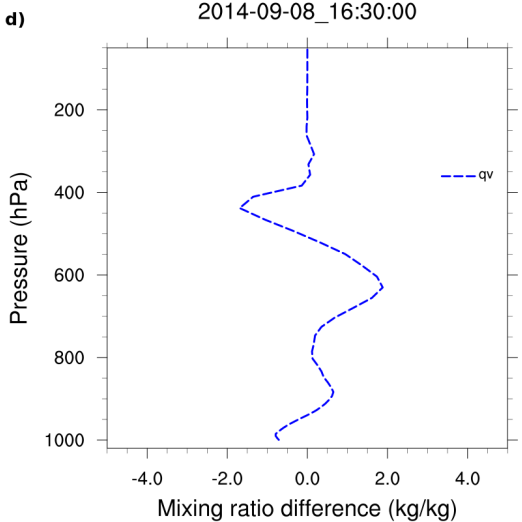

f)

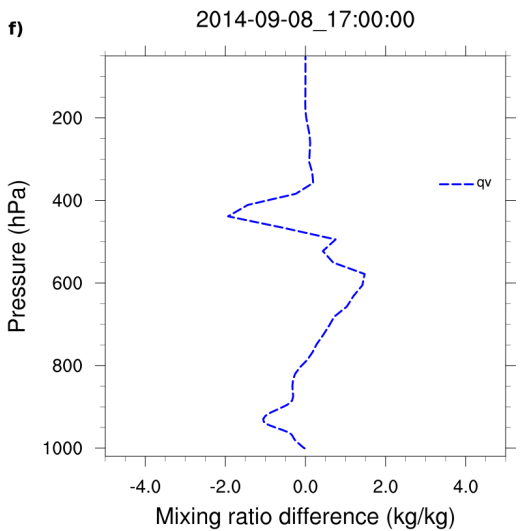

Figure 4.35: WRF zonal winds fields (left) and vapor mixing ratio (for box 3 - right) difference between the Morrison and Milbrandt schemes for September $08^{\text {th }}$ for a) 1600 UTC b) 1600 UTC, c) 1630 UTC, d) 1630 UTC, e)1700 UTC and f) 1700 UTC. 

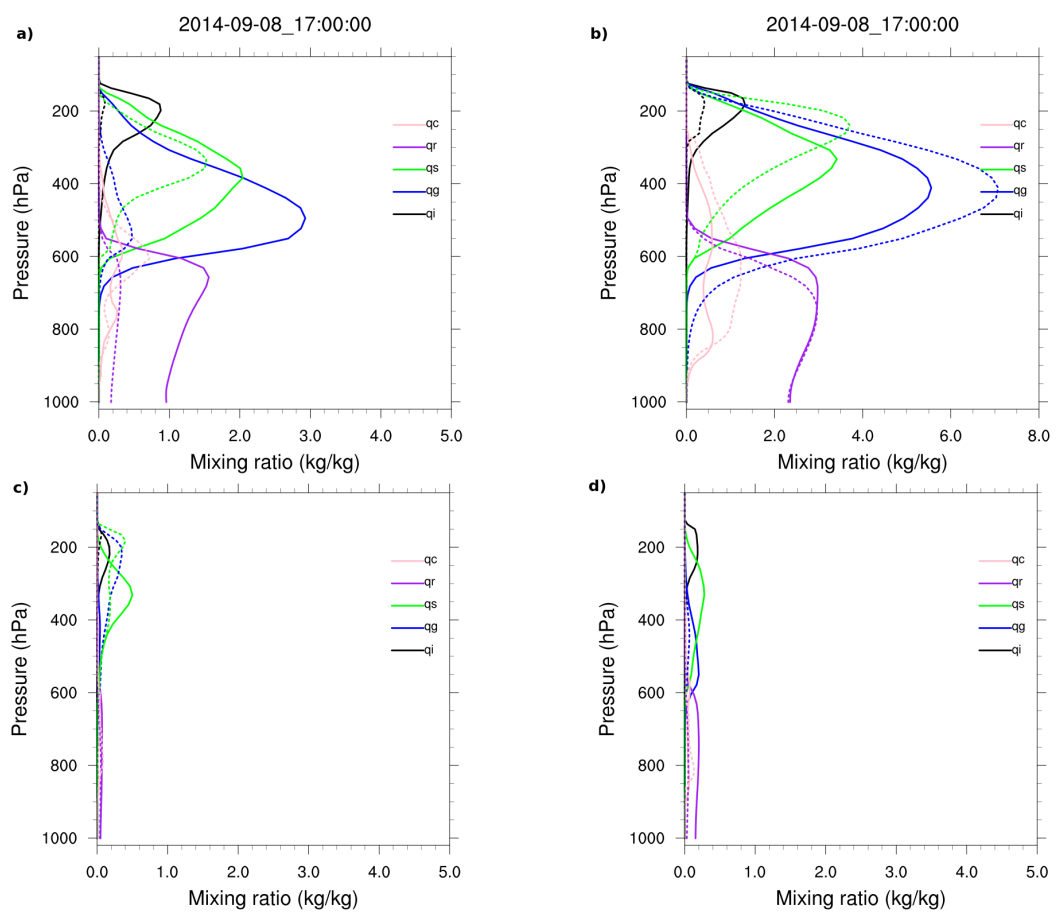

Figure 4.36: WRF summed mixing ratios for September $08^{\text {th }}$ at 1700 UTC for boxes a) 1 , b) 2, c) 3 and d) 4 for Morrison (solid) and Milbrandt (dashed) lines. PS: For box 2, the mixing ratio $\mathrm{X}$ axis maximum is $8 \mathrm{~kg} / \mathrm{kg}$.
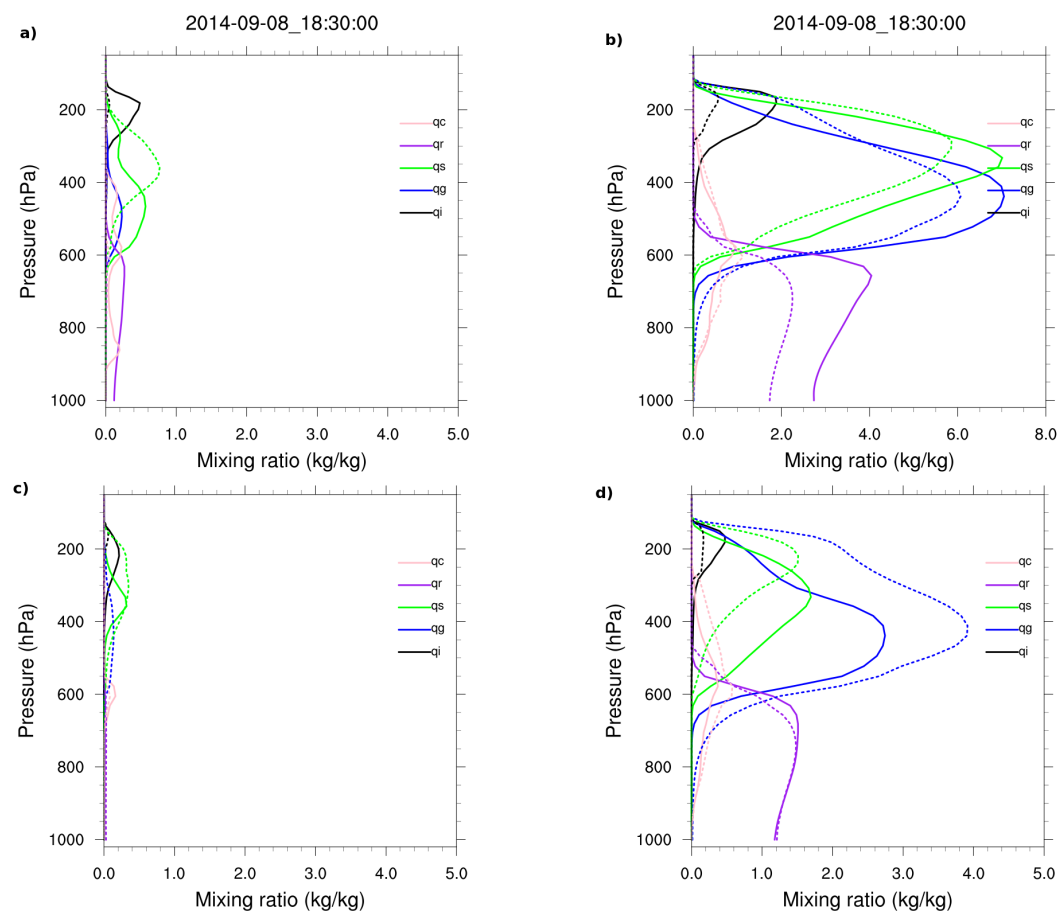

Figure 4.37: WRF summed mixing ratios for September $08^{\text {th }}$ at 1830 UTC for boxes a) 1 , b) 2, c) 3 and d) 4 for Morrison (solid) and Milbrandt (dashed) lines. PS: For box 2, the mixing ratio $\mathrm{X}$ axis maximum is $8 \mathrm{~kg} / \mathrm{kg}$. 

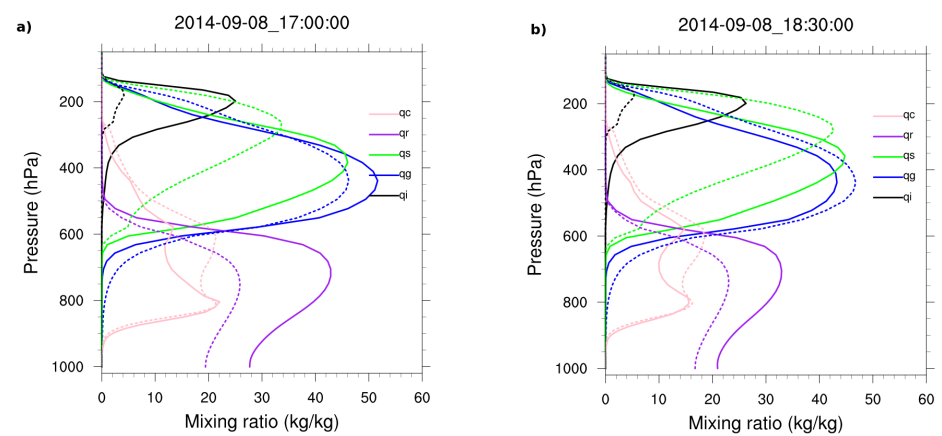

Figure 4.38: WRF summed mixing ratios for September $08^{\text {th }}$ at a) 1700 UTC and b) 1830 UTC inside the whole D04 for Morrison (solid) and Milbrandt (dashed) lines.

The IWP and WRWP can be seen in Figs. 4.39 and 4.40 for the radar data in Figs. 4.39- a and 4.40-a and for the simulation runs with Morrison and Milbrandt schemes in Figs. 4.39 and 4.40 from a to d. Note that all of the results were normalized by the number of points cited in Table 3.1 times two where it represents the number of points presented by WRF simulations.

Fig. 4.39-a shows that the IWP reaches almost $36 \mathrm{~g} \mathrm{~m}^{-2}$ in its most intense parts which in this case were showed in the northwestern and southern parts. Also for the northeastern and eastern boxes, the values do not trespass $30 \mathrm{~g} \mathrm{~m}^{-2}$. The phase difference between all the curves represents only the time where the system reaches the radar site. The southern and the eastern boxes represent the region where the system located in Fig. 4.3 c and Fig. 4.3 -d by the regions $10-\mathrm{B}$ and $10-\mathrm{A}$ respectively. It is interesting to note that the southern region is more intense than the eastern region even though both present very similar cloud top temperatures. However, in Fig. 4.3 c the portion assigned as system 8 also presents high IWP in Fig. 4.39-a.

Comparing both simulations with the radar retrievals, the IWP in the northwestern box in Fig. 4.39 b is the most intense one reaching almost $26 \mathrm{~g} \mathrm{~m}^{-2}$ for both simulations between 1700 and 2100 UTC. However, it can be noted that Morrison scheme generates high amounts of IWP also between 1200 and 1700 UTC which also must have contributed to the differences in the system propagation between both schemes. For the northeastern box, the radar retrievals account for almost $30 \mathrm{~g} \mathrm{~m}^{-2}$ in Fig. 4.39-a between 1930 and 2000 UTC where it is more intense. IWP simulated for both schemes show much less than that reaching a maximum of $16 \mathrm{~g} \mathrm{~m}^{-2}$ for Milbrandt scheme and almost $5 \mathrm{~g} \mathrm{~m}^{-2}$ for Morrison scheme between 1700 and 1900 UTC. This means that the model simulations not 
only underestimated the concentrations but also showed some differences in the phase in comparison with the radar retrievals. For the eastern portion of the system both simulations show values ranging from 2 to $12 \mathrm{~g} \mathrm{~m}^{-2}$ between 1600 to 2030 UTC. It is stressed that the Morrison scheme shows higher IWP in its peak close to 1800 UTC. The radar data retrievals show that the values from 2 to $24 \mathrm{~g} \mathrm{~m}^{-2}$ and between 1700 to 2200 UTC. This very large difference between the radar retrievals and the simulations also may be associated with the fact that the model simulations do not represent the surface winds. For example, in the southern box in Fig. 4.39 e, the Morrison scheme shows much higher IWP than Milbrandt scheme which also shows more intense surface winds in Fig. 4.32-b than in Fig. 4.21f.
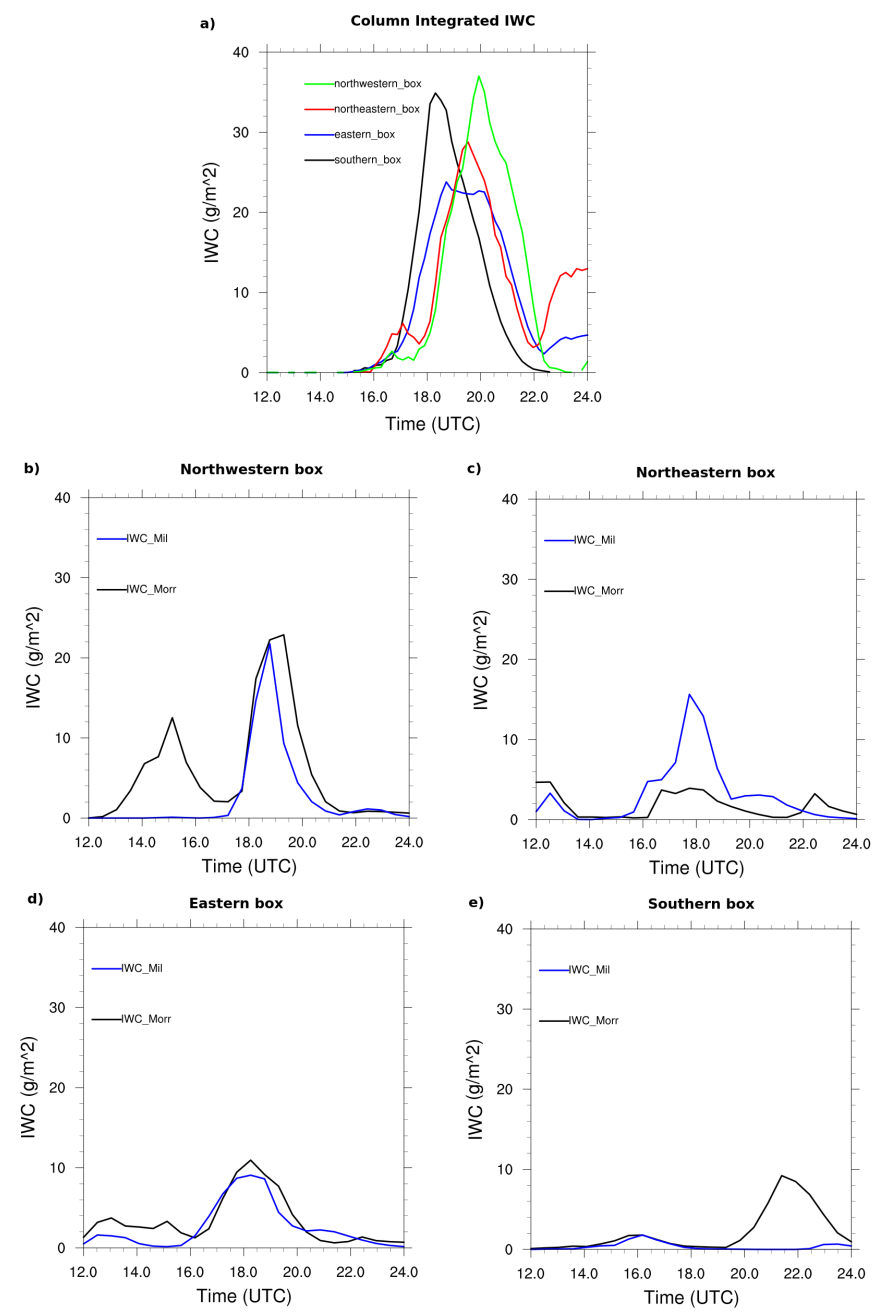

Figure 4.39: Column Integrated IWP for the a) radar data, b) northwestern, c) northeastern, d) eastern and e) southern box for September $08^{\text {th }}$ between 1200 UTC and 2400 UTC. Note that the blue lines represent the simulation for Milbrandt and the black ones represent the simulation for Morrison scheme. 
For the WRWP the results are similar for both simulations, but the radar data retrievals show large WRWP for all the regions that comprise the system observed in Fig. 4.3 c. For the northwestern box, the amount of WRWP reaches values around $10 \mathrm{~g} \mathrm{~m}^{-2}$ between 1500 and 1800 UTC and its peak at 2000 UTC when it reaches almost $20 \mathrm{~g} \mathrm{~m}^{-2}$ in Fig. 4.40-a which is simulated almost perfectly in the simulation for Morrison scheme in Fig. 4.40-b. The simulation for Milbrandt scheme shows the curve between 1800 and 2200 UTC but it shows the WRWP close to the radar retrievals while Morrison scheme shows more intense WRWP. However, for the northeastern box (Fig. 4.40-c), the simulation for the Morrison scheme shows underestimation in comparison with the simulations for the Milbrandt scheme which shows values closer to the radar retrievals in Fig. 4.40-a reaching its maximum WRWP at approximately $12 \mathrm{~g} \mathrm{~m}^{-2}$.

The WRWP for the Eastern box shows its peak at approximately 1830 UTC with a maximum ranging between 11 and $12 \mathrm{~g} \mathrm{~m}^{-2}$ in Fig. 4.40-a. The simulations show high WRWP values between 1200 and 1500 UTC which is not shown in the radar retrievals. The maximum WRWP values presented in the simulation for Morrison scheme show almost 10 $\mathrm{g} \mathrm{m}^{-2}$ while the maximum WRWP for Milbrandt scheme simulation shows around $7 \mathrm{~g} \mathrm{~m}^{-2}$ between 1700 and 1800 UTC. Though, the radar retrievals show a maximum around $12 \mathrm{~g}$ $\mathrm{m}^{-2}$ between 1800 and 1900 UTC. The model simulations, in this case, show lower WRWP and some phase differences between the observations. The same problem observed in Fig. 4.39-e is present in Fig. 4.40 e which the simulations show much lower concentration values when compared with the radar retrievals. The difference between both simulations also may be associated with the low level winds. In the overall, it is seen that the simulation made with Morrison scheme shows higher WRWP and IWP but for the northeastern portion of the system. Although, it shows concentrations more similar to the observations in Figs. 4.39- a and 4.40-a. 

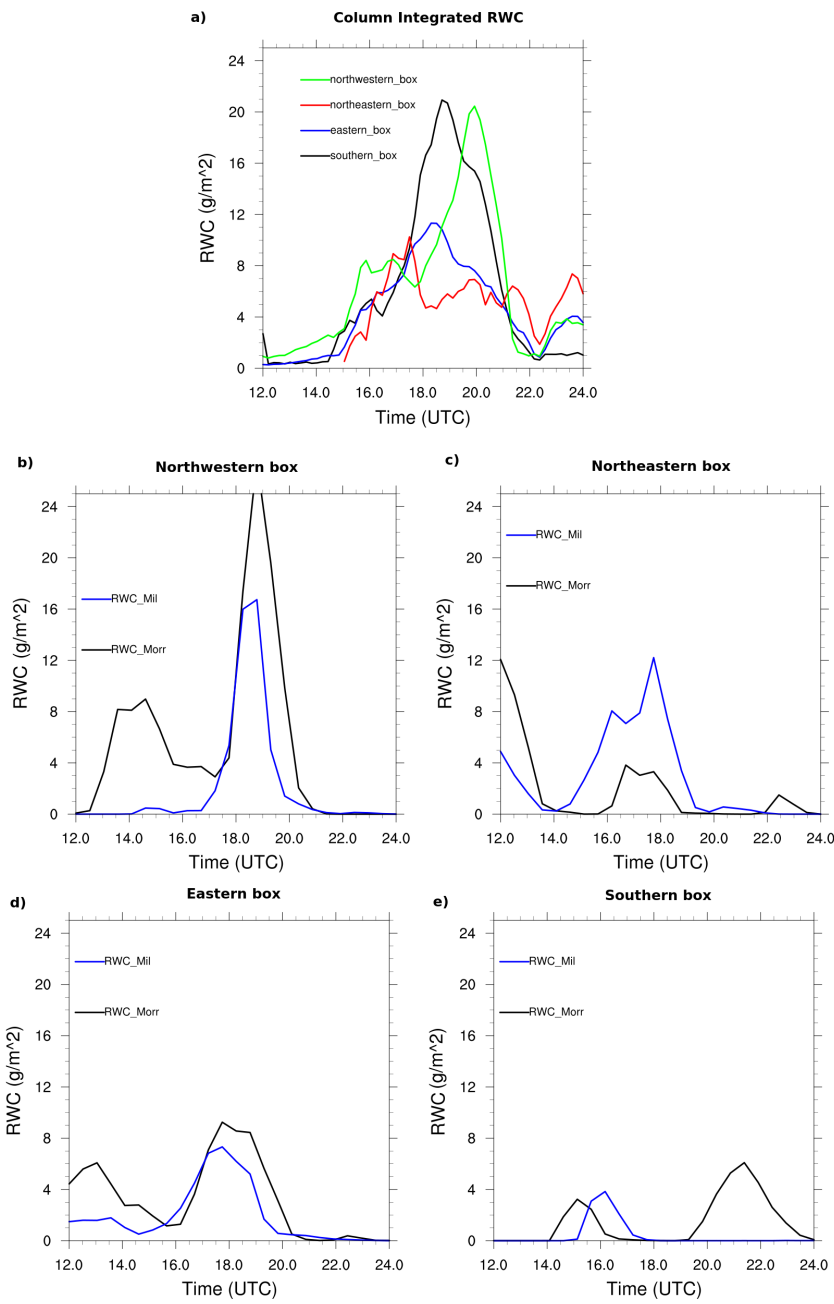

Figure 4.40: Column Integrated WRWP for the a) radar data, b) northwestern, c) northeastern, d) eastern and e) southern box for September $08^{\text {th }}$ between 1200 UTC and 2400 UTC. Note that the blue lines represent the simulation for Milbrandt and the black ones represent the simulation for Morrison scheme. 
Chapter 5

\section{Conclusions}

Atmospheric moist convection is one of the main topics discussed on climate modeling. Besides its importance in redistributing heat, moment and mass between different vertical levels of the troposphere, convection also largely contributes with the atmospheric large scale dynamical patterns in a tridimensional framework. Since the most part of climate models still deppend on convective parameterizations to generate those complex atmospheric interactions described above, it is extremely important that more research in cloud microphysics be done.

In order to study why different and similar cloud microphysics parameterizations produce different patterns of precipitation at the ground, the present study developed several numerical sensitivity tests aiming to extract useful information about the causes of such differences.

Using several types of data sets measured in the Amazon region, including satellite imagery, meteorological radar, GOAmazon special rawinsonde, precipitation fields derived from satellite measurements, and global numerical analysis GFS data, the characteristics of a squall line case observed on the Amazon region were revealed. In this particular case, the convection initiated over the dawn and reached its mature stage over the evening of September $08^{t h}, 2014$. The preferential winds were southeast and the squall line system was SW - NE oriented.

This squall line was simulated using WRF mesoscale model over the grids of $27 \mathrm{~km}$ (D01), $9 \mathrm{~km}$ (D02), $3 \mathrm{~km}$ (D03) and $1 \mathrm{~km}$ (D04) of spacing between grid points. The D01 grid is the large-scale domain and its results are very realistic when compared to the GFS analyzes, as demonstraded by synoptic-scale sea level pressure, low level winds and the upper level streamlines fields. Also, by downgrading the simulation, the rainfall results 
have been improved as it was first expected (Mass et al., 2002), and qualitatively the D01 showed the best rainfall simulations in the control experiment.

To reach the objectives of this work, four different bulk microphysics parameterizations were initially tested and compared against each other. They are known as Lin, WSM6, Morrison, and Milbrandt. After that, following the concept that the higher the degree of freedom of the meteorological model the better the simulation (Warner, 2010; Mass et al. 2002; Morrison et al., 2005; Milbrandt and Yau, 2005), the double-moment microphysics were emphasized in the present work. The simulations were designed to explicitly show the differences between the surface rainfall patterns associated with each microphysics scheme and through their comparison against satellite $(\mathrm{CMORPH})$ and radar rain rates data, as derived from the radar reflectivity fields. The simulations were also compared against the rawinsonde data, and the estimated vertically integrated radar microphysics variables. The results of two double-moment microphysics schemes chosen for this study were then compared.

Some interesting differences between the convective environment observed in the Amazon region and that which is usually observed in the subtropical region of Brasil, as São Paulo State (see, e.g., (Hallak, 2007)), appear in this study, mainly in regard to thermodynamic characteristics. For example, the amazon rawinsonde analyses show that local environment quickly recovers its previous vertical distribution of heat and moisture after the convective rain produced by a squall line as the one studied here. Thus, the convective environment returns to its unstable condition even after the rain shower, which is contrary to the physical behavior observed, for example, in the metropolitan area of São Paulo (Hallak, 2007; Abreu, 2016). The sequence of the analyzed rawinsonde data also showed that the environment is dominated by the presence of high values of CAPE during the whole time. CINE was also always present, which means that it is necessary some kind of lifting mechanism to start convection in that situation and, because of this, the convergence line related to the propagation of the squall line is the important fact in this case. In addition, cold pools verified by simulations contributed to the lifting processes. The sequence of radar and satellite imageries proved that at least in the selected case here shown, the Amazon region resembles a cauldron of boiling water, with the difference that the local surface heating alone is not sufficient to trigger the convection, as in a real cauldron. As a consequence, the convective cells observed in the Amazon region tends 
to be always highlighted when compared to convection observed in São Paulo, which is highlighted only in determined situations.

To better evaluate the simulated results, some statistical errors were also computed. The simulations tests comparisons between the rawinsonde data and the four microphysics parameterizations have shown that the traditional errors MSE, RMSE, and Bias do not change drastically among each other, nor among the high resolution grids with the low resolution grids. However, it is important to stress that the Bias are much lower for Milbrandt (double-moment) than for Lin (one-moment) and Morrison (double-moment) parameterization scheme for the wind speed. Also, the double-moment parameterization Morrison scheme were the one that, in the overall, displayed better results in respect to correlations between the radar rain rates with the simulated rain rates. While Morrison scheme showed 0.6 correlation in the western box, WSM6 and Lin schemes showed 0.39 and 0.05 correlation with the radar rain rates, respectively. Though, it was not the main fact that lead the choosing this scheme as the best one in between the simulations. It was also related to the fact that this scheme also showed good correlations with the radar rain rates over the entire system. Nevertheless, because this scheme presented good correlations with the radar rain rates, it also showed a fairly better system lifecycle, evolution and propagation when compared to the CMORPH data. It seems that the complexity that the way microphysics variables are treated in both one-moment and double-moment schemes in this case study do not highly affect the simulations results, but the three dimensional vertical cross-sections showed that the Purdue Lin and Morrison schemes display more intense systems compared to WSM6 and Milbrandt schemes, which, in our vision, may be associated with the ice-phase microphysics, as explained in the next paragraph.

One hypothesis to explain differences observed between the aforementioned microphysical schemes is related to the treatment of ice given by each parameterization (Milbrandt and Yau, 2005; Morrison et al., 2005) because of Morrison parameterization scheme presented more ice quantities than Milbrandt scheme, which certainly affected the rainfall pattern and rain rates. It also changed the total precipitable water content by melting, increased the total liquid water content of Morrison scheme in comparison to Milbrandt scheme as can bee seen in Fig. 5.1. Also, it was shown high differences between both rainfall patterns. This may be explained because the melting rate previously shown by Morrison and Milbrandt (2010) is larger for Morrison scheme than for Milbrandt, mainly 
because graupel is the dominant rimed-ice species for Milbrandt scheme. This can be surely affirmed, once the mixing ratio for graupel/hail is larger for Milbrandt scheme. On the other hand, its mixing ratio for rain is smaller than for Morrison scheme. This indicates that the fall speed for the total graupel/hail is lower for Milbrandt than for Morrison (Morrison and Milbrandt, 2010), which explains the larger mixing ratio for Morrison scheme. Also referring to Morrison and Milbrandt (2010), the mean-mass hail size in the region near the freezing level is generally much larger for Morrison scheme than the mean-mass hail size in Milbrandt scheme. Other question may also be answered with the same line of thought because the intensity, positioning and vertical distribution of hydrometeors inside the convective cells were highly modified due to the high amount of ice generated by Morrison compared with Milbrandt scheme. In fact, Milbrandt scheme showed smaller horizontal cold pools (i.e., cold pool fraction) in comparison with Morrison scheme. However, the minimum perturbation potential temperatures were observed in the Milbrandt scheme simulation, which indicates that the horizontal cold pool extension is more important than the lower perturbation potential temperatures. Also, the Morrison parameterization scheme shows more low level convergence and this makes the system to move faster than for Milbrandt scheme (Morrison and Milbrandt, 2010). It is important to stress out that the system is very sensitive to evaporation, which highly affects the system propagation. The system moves faster in Milbrandt scheme compared to Morrison because the scheme generated more graupel quantities, which is smaller in size than hail, and it evaporates easier in the processes inside the cloud due to its size. This fact also changed the more intense cold pools intensity for Milbrandt scheme compared to Morrison.

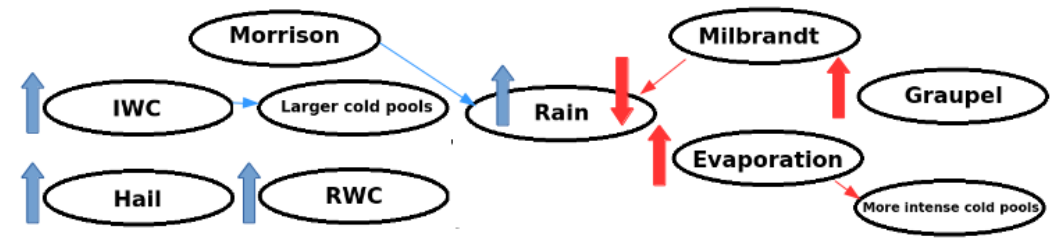

Figure 5.1: Detailed scheme with the conclusions with respect to cloud microphysics parameterization tests for Milbrandt (red) and for Morrison (blue) parameterization schemes. 
Chapter 6

\section{Suggestion for Further Studies}

The present work suggests that the model results are somewhat sensitive to microphysics parameterizations variations. Inside the convective system, the most important impacts were seen mainly in its intensity and propagation. However, other studies must be done about the complexity of the amazon convection and its differences among other kinds of convective systems formed along the tropical region.

- Perform simulations with higher horizontal grid spacing so that finner dynamic structures can be solved by the model and, thus, improving the microphysics results. The suggestion is to use grid spacing at least of $300 \mathrm{~m}$.

- Compare other microphysics parameterization schemes among the ones that were tested in this case study.

- Include in the data validation the comparison with the Chirps, Merge and polarimetric doppler weather radars microphysics variables.

- Perform the same study for other regions such as the city of São Paulo where there are more available data for the simulations validations.

- Use the SATOB data in the 3DVAR or 4DVAR assimilation cores in the pursuit of correcting the system phase and possibly improve the precision and accuracy of the numerical results. 


\section{Bibliography}

Abreu R. C., Análise de mesoescala de um evento convectivo em São Paulo e da assimilação de dados em simulações com o modelo WRF, São Paulo: Universidade 1, 2016, Master Dissertation, 127 p.

Alcântara C. R., Souza E. P. d., Dias M. A. F. d. S., Biezato B., Influence of medium and low level jet in cloud processes: numerical study of an amazon squall line, Revista Brasileira de Meteorologia, 2014, vol. 29, p. 29

Andreae M. O., Aerosols before pollution, Science, 2007, vol. 315, p. 50

Betts G., Grower R., Moncrief M., Structure and Motion of the Tropical Squal Lines over Venezuela, Quarterly Journal of the American Meteorological Society, 1976, vol. 102, p. 395

Bonell M., Hufschmidt M. M., Gladwell J. S., Hydrology and water management in the humid tropics. Cambrigde University Press: Cambridge, 1993, 99

Carey L. D., Rutledge S. A., The relationship between precipitation and lightning in tropical island convection: A C-band polarimetric radar study, Monthly weather review, 2000, vol. 128, p. 2687

Carvalho A., Conexões entre a circulação em altitude e a convecção sobre a América do Sul, São José dos Campos. 109p.(INPE-4923-TDL/383). Dissertação (Mestrado em Meteorologia)-Instituto Nacional de Pesquisas Espaciais, 1989

Carvalho L., Jones C., Silva A. E., Liebmann B., Silva Dias P. L., The South American monsoon system and the 1970s climate transition, international Journal of Climatology, 2011, vol. 31, p. 1248 
Carvalho L. M., Jones C., Liebmann B., The South Atlantic convergence zone: Intensity, form, persistence, and relationships with intraseasonal to interannual activity and extreme rainfall, Journal of Climate, 2004, vol. 17, p. 88

Cohen J. C. P., Dias M. d. S., Nobre C. A., Aspectos climatológicos das linhas de instabilidade na Amazônia, INPE, 1989, pp 34-40

Cohen J. C. P., Dias M. d. S., W. C., Características médias das linhas de instabilidade durante o período chuvoso do WETAMC/LBA, Anais. Rio de Janeiro: SBMET, 2000

De Oliveira A. S., Nobre C. A., Meridional penetration of frontal systems in South America and its relation to organized convection in the Amazon, 1985

De Oliveira A. S. C., Nobre C., Interactions between frontal systems in South America and tropical convection over Amazon, International Conference on Southern Hemisphere Meteorology, Wellington - New Zealand, 1986

De Souza D. O., dos Santos Alvalá R. C., Observational evidence of the urban heat island of Manaus City, Brazil, Meteorological Applications, 2014, vol. 21, p. 186

Drumond A., Marengo J., Ambrizzi T., Nieto R., Moreira L., Gimeno L., The role of the Amazon Basin moisture in the atmospheric branch of the hydrological cycle: a Lagrangian analysis, Hydrology and Earth System Science, 2014, vol. 18, p. 2577

Feng Z., Hagos S., Rowe A. K., Burleyson C. D., Martini M. N., Szoeke S. P., Mechanisms of convective cloud organization by cold pools over tropical warm ocean during the AMIE/DYNAMO field campaign, Journal of Advances in Modeling Earth Systems, 2015, vol. 7 , p. 357

Fernandez W., Environmental Conditions and Structure of the West African and Eastern Tropical Atlantic Squall Lines, Archive for Meteorology, Geophysics and Bioclimatology, 1982, vol. 31, p. 71

Ferraro R. R., Special sensor microwave imager derived global rainfall estimates for climatological applications, Journal of Geophysical Research: Atmospheres, 1997, vol. 102, p. 16715 
Ferraro R. R., Weng F., Grody N. C., Zhao L., Precipitation characteristics over land from the NOAA-15 AMSU sensor, Geophysical Research Letters, 2000, vol. 27, p. 2669

Ferreira A., Mello N. G. d. S., Principais Sistemas Atmosféricos Atuantes Sobre a Região do Nordeste do Brasil e a Influência dos Oceanos Pacífico e Atlântico no Clima da Região, Revista Brasileira de Climatologia, 2005, vol. 1, p. 15

Fisch G., Marengo J. A., Nobre C. A., Uma revisão geral sobre o clima da Amazônia, Acta Amazonica, 1998, vol. 28, p. 101

Garstang M., Massie Jr H. L., Halverson J., Greco S., Scala J., Amazon coastal squall lines. Part I: Structure and kinematics, Monthly Weather Review, 1994, vol. 122, p. 608

Gettelman A., Morrison H., Advanced two-moment bulk microphysics for global models. Part I: Off-line tests and comparison with other schemes, Journal of Climate, 2015, vol. 28 , p. 1268

Hallak R., Simulações numéricas de tempestades severas na RMSP, Universidade de São Paulo, 2007, Ph.D. Thesis

Hamilton R., Archbold J., Douglas C., Meteorology of Nigeria and adjacent territory, Quarterly Journal of the Royal Meteorological Society, 1945, vol. 71, p. 231

Hong S.-Y., Dudhia J., Chen S.-H., A revised approach to ice microphysical processes for the bulk parameterization of clouds and precipitation, Monthly Weather Review, 2004, vol. 132 , p. 103

Houze R., Mesoscale convective systems, Reviews of Geophysics, 2004, vol. 42

Houze R. A., Observed structure of mesoscale convective systems and implications for largescale heating, Quarterly Journal of the Royal Meteorological Society, 1989, vol. 115, p. 425

Houze Jr R. A., Structure and dynamics of a tropical squall-line system, Monthly Weather Review, 1977, vol. 105, p. 1540

Houze Jr R. A., Stratiform precipitation in regions of convection: A meteorological paradox?, Bulletin of the American Meteorological Society, 1997, vol. 78, p. 2179 
Houze Jr R. A., Cloud dynamics. vol. 104, Academic press, 2014, 314

Huffman G. J., Bolvin D. T., Nelkin E. J., Wolff D. B., Adler R. F., Gu G., Hong Y., Bowman K. P., Stocker E. F., The TRMM multisatellite precipitation analysis (TMPA): Quasi-global, multiyear, combined-sensor precipitation estimates at fine scales, Journal of hydrometeorology, 2007, vol. 8, p. 38

Johnson R. H., Hamilton P. J., The relationship of surface pressure features to the precipitation and airflow structure of an intense midlatitude squall line, Monthly Weather Review, 1988, vol. 116, p. 1444

Kain J. S., Fritsch J. M., A one-dimensional entraining/detraining plume model and its application in convective parameterization, Journal of the Atmospheric Sciences, 1990, vol. 47 , p. 2784

Kain J. S., Fritsch J. M., , 1993 in , The representation of cumulus convection in numerical models. Springer pp 165-170

Klingle D. L., Smith D. R., Wolfson M. M., Gust front characteristics as detected by Doppler radar, Monthly weather review, 1987, vol. 115, p. 905

Kousky V. E., Pentad outgoing longwave radiation climatology for the South American sector, Rev. Bras. Meteor, 1988, vol. 3, p. 217

Kummerow C., Hong Y., Olson W., Yang S., Adler R., McCollum J., Ferraro R., Petty G., Shin D.-B., Wilheit T., The evolution of the Goddard Profiling Algorithm (GPROF) for rainfall estimation from passive microwave sensors, Journal of Applied Meteorology, 2001, vol. 40, p. 1801

Laurent H., Machado L. A., Morales C. A., Durieux L., Characteristics of the Amazonian mesoscale convective systems observed from satellite and radar during the WETAMC/LBA experiment, Journal of Geophysical Research: Atmospheres, 2002, vol. 107

Laurent H., Machado L. A. T., Herdies D., Morales C., Características dos sistemas convectivos observados por satélite durante o experimento WETAMC/LBA, XI Congresso Brasileiro de Meteorologia, 2000, pp 16-20 
Lin Y.-L., Farley R. D., Orville H. D., Bulk parameterization of the snow field in a cloud model, Journal of Climate and Applied Meteorology, 1983, vol. 22, p. 1065

Lopes V. S., Análise diagnóstica e modelagem numérica de mesoescala de uma linha de instabilidade amazônica, Dissertação de Mestrado IAG/USP, 2017, pp 1-124

Macedo L. R., Tuchtenhagen P., Yamasaki Y., Avaliações De Prognósticos WRF Com Distintas Parametrizações, CongreMet IX, Mendoza. Anais do IX CongreMet, Argentina, 2012

Machado L., Rossow W., Structural characteristics and radiative properties of tropical cloud clusters, Monthly Weather Review, 1993, vol. 121, p. 3234

Machado L. A., Laurent H., Lima A. A., Diurnal march of the convection observed during TRMM-WETAMC/LBA, Journal of Geophysical Research: Atmospheres, 2002, vol. 107

Marengo J. A., Liebmann B., Kousky V. E., Filizola N. P., Wainer I. C., Onset and end of the rainy season in the Brazilian Amazon Basin, Journal of Climate, 2001, vol. 14, p. 833

Marengo J. A., Tomasella J., Alves L. M., Soares W. R., Rodriguez D. A., The drought of 2010 in the context of historical droughts in the Amazon region, Geophysical Research Letters, 2011, vol. 38

Markowski P., Richardson Y., Mesoscale meteorology in midlatitudes. vol. 2, John Wiley \& Sons, 2011, 252

Mass C. F., Ovens D., Westrick K., Colle B. A., Does increasing horizontal resolution produce more skillful forecasts?, Bulletin of the American Meteorological Society, 2002, vol. 83 , p. 407

Milbrandt J., Yau M., A multimoment bulk microphysics parameterization. Part I: Analysis of the role of the spectral shape parameter, Journal of the atmospheric sciences, 2005, vol. 62 , p. 3051

Minnis P., Sun-Mack S., Young D. F., Heck P. W., Garber D. P., Chen Y., Spangenberg D. A., Arduini R. F., Trepte Q. Z., Smith W. L., et al., CERES edition-2 cloud property 
retrievals using TRMM VIRS and Terra and Aqua MODIS data-Part I: Algorithms, IEEE Transactions on Geoscience and Remote Sensing, 2011, vol. 49, p. 4374

Molion L. C. B., Climatologia Dinâmica da região Amazônica: mecanismos de precipitação, Revista Brasileira de Meteorologia, 1987, vol. 2, p. 107

Morrison H., Curry J., Khvorostyanov V., A new double-moment microphysics parameterization for application in cloud and climate models. Part I: Description, Journal of the Atmospheric Sciences, 2005, vol. 62, p. 1665

Morrison H., Milbrandt J., Comparison of two-moment bulk microphysics schemes in idealized supercell thunderstorm simulations, Monthly Weather Review, 2010

Nobre C. A., Obregón G. O., Marengo J. A., Características do Clima Amazônico: Aspectos Principais, Amazonia and Global Change Geophysical Monograph Series, 2009, vol. 186 , p. 149

Nunes A. M. P., Silva Dias M. A. F., Anselmo E. M., Morales C. A., Severe Convection Features in the Amazon Basin: A TRMM-Based 15-Year Evaluation, Frontiers in Earth Science, 2016, vol. 4, p. 37

Orlanski I., A rational subdivision of scales for atmospheric processes, Bulletin of the American Meteorological Society, 1975, vol. 56, p. 527

Pereira Filho A. J., Silva Dias M. A., Albrecht R. I., Pereira L. G., Gandu A. W., Massambani O., Tokay A., Rutledge S., Multisensor analysis of a squall line in the Amazon region, Journal of Geophysical Research: Atmospheres, 2002, vol. 107

Petersen W. A., Rutledge S. A., Regional variability in tropical convection: Observations from TRMM, Journal of climate, 2001, vol. 14, p. 3566

Ribeiro Macedo L., Martins Basso J. L., Yamasaki Y., Avaliação do WRF-4DVAR em um caso de evento severo no Rio Grande do Sul, Ciência e Natura, 2016, vol. 38

Rotunno R., Klemp J. B., Weisman M. L., A theory for strong, long-lived squall lines, Journal of the Atmospheric Sciences, 1988, vol. 45, p. 463

Roy S. B., Mesoscale vegetation-atmosphere feedbacks in Amazonia, Journal of Geophysical Research: Atmospheres, 2009, vol. 114 
Rutledge S. A., Hobbs P., The mesoscale and microscale structure and organization of clouds and precipitation in midlatitude cyclones. VIII: A model for the "seeder-feeder" process in warm-frontal rainbands, Journal of the Atmospheric Sciences, 1983, vol. 40, p. 1185

Silva Dias M. d., Rutledge S., Kabat P., Silva Dias P. d., Nobre C., Fisch G., Dolman A., Zipser E., Garstang M., Manzi A., et al., Cloud and rain processes in a biosphereatmosphere interaction context in the Amazon region, Journal of Geophysical Research: Atmospheres, 2002, vol. 107

Siqueira J. R., Rossow W. B., Machado L. A. T., Pearl C., Structural characteristics of convective systems over South America related to cold-frontal incursions, Monthly weather review, 2005, vol. 133, p. 1045

Skamarock W. C., Klemp J. B., Dudhia J., Gill D. O., Barker D. M., Duda M. G., X. H., Wang W., Powers J. G., A Description of the Advanced Research WRF Version 3, NCAR/TN 475+STR Technical Notel, UCAR, 2008

Skamarock W. C., Klemp J. B., Dudhia J., Gill D. O., Barker D. M., Wang W., Powers J. G., A Description of the Advanced Research WRF Version 2, NCAR/TN 475+STR Technical Notel, UCAR, 2005

Van Weverberg K., Vogelmann A. M., Morrison H., Milbrandt J. A., Sensitivity of idealized squall-line simulations to the level of complexity used in two-moment bulk microphysics schemes, Monthly Weather Review, 2012, vol. 140, p. 1883

Velasco I., Fritsch J. M., Mesoscale convective complexes in the Americas, Journal of Geophysical Research, 1987, vol. 92, p. 9591

Warner T. T., Numerical weather and climate prediction. Cambridge University Press, 2010

Yau M. K., Rogers R., A short course in cloud physics. Elsevier, 1996

Zheng Y., Alapaty K., Herwehe J. A., Del Genio A. D., Niyogi D., Improving highresolution weather forecasts using the Weather Research and Forecasting (WRF) Model with an updated Kain-Fritsch scheme, Monthly Weather Review, 2016, vol. 144, p. 833 
Zipser E., Mesoscale and convective-scale downdrafts as distinct components of squall-line structure, Monthly Weather Review, 1977, vol. 105, p. 1568 